\title{
The role of the dean in the pastoral care structure of a secondary school
}

\author{
Jennifer Harriet Fraser
}

A four paper thesis submitted in fulfilment of the requirements for the degree of Master of Education

Victoria University of Wellington

July 2014 



\begin{abstract}
Pastoral care structures in New Zealand schools often include a middle management role of dean. This position has existed in New Zealand schools for decades, influenced by the existing systems and structures adopted from the United Kingdom. The responsibilities included in this role are often defined by schools at the local level in order to satisfy growing expectations of schools' responsibility for student well-being and achievement. There has been little research concerning this position within the pastoral care structure of schools.

This study aimed to explore the perceptions of members of the school community on the role of the year-level deans within one New Zealand secondary school. Senior managers, deans, teachers, and students from a state co-educational, urban, secondary school were interviewed regarding their views on the role, responsibilities, and effectiveness of the position of the year-level dean within their school. Deans also completed a daily log to record the nature of their tasks completed pertaining to this responsibility. Participants' responses were analysed for major themes. The themes discussed include the intention of the role of the dean, tensions between the management of academic and pastoral issues, the exploration of the challenge in providing care for all students, and how resources available to the school and the dean can impact their role. A difference in the role between the junior school (Years 9 and 10) and senior school (Years 11, 12, and 13) was reported by all participants. Deans reported engaging in reactive tasks more than proactive, preventative tasks.
\end{abstract}

Defining the role of the dean and its relationship to other roles within the school proved challenging for the perspectives, and this confusion was evident through a lack of clarity around lines of authority described in the job descriptions. Deans reported some difficulty in understanding their role in relation to managing form teachers, particularly where that staff member may hold a position of responsibility in curriculum.

The reactive nature of the role was revealed. This indicated that deans continue to provide predominantly reactive care concerned with individual students, often meaning that only a small group of students receive direct care from deans. The predominantly reactive nature of the role creates implications for schools in the challenge of delivering care to all students. A more collaborative approach to pastoral care from all staff members may improve the provision of pastoral care for students. A proposed job description that may reflect the role of the dean more accurately is presented. 



\section{Acknowledgements}

I would like to express my heartfelt gratitude to my supervisor, Robin Averill. She was a constant source of inspiration and encouragement. Her valuable feedback and patient, methodical guidance was motivating and challenging. I thoroughly enjoyed my time with Robin and feel privileged to have worked with her.

This study was possible thanks to the school where I conducted my research. The staff and students were accommodating, efficient and genuinely interested in educational improvements. I would like to express my appreciation to them for welcoming me into their community.

Throughout this study I was the recipient of scholarships from Victoria University and the Wellington branch of the New Zealand Federation of Graduate Women. I would like to thank both of these organisations for enabling me to enjoy this journey all the more so.

To my wonderful dad, Nigel, thank you for never faltering in your belief in me. My lovely mum, Cathrine, for everything, thank you.

For the personal support of my husband, Cameron, I am truly grateful. Thank you for your partnership, encouragement and for making me laugh when I needed it.

To my beautiful daughter, Imogen Grace, who was born just after I completed my data collection, I wish a lifetime of love and learning. 



\section{Contents}

Chapter 1: Introduction 1

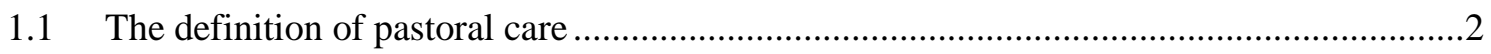

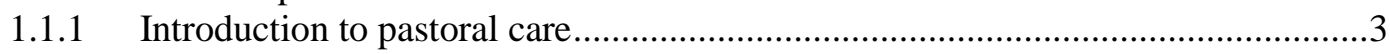

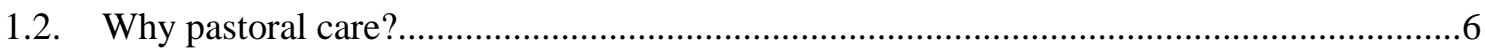

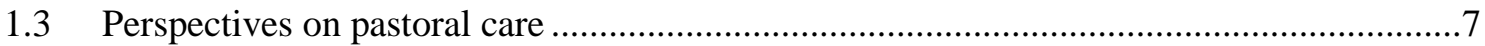

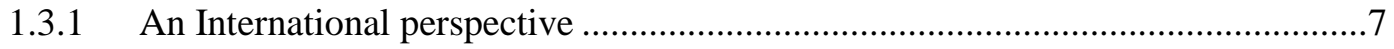

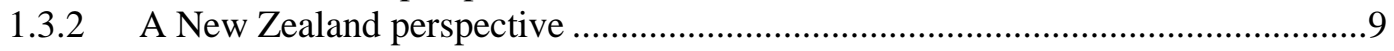

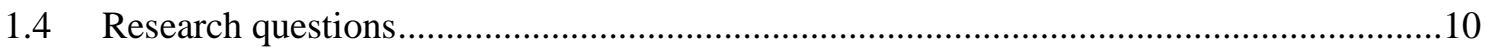

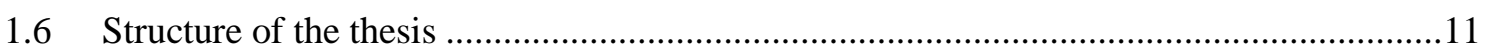

Chapter 2: Literature Review

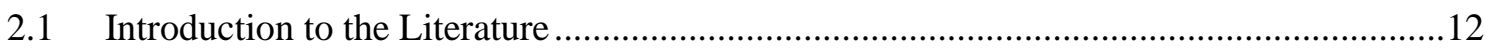

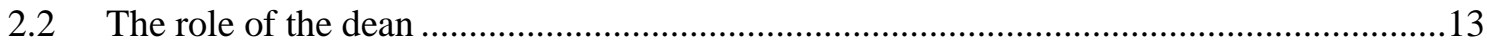

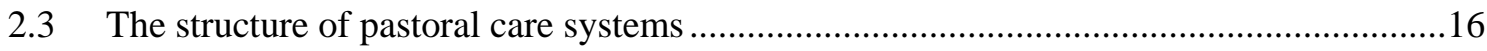

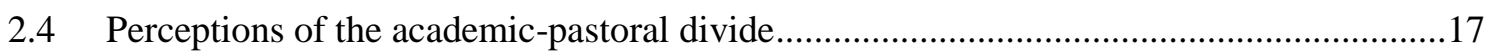

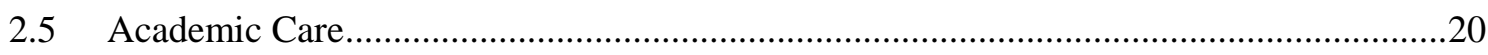

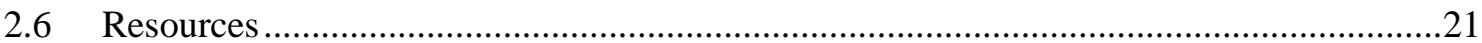

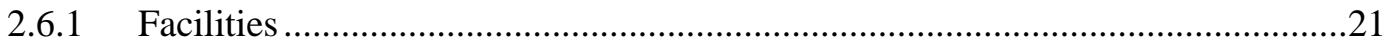

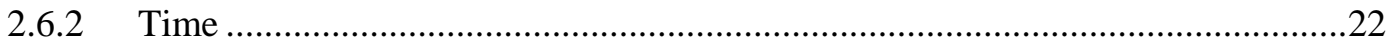

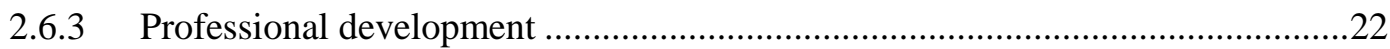

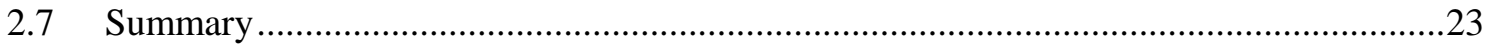

Chapter 3 Methodology and Method $\quad 24$

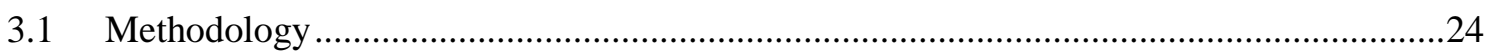

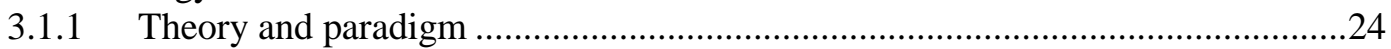

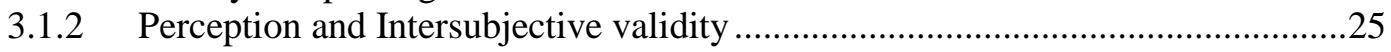

3.1.3 Theoretical underpinnings for mixed-methods design........................................26

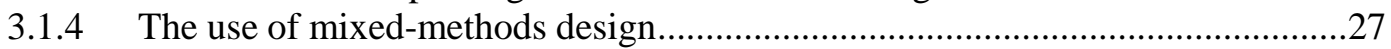

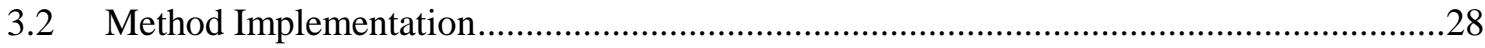

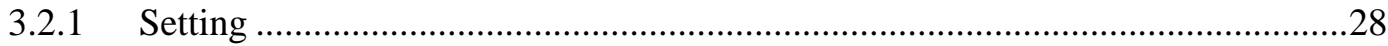

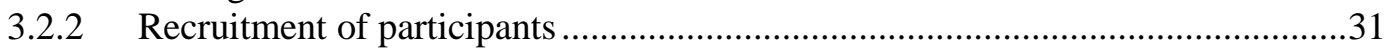

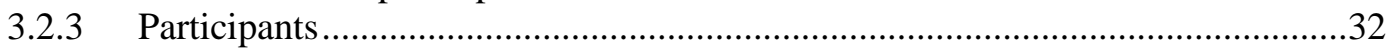

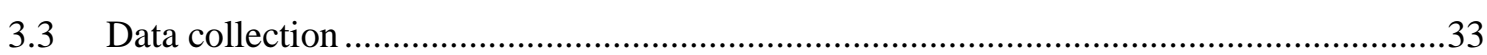

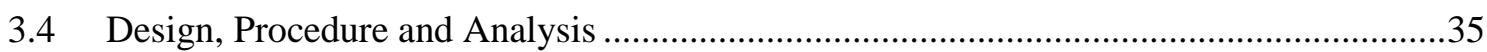

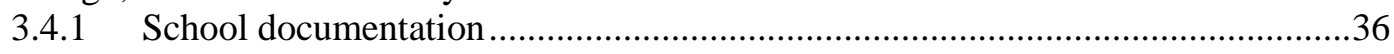

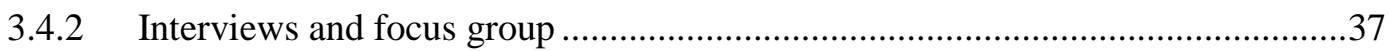

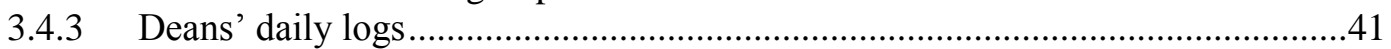

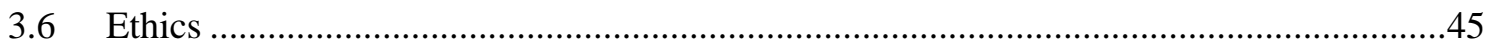

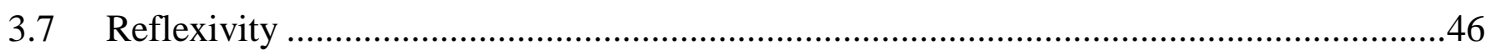

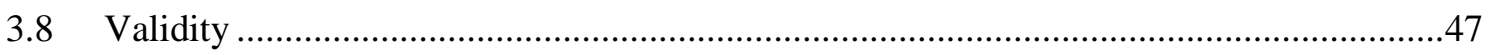

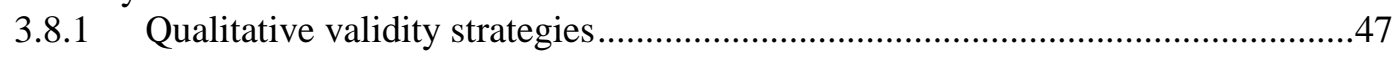




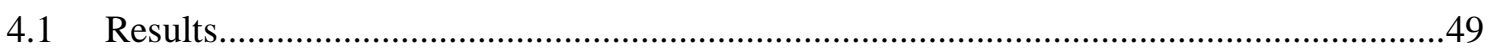

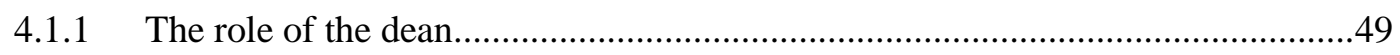

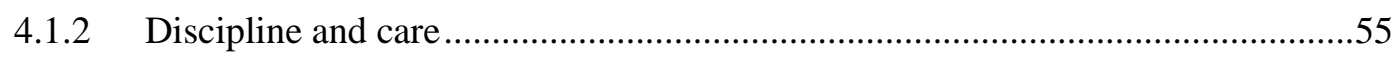

4.1.3 A distinction between the junior and senior schools .........................................57

4.1.4 Reactive versus proactive care ......................................................................60

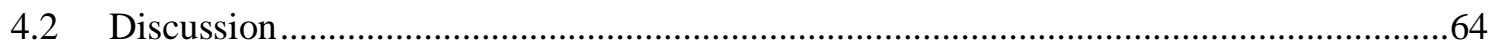

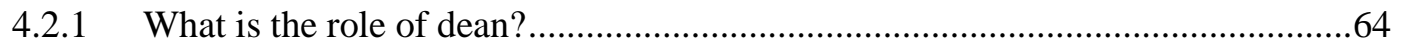

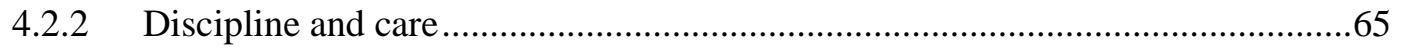

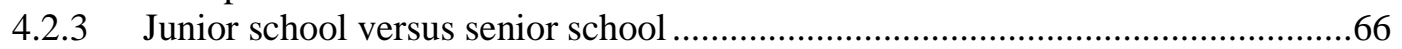

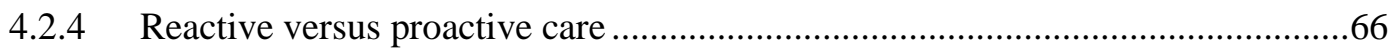

4.2.5 Behavioural versus academic focus .............................................................67

Chapter 5: Challenges and affordances of the role of the dean 69

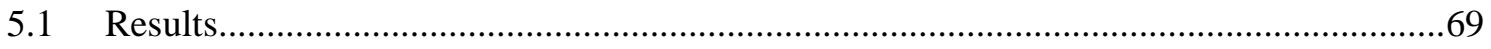

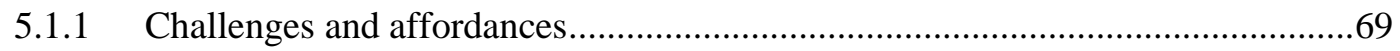

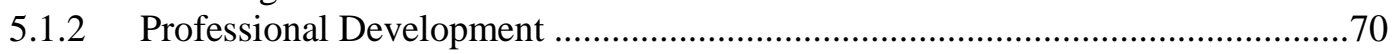

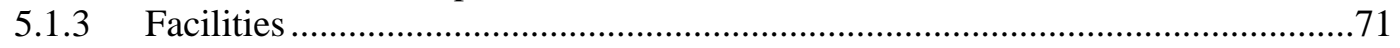

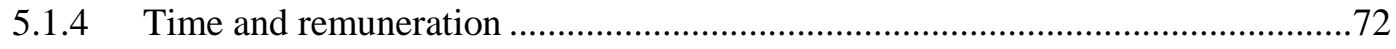

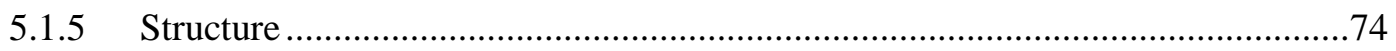

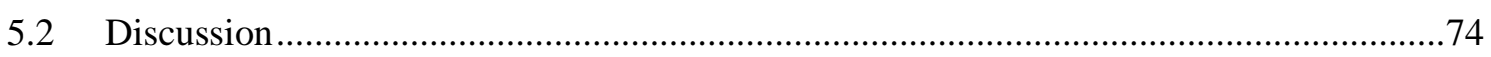

$\begin{array}{ll}\text { Chapter 6: Conclusion } & 77\end{array}$

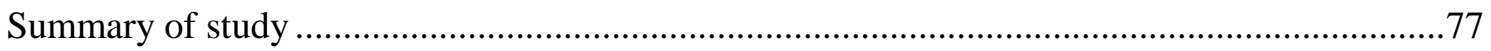

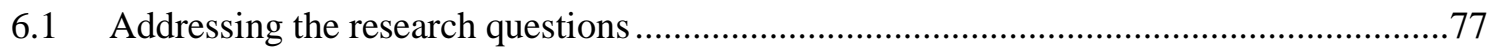

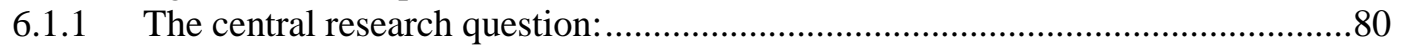

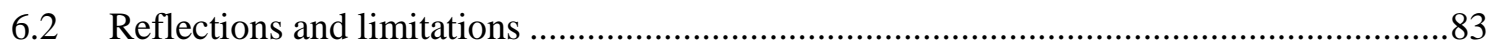

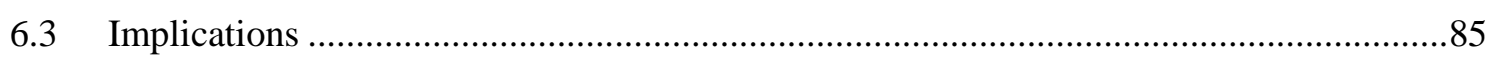

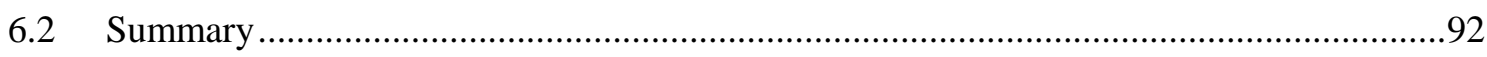

$\begin{array}{ll}\text { References } & 95\end{array}$

$\begin{array}{ll}\text { Appendices } & \mathbf{1 0 5}\end{array}$

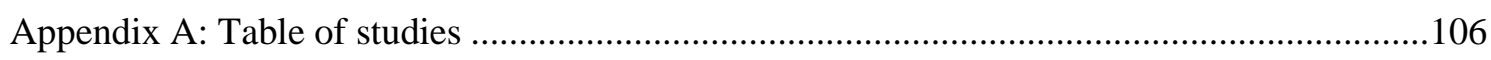

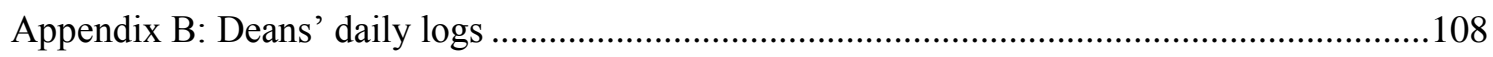

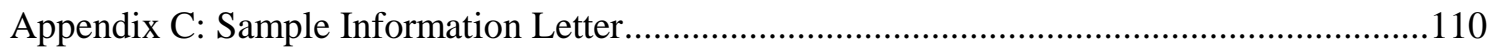

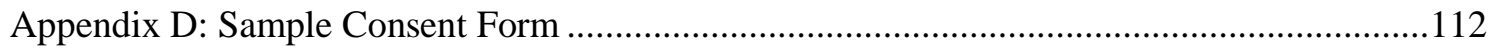

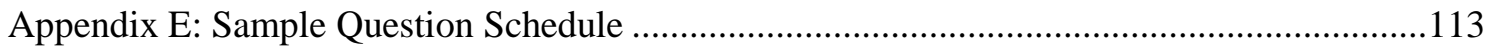

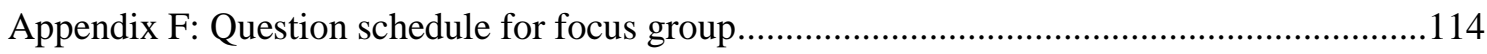

Appendix G: Job Description of the Dean at Northside College .............................................115

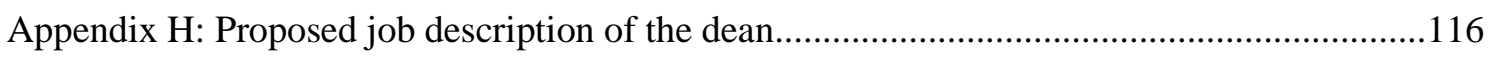




\section{List of Tables}

Table 1. Rationale for criteria for selection of study school 29

Table 2. Number of students in each year level $\quad 30$

Table 3. Teacher participant responsibilities $\quad 33$

Table 4. Example items developed to measure time spent on reactive casework 42

$\begin{array}{ll}\text { Table 5. Definition of ranges } & 44\end{array}$

Table 6. Lines of authority from job descriptions of dean, head of department, and form teacher 50

Table 7. Deans' tasks as detailed in job description and their nature using identified categories informed by

$\begin{array}{ll}\text { Best (1999) } & 51\end{array}$

Table 8. Statements describing the contrasting roles of the dean 56

Table 9. Key aspects of pastoral care evident in the role of the dean as informed by the definition pastoral care (Section 1.2)

\section{List of Figures}

Figure 1. Codes, categories and themes utilised in data analysis ........................................................ 40

Figure 2. Percentage of time deans spend on different aspects of care ......................................................55

Figure 3. Percentage of time spent on tasks associated with social, emotional, and behavioural issues

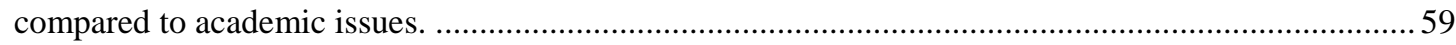

Figure 4. Percentage of time spent on tasks categorised as reactive or proactive tasks ...............................6 61

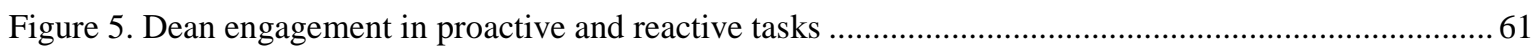

Figure 6. Interpretation of the interrelationship between Best's (1999) pastoral tasks ............................... 83 


\section{Glossary and Abbreviations}

Ākonga

Dean

ERO

Form teacher

HoD

KAMAR

MOE

National Certificate of Educational

Achievement (NCEA)

NZTC

Tikanga Māori

Whānau
Māori term for student or learner

A teacher with pastoral care responsibility for a defined group of students, often an entire year level. This role is also referred to as head of house, year level dean, head of year, year head, house master, head tutor, and guidance teacher.

Education Review Office

A teacher responsible for a range of pastoral care and administrative duties of a smaller group of students. This role is often referred to as form tutor, year level mentor, home room teacher.

Head of Department

A school administration software with features that support for general administration, mark books, fees, calendars, and more for students, parents, and the school

Ministry of Education (New Zealand)

A New Zealand national qualification for senior secondary students

New Zealand Teachers Council

Māori term for general behaviour guidelines for daily life and interaction in Māori culture

Māori term for extended family 


\section{Chapter 1: Introduction}

In my experience as a secondary school teacher, I began to notice the differences between and within schools in pastoral care structures and policies. I found that the role of the dean was included within a school in order to promote the learning, behaviour, and welfare of students along with other administrative and disciplinary tasks. The job appeared to be large and varied. Observing that the policies and structures that informed the role of the dean varied between and within schools, I became interested in the purpose of this role and its effect on student well-being.

The structure of pastoral care systems is administered at local level in New Zealand. Schools have the autonomy to create positions to address the needs of their school. In my experience, most schools appoint a teacher to the management position of dean or head of year, or both. One school I taught at allocated a dean within a house structure, ensuring that students had the same dean for all of their years at secondary school, and a form teacher from the pool of teachers who belonged to that house. Another school allocated a dean to each year level, and generally, form teachers remained with a year level also. There are many arrangements that exist within New Zealand secondary schools, each with its own benefits and detriments.

The role of the dean appeared to function as a core component in the provision of pastoral care to students. My understanding of the role of the dean was that the dean provided care and support to all of the students they were responsible for; however, deans appeared to work in a reactive nature, dealing with problems that the students in their care were facing. I began to wonder about why pastoral care systems were structured in this way and whether there was a more effective way of providing care for students. I also observed the large workload that the deans were subject to, the serious issues that they were dealing with often on a daily basis, and the attempts to coordinate a large number of specialist subject teachers in the delivery of a specialised programme for one student. I began to wonder what it was that the deans predominantly spent their time on, whether this was the intention of their role, and whether or not this role was effective in providing care to students. As there is little information available on this area of the education system, I chose to focus my investigation on the role of the dean in order to understand how it contributes to the provision of pastoral care to students in the school. 
This chapter introduces the difficulty associated with defining the term 'pastoral care', and details the definition that will be utilised throughout this study. Following this is a brief justification of the importance of the provision of pastoral care to students. The international perspective on pastoral care is briefly outlined, giving some context for the New Zealand perspective on pastoral care. Principles, such as models of pastoral care that were used to inform the study, are outlined. The chapter concludes with presentation of the research questions and an outline of the structure of this thesis.

\subsection{The definition of pastoral care}

Defining pastoral care has proven challenging over the last century (Best, 1995; Calvert, 2009). The etymology of the word is suggestive of "ecclesial or agricultural roots" (Calvert, 2009, p. 61). Where the term 'pastoral care' is not a commonly used term in education, the concepts behind it often are (Lang, Best, \& Lichtenberg, 1994). Going under different guises, the term 'guidance and counselling' is often used in Canada and in Scotland with similar meaning (Howeison \& Semple, 1996, 2000; Lang et al., 1994). The American concept of guidance and counselling maintains its roots in a more clinician-client based provision of care in schools with aspects of vocational guidance included (Gysbers, 1994). This model is different from the United Kingdom's (UK) model on pastoral care; however, both systems have experienced evolution to encompass a focus on the social, emotional, behavioural, and developmental aspects of care for students in schools (Lang et al., 1994).

The term pastoral care is used within the New Zealand schooling system and utilised by the Ministry of Education [MOE] (New Zealand Qualifications Authority, 2013). However, the term is used broadly and vaguely. When I asked the MOE for a definition of pastoral care, a Senior Policy Analyst responded with "care, support and guidance for students outside academic matters" ${ }^{1}$ (W. Yang, personal communication, 6 April 2013) but further clarified that there was no legal definition and that only one document in the MOE utilised this term.

The definition that will be used for this thesis includes the guidance for students in aspects of behaviour, academic achievement, and social and emotional well-being:

1 The MOE informed me that "orientation on the school facilities and programmes (in terms of what they are about, involve or will lead to further study or work), health and safety, career counselling and other counselling, insurance and refund, accommodation arrangement, and community activities, are regarded as pastoral care matters" (W. Yang, personal communication, 6 April, 2013). 
Pastoral care is concerned with promoting pupils' personal and social development and fostering positive attitudes: through the quality of teaching and learning; through the nature of relationships amongst pupils, teachers and adults other than teachers; through arrangements for monitoring pupils' overall progress, academic, personal and social; through specific pastoral and support systems; and through extra-curricular activities and the school ethos. In such a context it offers support for the learning, behaviour and welfare of all pupils and addresses the particular difficulties some individual pupils may be experiencing. (Department of Education and Science, 1989 , p. 3)

This definition is sourced from the UK Department for Education [DfE] (1989) report and has been selected as it is a detailed and frequently cited definition (e.g., Collins \& McNiff, 1999; Fleming, 2012; Hearn, Campbell-Pope, House, \& Cross, 2006; Purdy, 2013). The definition is lengthy, and demonstrates the complexity of the term and its multifaceted nature.

\subsubsection{Introduction to pastoral care}

Different theorists and researchers have proposed different models of pastoral care and attempts to analyse the structures and process are numerous (Best, Ribbins, \& Jarvis, 1977; Lang, 1983; Watkins, 1985). Best's (1999) model of five pastoral tasks is based on the "accumulative wisdom" of previous studies (p. 57) and because of this, it is utilised throughout this thesis to inform instrument development and the deductive approach to data analysis (Section 2.4). The pastoral care systems in schools can be complex and multifaceted. The systems lend themselves to analysis in many different categories, some that overlap and repeat. Best's (1999) model summarises and describes in detail the two contrasting functions of pastoral care systems: reacting to issues, and preventing such issues from occurring. A third function that exists within the pastoral care system and which is often discussed in context of the dean's position is that of administration and management (Carnell \& Lodge, 2002). Best's (1999) model was also utilised and interpreted in an Australian review of pastoral care (Hearn et al., 2006). The model, from the UK, and utilised in the Australian school setting, contributes to its appropriateness for use in this New Zealand study.

The intervention-prevention-promotion model is also discussed by Best (1999). Best proposes a model of five pastoral tasks in schools:

1. Reactive pastoral casework undertaken on a one-to-one basis in response to the needs of children with problems of a social, emotional, behavioural, moral or spiritual nature; 
2. Proactive, preventive pastoral care, often in the form of presentations or activities in tutor or form periods and assemblies, which anticipate 'critical incidents' in children's lives (Hamblin, 1978) and are aimed at pre-empting the need for reactive casework;

3. Developmental pastoral curricula, aimed at promoting the personal, social, moral, spiritual and cultural development and well-being of children through distinctive programmes of [personal and social education], tutorial work and cross-curricular activities;

4. The promotion and maintenance of an orderly and supportive environment by building a community within the school, through extra-curricular activities, the 'hidden curriculum' of supportive systems and positive relations between all members, and the promotion of a pervasive ethos of mutual care and concern;

5. The management and administration of pastoral care in the form of planning, motivating, resourcing, monitoring, supporting, evaluating, encouraging and otherwise facilitating all of the above. (1999, pp. 57-58)

This thesis examines tasks 1,2 and 4 as they encompass the promotion of well-being, and individual casework and are proactive or reactive in nature.

\section{School organisation}

The term pastoral care is often discussed in the context of an enduring hierarchy within secondary schools (e.g., Best, 1999; Brenton, 1989; Calvert, 2009; Carnell \& Lodge, 2002). The hierarchy, and bureaucracy that accompanies it, is discussed as having negative implications for the provision of pastoral care to students with the main emphasis in schools being on academic achievement, leaving pastoral care under resourced and lacking recognition (Calvert, 2009; Clark, 2008; Watkins, 1999). Watkins (1999) describes some secondary schools as "the most hierarchical organisations in Western Europe" (p. 3). He likens the school's basic organisation to a Victorian factory, citing distinct departments operating independently, contributing to the final product. Often the compartmentalised silos that subject departments operate in are held accountable for the entrenched, fragmentary approach to education, at times, creating a dichotomy for teachers in their roles as subject teachers and their roles as pastoral carers (Clark, 2008). 
Watkins (1999) explains that while "many organisations in our changing world develop new structural forms, the secondary school soldiers on, mainly unchanged" (1999, p. 3). Hoy and Sweetland (2000) agree; however, their research indicates that it is not the hierarchy in itself that can embody the negative connotations that the term conjures but instead, it is the way the hierarchy functions which does.

The pastoral care system, as it presently exists in Australia and New Zealand, has evolved from the traditional British house system (Arnott, 1994; Best, 2003; Hearn et al., 2006). The vertical house system, traditionally used in Britain, delegating staff with specific responsibility for pastoral care, has been combined with aspects of the American guidance system to influence the current New Zealand system (Arnott, 1994).

Research by Best (1999) investigated the structure and organisation of schools in the UK following the Education Reform Act 1989. The Act is described as placing emphasis on "the curriculum, on teaching and on students' performance" (Carnell \& Lodge, 2002, p. 109). Best's (1999) survey indicated that, despite the fears of those working in the pastoral care field, pastoral care teams remained valued in many schools. This indicates that whilst policymakers, like those in New Zealand, do not run an official line on the pastoral care of students in our education systems, the power of schools to make autonomous decisions at ground-level has enabled them to retain the structures that they see as important, including those that seek to provide pastoral care. It is this selfgoverning autonomy that has empowered schools to retain potentially stagnant structures (Calvert, 2009; Watkins, 1999), or preserve the traditional hierarchies within school organisation that can hinder progress and collaboration (Hoy \& Sweetland, 2000, 2001).

The term 'Head of Year' (e.g., Best, 2003; Lodge, 2006; Swinson, 2010) denotes a responsibility for an entire year group. This responsibility often involves the students' well-being and progress as a whole person, for example, the students' social and emotional well-being, behaviour management, and academic progress (Howeison \& Semple, 1996; Tucker, 2013). Studies that have examined aspects of the role and that focus on interaction between individual students and the dean (described as 'casework' by Best (1999) include those by Tucker (2013), Farrand, Parker, and Lee (2007), and Nelson $\&$ While (2002). The intention of the role of the dean is also often recorded as involving the monitoring and mentoring of student academic progress (Best, 1999; Clark, 2008; 
Farrand et al., 2007; Nelson and While, 2002) but the successful integration of the pastoral and the academic needs a collaborative approach from staff (Clark, 2008).

\subsection{Why pastoral care?}

The concept of pastoral care in schools has evolved over the last century. In the 19th century, schools became aware of the teacher's "responsibility for the general and moral welfare of the pupils" in their care (Lang, 1983, p. 61). This awareness slowly evolved into the comprehensive definition that is applied to pastoral care in schools today (Section 1.2).

The role of pastoral care in schools has become more important as schools and systems place emphasis on promoting the well-being of students (Best, 1999; Hearn et al., 2006; Lang et al., 1994). The importance of pastoral care in secondary schools is an area supported by research into the value of strong teacher-student relationships, school connectedness (Bishop, Berryman, \& Wearmouth, 2014; Durie, 1985; Frydenberg, Freeman, \& Chan, 2009; Jose \& Pryor, 2010) and the relationship between positive social and emotional well-being for adolescents and their academic achievement (Battistich, Schaps, \& Wilson, 2004; Birch \& Ladd, 1998; Hamre \& Pianta, 2001). Teachers report that student emotional health and wellbeing is inextricably linked to teaching and learning (Kidger, Gunnell, Biddle, Campbell, \& Donovan, 2010). However, there is a gap in the literature around how schools as organisations can promote the well-being of students past the teacher-student relationship (RimmKaufman, 2012). Noddings (1992) proposes that an alternative approach to education is a system based on the care of the students that goes beyond the traditional liberal arts curriculum. The philosophy behind this proposition would see a transformation in education and school structure with a move away from hierarchical organisation in schools. Noddings emphasises the importance of care in schools and philosophises around what is necessary to achieve such a transformational, idealistic change. My experience and the broad theory on care in schools justify further investigation into this field.

The benefits of strong school-home partnerships have been advocated in documents released in New Zealand by the MOE. The School Leadership and Student Outcomes Best Evidence Synthesis (Robinson, Hohepa, \& Lloyd, 2009) also outlines the importance of pedagogical school leadership, a focus on educational outcomes, and 
ensuring that there is "consensus on schools goals" (p. 38). Establishing clear, schoolspecific, school-wide goals in relation to the aims of pastoral care could impact on the quality of care provided for all students (Lodge, 2006). The Teacher Professional Learning and Development Best Evidence Synthesis (Timperley, Wilson, Barrar, \& Fung, 2007) advocates goal setting as part of an inquiry cycle. The cycle prompts teachers and schools to evaluate their actions by addressing key questions, (e.g., "How effective has what we have learned and done been in promoting students' learning and well-being?" (p. xiii)).

The use of community voice, including student, parent and staff perceptions, can be a powerful tool in informing school policy and expectations (Epstein, 2001; Gamage, 1993; Rose \& Shevlin, 2004). Utilising this perception can empower members of the schools' community and increase buy-in and compliance with school policy and expectations (Education Review Office [ERO], 2012; Robinson, Hohepa, \& Lloyd, 2009). There is little evidence relating to how secondary schools can utilise community voice to inform the role of the dean in relation to promoting student well-being, particularly in a New Zealand context.

Howeison and Semple (2000) utilise student voice as a key informant in educational improvement. Their study revealed some similarities and some discrepancies in the way students and teachers experience the guidance system within the school. Staff in the study questioned if these students felt that the guidance system was germane to them. The students, however, reported that they did feel the guidance system was relevant for them, mentioning that they too should be assisted along with the targeted group of high needs students. This indicates a conflict in perspective within the school community and the importance of utilising student voice to inform decisions.

\subsection{Perspectives on pastoral care}

\subsubsection{An International perspective}

Internationally, countries including England, Northern Ireland, and Scotland (referred to collectively as the UK), Australia, and Singapore have a larger amount of research and policy on the definition and function of pastoral care than New Zealand. For example, the UK has an organisation (National Association of Pastoral Care in Education) that publishes the journal Pastoral Care in Education and the Northern Ireland Government has commissioned reviews of pastoral care in schools (Department of Education 
Northern Ireland, 2008). England has created National Occupational Standards for Supporting Teaching and Learning [STL] which detail a section on pastoral care and welfare (Department for Education United Kingdom, 2012). These standards advocate the importance of quality pastoral care in order to support teaching and learning; for example, managing behaviour, academic attainment, and liaising with external agencies in the community (e.g., STL50 Facilitate children and young people's learning and development through mentoring). This range of tasks is expected to be addressed by staff who have the necessary skills and knowledge to deliver pastoral care. Skills and knowledge required by staff are clearly and specifically detailed in ten different standards, each comprising between 30 and 40 performance criteria and between 10 and 20 areas of knowledge and understanding. Staff should be familiar with all criteria in order to effectively perform the aspect of pastoral care that is specified in each standard (Department for Education United Kingdom, 2012). I have been unable to find information as to how these standards are utilised by schools.

Calvert (2009) explains that key stages in the evolution of pastoral care, whilst a UK phenomenon, may be recognisable to other countries, due to our "colonial inheritance" (Best, 1995) of education structures and systems, as in New Zealand and Singapore (Lang et al., 1994). These stages evolved from reactive care, that addressed issues as they arose, to proactive care approaches that were intended to pre-empt the issues that students were going to face (Calvert, 2009).

The Government of Western Australia commissioned a report on pastoral care (Hearn et al., 2006). The Western Australia Department of Education's website ("Behaviour and wellbeing", 2010) features some information on the provision of pastoral care in schools. A survey of sectors responsible for Australian schools indicated that four out of 29 sectors reported having a pastoral care policy (Hearn et al., 2006). Sectors in the survey reported understanding the importance of policies in pastoral care but cited "their fundamental complexity ... the burden of overload in meeting these obligations ... the lack of professional education and guidance for teachers ... and how policy may be operationalised by schools at the local level" (p. ii) as reasons why they did not have a policy for pastoral care. This indicates a perceived difficulty in administering a pastoral care policy for schools and addressing how such a policy would manifest itself in unique, self-governing schools, a concern pertinent to New Zealand. 


\subsubsection{A New Zealand perspective}

To date, no guidelines or goals have been provided by the MOE to the education sector concerning pastoral care for all students in New Zealand. There is a policy surrounding the pastoral care of international students (NZQA, 2013). The policy describes the care provisions required for international students living and studying in New Zealand but excludes any reference to academic care.

The National Education Goals (MOE, 2004), as part of the National Educational Guidelines mentioned in the Education Act 1989 (2014), do not make explicit mention of pastoral care, nor the promotion of well-being for all students in New Zealand schools. They do specify, under the National Administration Guidelines (MOE, 2013), that the Board of Trustees for each school must provide "a safe physical and emotional environment for students." (NAG 5a). Whilst there is an expectation from the Government that schools take increasing responsibility for student well-being (Parata, 2012), there remains no requirement under statute for schools to prioritise pastoral care, except in the provision of a safe school environment (MOE, 2013). This allows each secondary school within New Zealand to provide pastoral care in whichever way they deem appropriate.

The New Zealand Teachers Council [NZTC] Registered Teacher Criteria emphasise the promotion of fostering well-being. The first two criteria state that teachers should:

1. establish and maintain effective professional relationships focused on the learning and wellbeing of ākonga ${ }^{2}$.

2. demonstrate commitment to promoting the well-being of all ākonga. (New Zealand Teachers Council, 2009, p. 2)

The presence of these criteria indicates that the promotion of well-being and the care of students is an important part of the education system in New Zealand; however, further clarification of the terms and implementation of care provisions for students are needed. Within New Zealand secondary schools, pastoral care can be overseen by a deputy or assistant principal who leads a team of year level deans (there are variations on this model in New Zealand including whānau groups ${ }^{3}$, vertical tutor groups ${ }^{4}$ and house

2 Ākonga refers to all learners or students (NZTC, 2009, p. 2).

3 A concept based on the idea of extended family where the school is divided into smaller whānau groups. These groups are vertical and include students from across the year levels of the school.

4 Vertical tutor groups are groups looked after by one tutor teacher or home room teacher that include students from across the year levels. 
systems $^{5}$ ). Generally, within New Zealand schools, there are two different middle management groups- pastoral care roles manifesting in the role of the dean, and curriculum roles manifesting in the role of Head of Department (Clark, 2008; Joyce, 2013; Murphy, 2011). As the concept of promoting well-being in schools becomes more of a priority in secondary education (New Zealand Council of Educational Research, 2013), it is important to examine the role and effectiveness of our current pastoral care structures. The ability of schools to make autonomous decisions about the delivery of pastoral care in the absence of nationwide guidance means that the role of the dean is context specific (Best, 1999).

As indicated by the New Zealand Curriculum (MOE, 2007), the concept of pastoral care can be taken to encompass the delivery of personal and social education, termed in New Zealand as falling in the learning area of Health and Physical Education. This thesis is concerned only with the guidance and counselling aspects of pastoral care (Section 1.1) and not with the Health and Physical Education curriculum.

\subsection{Research questions}

In summary, the benefits and complexities of the provision of pastoral care highlight the importance of exploring pastoral care in relation to New Zealand schools. Given the dean has a major responsibility for pastoral care, the following research questions have been proposed to further explore this role.

The central question for this thesis is:

What aspects of pastoral care are evident in the role of the dean as intended by school policy and documentation, as enacted by the deans and as received by the students?

The sub questions are:

1. What is the role of the dean as perceived by members of the different groups in the school community, including the senior managers, the dean themselves, teachers, and students?

5 The house system is a broader division of the school vertically. Some schools provide care through the house system, whereas some schools use it as a form of competition to promote sporting, academic and cultural achievement. 
2. What is the role of the dean as defined by documentation designed to inform the management of the school, including staff role descriptions, school policy and strategy documentation?

3. How are staff spending their time in their role as dean?

4. How do perceptions and documents concerning the role of the dean and the dean's practice compare in evaluating the aspects of pastoral care addressed by the dean?

5. What challenges and affordances do deans experience in relation to addressing aspects of pastoral care, and therefore promoting student wellbeing?

\subsection{Structure of the thesis}

This section outlines the structure of the thesis, detailing the content of each chapter.

Chapter Two is a review of the current literature on pastoral care and the role of the dean. The literature that is utilised throughout this thesis is introduced and explained, followed by thematic sections including the role of the dean, the structure of pastoral care systems, perceptions on the academic-pastoral divide, academic mentoring, and resources that impact the role and function of the dean.

Chapter Three outlines the methodology and method developed and utilised in the study for this thesis.

Chapter Four and Chapter Five present the findings of this study to address the research questions. In Chapter 4, data from the three data sources are presented in an attempt to address research sub questions 1, 2, 3, and 4 on the role of the dean. Chapter Five presents the results of the study to address research sub question 5 on the challenges and affordances in the performance of the role. The chapters end with a discussion of the major findings, and a comparison with existing literature.

Chapter Six summarises the key findings of the thesis, relating them to the wider context of the New Zealand education system. Implications for stakeholders, as well as limitations of, and reflections on the current study are considered. Possible areas for future study are suggested. 


\section{Chapter 2: Literature Review}

This literature review examines the current body of literature concerning pastoral care and the role of the year level dean in secondary schools. The purpose of this literature review is to describe the history and evolution of pastoral care, and the research on the organisation of schools and how they cater for the pastoral needs of their students. The discussion details the theoretical basis of aspects of pastoral care and organisational structure, and common issues that schools face in the provision of care to students. The review also aims to examine the role of the year level dean in order to establish and investigate the research questions for this thesis. The chapter includes the following sections:

2.1 An introduction to the literature included in the review.

2.2 The role of the dean.

2.3 Theory and applications of pastoral care structures in schools.

2.4 Perceptions of the pastoral-academic with a brief focus on the role of bureaucracy in school organisation.

\subsection{Academic care.}

2.6 The impact of resources in the fulfilment of the role of the dean.

\subsection{Introduction to the Literature}

There is little empirically based research examining how the role of the dean functions in the promotion of well-being for students, whether they are effective in promoting student well-being and which pastoral care structure is most effective in secondary schools. The literature in this review has emerged from the UK and Australia. The UK's influence on the colonial and contemporary New Zealand education system is notable. The systems and processes continued to evolve here with the influence of the tikanga of the indigenous Māori population and trends from the United States of America, creating a unique education system (Arnott, 1994). As there is limited literature written on the New Zealand school pastoral care structures, work from the UK, Australia, and other countries will be used to inform this literature review.

Practice-based accounts of in-school developments (Lodge, 2006; Nadge, 2005; Reading, 1999; Rose \& Pelleschi, 1998) have been included alongside qualitative research in the literature sections of each chapter. Whilst these individual accounts are personal and 
subjective in nature, collectively, they reveal ideas surrounding the role of dean. A table of key empirically-based studies is included (Appendix A).

\subsection{The role of the dean}

The role of the dean is intended to provide students with a nominated person to assist them with a range of issues as well as encourage positive relationships, not just between themselves and the students, but between all staff members and students (Griffiths, 1995; Howeison \& Semple, 2000; Lodge, 2006). Whilst there is limited literature around the role of the dean specifically, there is research to support strong teacher-student relationships, school connectedness and aspects of mentoring that have a positive relationship to social and emotional well-being in adolescents and their academic achievement (Battistich et al., 2004; Birch \& Ladd, 1998; Frydenberg et al., 2009; Hamre \& Pianta, 2001; Jose \& Pryor, 2010).

The role of the dean within the pastoral care structure attempts to address those aspects of care that can create a sense of belonging and therefore well-being for their students (Lodge, 1999). The importance of teacher-student relationships, student-student relationships, mentor or leadership programmes, and extra-curricular activities in schools indicates the value of strong personal relationships within the school community (e.g., Booker, 2006; Cemalcilar, 2010; Karcher, 2005; King, Vidourek, Davis, \& McClellan, 2002; McNeely, Nonnemaker, \& Blum, 2002; Waters, Cross, \& Shaw, 2010). Academic mentoring has been found to have positive impacts on student outcomes such as attitude and motivation (Eby, Allen, Evans, Ng, \& DuBois, 2009).

One of the issues with much of the research that has been conducted in this area is that it is correlational in nature, and hence does not allow causality to be established (e.g., Booker, 2006; Cemalcilar, 2010; Karcher, 2005). It is difficult to determine if it is the characteristics of the school that promote a sense of well-being or that students holding a stronger sense of belonging and well-being ultimately influence other characteristics of the school, such as participation in extra-curricular activities or interpersonal relationships.

The second difficulty with some of the literature (Booker, 2006; Cemalcilar, 2010; Eby et al., 2009; Karcher, 2005; King et al., 2002; McNeely et al., 2002; Rowe, Stewart, \& Patterson, 2007; Waters et al., 2010) is that these studies investigate several variables in 
the form of characteristics (e.g., student-teacher relationships, mentor or leadership programmes, and extra-curricular activities) at the same time. It becomes difficult to distinguish which characteristic is more, or less, related to a sense of well-being if we do not have an understanding of the function of the characteristic. For example, a stronger relationship with a dean or other adult in a New Zealand school often entails more than just having someone the student trusts. It may mean that the student learns different skills through this relationship, including academic mentoring or conflict resolution, or that the student is perceived differently by others in the school community. Whilst examining many variables in the form of characteristics at the same time is problematic, because it makes it difficult to establish which is producing an effect, this example makes it clear that understanding why a particular characteristic is associated with a heightened sense of well-being is important. In this circumstance, the complex nature of the role of the dean highlights a need to further understand which functions of the role provide students with the most benefits of academic and pastoral care.

Theory suggests that trusting relationships established through honest and open communication and positive involvement between young people and adults can assist adolescents in developing relationships with teachers that cognitively represent caregiver-child attachment (Murray \& Pianta, 2007). This is representative, often, of the relationship between the student and the dean and links to the concept that the sense of belonging that begins at a personal level can promote a positive, protective sense of belonging between the student and the school (Jose \& Pryor, 2010).

In a study conducted in New Zealand (Averill, 2009), two deans reported through qualitative interviews that they felt there was a conflict between their role as dean and the role of subject teacher who is needed to help students learn. Student perspectives in a study by Howeison and Semple (2000) revealed that they too found the conflicting roles of staff, who were pastoral carers and also subject teachers, challenging. Students explained the difficulty of "getting a row for not doing your maths homework and then you're meant to tell [the dean] your problems" (p. 379), or the fact that one area of their work may suffer because of their dual role: "my guidance teacher, she's always rushing around cos she's got classes...she's got no time" (p. 380) and "they've always got meetings...you're waiting to get your work done and they're away chatting to other people." (p. 380). In Scotland, where this study was conducted, some schools had tried to separate the disciplinary from the supportive aspects of their role; however, this study 
reports students viewing the ability "to maintain discipline and to defuse situations effectively" as a valuable attribute of effective pastoral staff (p. 383). The challenges between balancing the nurturance and control required in being a teacher are likened to those of parenting styles, the most effective being the authoritative, emphasising the positive impacts of high levels of support with firm boundaries (Turliuc \& Marici, 2013; Walker, 2009).

The role of the dean remains associated with its traditional function of individual reactive casework. Carnell and Lodge (2002) describe this distortion as "watered-down welfare" (p. 112) in that it attempts to assist only a small number of high needs students. Changes made to the discipline policies and teaching strategies which meant the dean working with a small group of students more intensely, were seen as an effective and positive shift by teachers, pupils, and deans in the evaluation (Swinson, 2010). Howeison and Semple (1996) report that all of their study participants indicated that staff with pastoral care responsibilities were responsible for "guidance for all pupils" (p. 238); however, the pastoral staff themselves did not believe this could be fulfilled. This could link to a study by Farrand et al., (2007) that examined pastoral roles as reactive positions to assist students in need. The "unduly reactive" (Howeison \& Semple, 1996, p. v) nature of the role may explain concerns that limited resources of the role mean that deans find it challenging to address the needs of all students within a year level or group (Howeison \& Semple, 1996; Tucker, 2013).

Deans (after form teachers) were found to be someone young people would go to for help with issues involving school, friends and family (Farrand et al., 2007). Farrand et al. asked students to indicate which person out of a list provided (form teacher, head of year/dean, special educational needs coordinator, teaching assistant, Connexions ${ }^{6}$, doctor, school nurse) they were most likely to go to for help when encountering any one of 12 difficulties "reflecting a range of milder emotional or behavioural problems" (p. 467). Deans were the most likely person that the students in the study would go to if they "had been unfairly treated or spoken to by a teacher" (p. 470). In every other category, students were more likely to go to their form teacher for help; for example, if the student "was really worried" about exams or coursework. Fourteen percent identified their dean as someone they would go to for help compared to $64 \%$ identifying their form teacher.

6 Government organisation to provide advice and guidance to young people aged 13-19. 
Rose and Pelleschi (1998) documented changes made in a secondary school when smaller tutor groups were introduced. Staff reported this initiative as being effective in reducing their pastoral workload by spreading it across staff. Pupils reported valuing the time they had with their form teacher and wanted more contact time with them, with $87 \%$ believing the pastoral system was better than before. Howeison and Semple (1996) report time pressures as contributing to deans only being able to "concentrate on pupils in trouble or those with obvious problems at the expense of 'ordinary' pupils" (p. v). However, staff interviewed were "virtually unanimous" in the view that all pupils should have ongoing, one-on-one interaction with a guidance teacher (p. 73). Staff identified students with truancy and attendance issues as the main group with whom they spent their time, explaining that this was often an indicator of deeper issues. This discrepancy aligns with Marland's assertion that "the largest and most complex step in our profession is that from being responsible for pupils to being responsible for adults" (Marland, 1988, as cited in Marland, 2001, p. 31). Marland cites a previous argument of his own here, indicating minimal change in the role of the dean.

\subsection{The structure of pastoral care systems}

Secondary schools typically implement a horizontal structure with dedicated staff responsible for each year level (Arnott, 1994; Best, 1999; Galassi, Gulledge, \& Cox, 1997). Best's (1999) study of pastoral care structures in schools indicates that whilst vertical structures exist in schools, "over $80 \%$ of respondents reported horizontal systems" (p. 62), confirming anecdotal evidence of the growing popularity of this system. Lodge (2006) discusses the horizontal grouping of students as being "embedded in the UK education system" (p. 6). In a survey of 20 schools in the UK, 17 had a horizontal system in place (Fincham, 1991). Similarly, the horizontal system has remained a feature of the New Zealand secondary school system as reviewed in the early 1990s (Arnott, 1994).

The vertical structure utilises groups sometimes called family groups or whānau groups. A study conducted in the UK reported varying opinions from head teachers as to the effectiveness of the two structures, with some championing the vertical for "developing close links with parents" (Nelson \& While, 2002, p. 22) and others supporting the horizontal describing it as a "backbone" and a better way to administer pastoral care (Nelson \& While, 2002, p. 22). 
A report by ERO (2012) described the positive effects of the vertical grouping, system. These effect include; that the form teacher develops a full understanding of the "whole student' during their time at school, the form teacher forms a positive relationship with the student, and the structure provides the opportunity to build strong connections with families' and students' career aspirations. This, in turn, makes it easier for parents, including the parents of Māori and Pacific Island students, to make contact with the school. Neither these studies nor the ERO report discuss the benefits of either system from the perspective of the student.

This ERO report (2012) did not clearly describe the processes involved with this structure within the school. For example, there is variation between schools in how teachers are attached to groups within both horizontal and vertical structures. In New Zealand secondary schools, deans tend to be either attached to a year group and follow that year through from Year 9- 13 (rotating) or remain at one year level, for example, employed as the Year 11 Dean for several years (static). The report neglects to consider that like a vertical system, some horizontal systems will employ the rotating system, and others, a static system.

Students having one dean for their entire time at secondary school can have positive implications. Having students and teachers working together for more than one year may help establish more enduring relationships, increase familiarity (George \& Alexander, 1993), and promote caring student-teacher relationships (Galassi, et al., 1997). Contrarily, students may become frustrated if there is a personality mismatch between them and their dean (Bulman, 1987) in a rotating system. The static system provides staff with the opportunity to develop expertise in dealing with issues that are specific to one year level (Bulman, 1987). Bulman discusses the possibility of introducing a combination of rotating and static systems in order to reap the benefits of both systems.

\subsection{Perceptions of the academic-pastoral divide}

A review of Australian school structures found that the pastoral care section of the school "took the classical pyramidal form of Weberian bureaucracy and [was] frequently separated from parallel academic or curricular structures in unhelpful ways” (Best, 1999). Best's (1999) study investigated the pastoral care structures in schools, expecting to see dramatic changes in structure after the Education Reform Act (1988) in the UK. The study found that there had not been significant changes, as expected, and that the orthodox structure of the pastoral-academic split remained. 
A qualitative survey conducted by Best (1999) demonstrated that a small number of participants recognised the 'divide' between the pastoral and the academic. Academic progress is, at times, referred to as a separate issue outside of the realm of pastoral care, yet it is acknowledged that these two aspects are inextricably linked (Best, 1999; Clark, 2008; Lodge, 2006; Nadge, 2005; Reading, 1999; Rose \& Pelleschi, 1998; Swinson, 2010). Accounts of in-practice development discuss the importance of pastoral care and academic mentoring functioning in a complementary way (e.g., Best, 1999; Reading, 1999; Nadge, 2005; Lodge, 2006; Clark, 2008; Rose \& Pelleschi, 1998; Swinson, 2010). The consideration of academic and pastoral care as interdependent is necessary in order to best meet the needs of the whole child and address the primary goal of pastoral care which is to support the learning process (Reading, 1999).

Redefining the role of the dean has been discussed in order to better recognise the needs of the students by breaking down traditional distinctions between head of department and dean (Lodge, 2006; Reading 1999; Rose \& Pelleschi, 1998). Examples of the new titles for these positions were head tutor (Rose \& Pelleschi, 1998), and cross-curriculum manager (Reading, 1999). Whilst some working in the field would welcome a restructure of the pastoral care system in schools to redefine how care is administered to promote learning for students (Calvert, 2009; Watkins, 2009), the complete abandonment of any pastoral care responsibilities creates "fear" in others (Carnell \& Lodge, 2002).

\section{Making bureaucracy work}

An "enabling approach" (Hoy \& Sweetland, 2000, p. 531) may assist in integrating the academic and the pastoral and reduce the dichotomy that teachers experience, categorising them as either a pastoral carer or a subject teacher (Clark, 2008). The original concept of enabling hierarchies in schools is addressed by Hoy and Sweetland in two studies $(2000,2001)$. Their 2001 study helped to confirm their theory that schools with enabling bureaucracies can actually be helpful in problem solving. An enabling bureaucracy is one where "the rules, regulations, and procedures are helpful and lead to problem solving among members rather than rigid, coercive activities that demand conformity" (2001, p. 301). The study found that staff dependence on rules to make professional decisions was negatively related to the measure of enabling bureaucracy. They related this finding to "job codification" (p. 305). Job codification is the extent to which a job description is defined (Pandey \& Gordon, 2000) and the rigidity of the description. High levels of job codification, with strict rules for decision making and a 
dependence on superiors, were found to relate negatively with enabled bureaucracy, and enabled bureaucracy therefore related negatively to role conflict (Hoy \& Sweetland, 2001). Enabling organisations provide the right conditions to minimise role conflict (Hoy \& Sweetland, 2001).

Practice-based accounts of developments within schools around the role of the dean indicate a shift towards the abolition of separate managers for these areas (Lodge, 1999, 2006; Reading, 1999; Rose \& Pelleschi, 1998). The studies generally support a learningcentred model with a team of form teachers, led by one more senior form teacher addressing the academic and pastoral needs of the students (e.g., Reading, 1999; Rose \& Pelleschi, 1998).

The work of Hoy and Sweetland $(2000,2001)$ can be linked to these developments, creating the proposition that even if the staff structure or role definitions change, how the new hierarchy is implemented will impact on the efficiency of the new system. Best's (1999) analysis of the school structure as that of "Weberian bureaucracy" (p. 4) seems to over-simplify the complex nature of bureaucracy in secondary schools. Best (1999) suggests that pastoral care structures within the schools fail to align with the academic structures without explaining why this specific structural distinction contributes to a form of bureaucracy that limits functionality.

The complex nature of bureaucracy in secondary schools is traditional, entrenched and constructed over a long period of time within a range of educational institutions (Hoy \& Sweetland, 2001). Hoy and Sweetland also propose both positive and negative effects of bureaucracy. The factors of how the bureaucracy functions, how hierarchies are implemented, and how dependent staff are when making professional decisions are all factors to consider when analysing why a school structure is not working. Additionally, how well staff communicate and demonstrate flexibility within their roles and rules when problem solving can impact the efficiency of a school structure (Hoy \& Sweetland, 2001). It is evident that some clear guidelines on responsibilities within pastoral roles can enhance staff perceptions of their roles and minimise confusion within this complex and multi-faceted area of responsibility (Howeison \& Semple, 1996). 


\subsection{Academic Care}

One study adopted the term 'Academic Care', advocating that pastoral care and academic progress are inextricably linked (Nadge, 2005). Nadge's study revealed that teachers saw value in understanding how they could impact student well-being, supporting Chittenden's (2010) claim that every teacher is a pastoral carer. A New Zealand study claimed that "teachers and principals reported that more accurate assessment results were gained when a student's social or pastoral needs were met” (Mutch et al., 2011, p. 241), however, the study does not detail how the accuracy of the assessment results was determined beyond teacher opinion.

Several studies detail the development of the dean's role into a position that places more emphasis on the academic mentoring and monitoring of students than was traditionally given, developing stronger links between pastoral care and academic care (Lodge, 2006; Reading, 1999; Rose \& Pelleschi, 1998). The role of a cross-curriculum manager, as developed by Reading (1999), describes the main purpose of this role as academic and behavioural monitoring. Reading's account of the practice-based development of this role within three schools describes immense demands on the time of the cross-curriculum manager due to the amount of academic monitoring of individuals and classes encompassed by the role. Form teachers were assigned to groups as well, to support the students in both pastoral and academic realms and to support the cross-curriculum manager. There was only an anecdotal account from one individual in this article to support whether or not this development was effective. Rose and Pelleschi (1998) also detail a practice-based development to address a school's pastoral needs by reengineering a school's pastoral structure and system from horizontal to a semi-vertical 'family' system (Section 2.3). This decrease in work needed in administrative areas enabled increased time spent for mentoring and developing individual action plans.

In Rose and Pelleschi's (1998) account, form teachers used half-termly formative assessment with each student to formally record academic goals. The senior managers and staff who were interviewed for this study noted that the academic mentoring was not effective immediately after the changes had been made, but their commitment to improving the mentoring programme was indicated by the fact that they were determined to continue working on this area. A limitation of the concept of academic mentoring that may explain the lack of success in this account is that mentoring programmes often fail because of the difficulty in synthesising a genuine mentoring relationship (Darling \& 
Hamilton, 1996). It may be that the label of 'academic tutor' as someone who assists students towards their academic goals in a formal way is a more appropriate description than mentor.

Rose and Pelleschi (1998) noted that there was some discrepancy between staff from the senior school (Years 10 and 11) and staff from the junior school (Year 7, 8 and 9) in their evaluation of the structural staff changes. Senior school staff were less satisfied with the changes overall than those working in the junior school, and in particular, thought that the induction process for students in the senior school was not an improvement.

The importance of the new role of cross-curriculum manager is in supporting the learning process, and most strategies to achieve this (including monitoring and mentoring) could be proactive and/or reactive (Reading, 1999; Rose \& Pelleschi). The monitoring enabled staff to identify under-achieving students and arrange for mentoring. This strategy is both reactive in that it responds to the underachievement of students, and proactive, in that it designs a programme going forward in order to improve outcomes for that student (Reading, 1999; Rose \& Pelleschi, 1998). In studies by Howeison and Semple (1996, 2000), deans' (guidance teachers') work was named 'caseloads', indicating the reactive nature and individual casework conducted by these teachers. Where proactive care is discussed (e.g., Best, 1999; Mowat, 2010; Rose \& Pelleschi, 1998), it is done so in relation to existing school practices, for example, explicitly teaching pastoral curricula or delivering information in assemblies and induction programmes; however, they do not detail how these initiatives were developed or implemented and whether or not they were in response to student needs.

\subsection{Resources}

Nelson and While (2002) identified several factors in their qualitative study across 19 schools that constrained pastoral care. Three of these factors- facilities, time, and professional development- directly related to the role of the dean.

\subsubsection{Facilities}

Participants from several studies identified privacy as an important factor in the provision of pastoral care (Howeison \& Semple, 1996, 2000; Nelson \& While, 2002; Tucker, 2013). Evidence from one study (Tucker, 2013) indicated the importance of allocating a physical space for private conversations with staff "without feeling threatened or judged" (p. 284). 
One study found a dissatisfaction among pupils when asked by their deans to discuss their issues in a public area, finding this a difficult conversation to navigate (Howeison \& Semple, 2000); however, staff participants were wary of the risk of "litigation for teachers who might find themselves compromised when alone" (Nelson \& While, 2002, p. 25). The practice of leaving doors open or having another person present, whether staff or student, was accepted and participants recognised that this may negatively influence their ability to assist a student. Recommendations from the New Zealand Educational Institute (2006) state that schools should enforce policy concerning "Visibility in the workplace which protects both members and children" and "Practices which prevent members from being vulnerable to allegations" (p. 1).

\subsubsection{Time}

High job demands, including time pressures, contribute significantly to job stress and teacher burnout and this area of concern is well documented within the teaching profession (Hakanen, Bakker, \& Schaufeli, 2006). Best's (1999) studies on teachers' perceptions of pastoral care a decade after the ERA (Education Reform Act, 1988) indicate that participants did not note a significant change after the ERA was enacted. There was a general perception that the importance of pastoral care increased with $73 \%$ and $58 \%$ of respondents indicating that they thought more importance had been given to the areas of casework and tutorial work respectively (Best,1999). However, when asked if more time had been given to casework, only $26.3 \%$ of participants agreed. When asked if allocation of time to tutorial work had increased, only $29.9 \%$ of participants responded positively (Best, 1999).

Deans use non-pastoral allocations of time, including lunchtime and curriculum planning time, to complete pastoral responsibilities (Howeison \& Semple, 1996, 2000; Nelson \& While, 2002). The studies where the role of the dean is developed or redefined cite time and resource restrictions, along with case overload, for deans as reasons for making the changes to the role within the schools (e.g., Reading, 1999; Swinson, 2010).

\subsubsection{Professional development}

Participants in Best's (1999) study gave a positive assessment of professional development in pastoral care areas, indicating that they found development in this area beneficial and that they preferred school-based professional development. Another qualitative study found that subject specific professional development was given priority over pastoral care development courses (Nelson \& While, 2002). Students in one study 
identified a difference between the skills needed for subject teaching and pastoral care responsibilities (Howeison \& Semple, 2000), noting that teachers who have pastoral responsibilities should attend courses like they do for their subject related responsibilities. Based on findings from her New Zealand study, Murphy (2011) concludes that ongoing and specific training for staff with pastoral responsibility is necessary for these staff to meet the needs of this increasingly complex role.

\subsection{Summary}

The literature presented in this chapter has provided a general overview of the benefits and issues that arise in the provision of pastoral care to students in secondary schools. The range of literature highlights a distinct lack of empirically based evidence, particularly that which reflects the state of pastoral care in New Zealand. In order to evaluate the effectiveness of the role of the dean within the pastoral care structures in New Zealand secondary schools, it is important first to attempt to understand how this role functions and what the essence of the role is as experienced by the school community (Section 1.4). 


\section{Chapter 3 Methodology and Method}

This chapter details the empirical phase of this study. Section 3.1 details the theoretical basis of the phenomological nature of the study. The chapter then explains the theoretical underpinnings of a mixed methods approach. Section 3.2 outlines the implementation of the method, including the characteristics of the study and the context. Section 3.3 includes the methods of data collection. Section 3.4 details each method of data collection, in turn, presenting the instrument development, use, and analysis of each form of collection. The final sections detail issues pertaining to the study surrounding ethics (Section 3.6), reflexivity (Section 3.7) and validity (Section 3.8).

\subsection{Methodology}

The study was designed as a phenomenological case study with a social constructivist perspective. The design of the study was informed by Moustakas' (1994) philosophy on the phenomenological paradigm.

\subsubsection{Theory and paradigm}

The paucity of research exploring the role and function of pastoral care, in particular the administration of pastoral care through the significant role of the dean in New Zealand secondary schools, indicates that this specific human experience "stands in need of explanation", and that it remains "something of which we are aware but something that, as yet, remains known to us only in terms of how it appears to us directly through our senses" (Denscombe, 2007, p. 77). This need for further, in-depth explanation led me to utilise a phenomological paradigm in planning, executing and analysing this study as it is well suited to the exploratory intention of the study (Patton, 2002).

In order to represent the experience of those involved and provide rich description of this phenomenon, a case study approach was utilised. This case study sought "to engage with and report the complexity of social activity in order to represent the meanings that individual social actors bring" to this particular school setting (Stark \& Torrance, 2005, p. 33). Whilst the use of a year level dean, in my experience, remains a commonly employed strategy in the provision of pastoral care, for the purposes of this study, the investigation of "an instance in action" (Walker, 1974 as cited by Stark \& Torrance, 2005 , p. 33) aligns with the phenomenological perspective and fits within the social constructivist paradigm. 
The study examined the school (assigned the pseudonym 'Northside College' for this study) as the case. The participants were different members of the school community (Section 3.2.3) in order to understand how the different parts of the school function together and, therefore, understand the school as a whole (Johnson \& Christensen, 2012). Aspects of the school's internal and external context will be examined in Section 3.2.1 in order to detail the context of the case study (Johnson \& Christensen, 2012).

In order to further understand the role of the dean in a secondary school, the research questions were designed to ascertain "how and what meaning [the participants] construct" (Bogdan \& Biklan, 2007) around this role. The phenomenological perspective- that there are multiple ways of interpreting experience available to each of us (Bogdan \& Biklan, 2007; Creswell, 2013)- influenced the construction of the research questions (Section 1.4) in order to gather data from multiple perspectives within the school community and describe how the pastoral care structure within the school was experienced first-hand by those involved (Denscombe, 2007).

\subsubsection{Perception and Intersubjective validity}

Moustakas (1994) states that the primary source of knowledge in phenomenology is perception, and that perception as a source cannot be doubted. The value that is found in perception was utilised in this study through the qualitative methods of interviewing and the use of a focus group. By giving participants the opportunity to divulge their perception of the role of the dean through this study, I aimed to discover new perceptions of this role and contribute knowledge and understanding around the function of this phenomenon (Gurwitsch, 1966).

The use of multiple perspectives sought to address the concept that there are many and diverse perceptions of an experience. Husserl (1960) outlined the philosophical principle of perception, explaining that an entity's meanings are endless and can never be fully known. The use of multiple participant groups and participants within those groups in this study was an attempt to provide a range of perceptions on the role of the dean within the school.

Theoretically, the philosophical concept proposed here by Moustakas (1994) and Husserl (1960) is that just as perception cannot be doubted, the exhaustive nature of perception cannot be fully known. If, as is stated, perception varies not only between 
people but also time and interpretation, the understanding of an event through perception will never be 'known' as the experiences and essence can only be described rather than explained as is the function of transcendental phenomenology (Moustakas, 1994). The limitations of understanding through perception were further exacerbated by the practical considerations of this study. It was necessary to limit the number of participants to a manageable number within the imposed timeframe.

Moustakas outlines the issue of 'misperception' in that "we can easily perceive properties of a thing that it does not possess" (1994, p. 54). In order to address this limitation within the phenomenological framework, and address research question 3 (Section 1.4), the quantitative measure of a dean's daily log was introduced. This tool aims to measure the reality of the dean's role and is further discussed in Sections 3.3 and 3.4.3.

The perception of the dean's role was examined from multiple perspectives, and groups (e.g., the teachers) were asked about what another group of participants' (e.g., the students') perception of the role of the dean was. This, along with a comparison of viewpoints on the role of the dean, was implemented to address Moustakas' (1994) theory of intersubjective validity grounded in Husserl's (1960) work on intersubjective knowledge and labelled as an "interchange of perceptions" (Moustakas, 1994, p. 57). This interchange provided me with the opportunity to view the individual perceptions of participants in the context of community in order to further understand the complexity of the role of the dean within this school.

\subsubsection{Theoretical underpinnings for mixed-methods design}

The theoretical basis of the mixed-methods design of this study is that of pragmatism, in that the method chosen adheres to the methodological appropriateness (Patton, 2002) in response to the research questions. Whilst phenomenology and social constructivism are usually associated with qualitative research (Creswell, 2013), in order to effectively examine the phenomenon of the role of the dean and how it presents itself within the study school, multiple sources of data collection were utilised (Section 3.3). The use of qualitative interviews and a focus group, along with the quantitative data collected to measure the deans' activities during a five-day period, was designed in an attempt to address the "importance of conducting research that best addresses the research problem" (Creswell, 2013, p. 29) as stated in the research questions (Section 1.4). 
In order to effectively address the questions surrounding perceptions of the school community ${ }^{7}$, social constructivist assumptions apply and the study is situated in a sociocultural epistemological framework. Bryman (2012) states that the formation of the research questions should examine whether the organisation and its impact on individuals, or the individuals' social construction of the organisation is to be examined. The researcher is likely to "emphasise the formal properties of organisations or the beliefs and values of members of the culture" (p. 34) as is indicated by the research questions of the current study.

The reality of the role of the dean was necessary to explore alongside the multiple perspectives that exist around the function of this role, including the perspective of the deans themselves on their reality. For this reason, the actual time deans report spending on interactions and tasks concerned with this role were recorded using quantitative methods, and the perspectives of several groups from within the school (e.g., senior managers, deans, teachers, and students) were investigated through qualitative measures in order to better understand how these groups assimilate the role of the dean into the organisation and their own personal beliefs (Creswell, 2013).

Within the social-constructivist worldview, individuals construct subjective understandings of the world and their experiences within that world (Creswell, 2013; Moustakas, 1994). This subjective understanding can be altered through interactions with others, and historical and cultural norms. In order to minimise the influence of the interaction of the study itself in influencing the deans' perception of their role, the order of data collection was carefully considered (Section 3.4).

\subsubsection{The use of mixed-methods design}

A convergent parallel design was utilised in this study for the purposes of triangulation (Creswell, 2014; Creswell, Plano Clark, Gutmann, \& Hanson, 2003). Qualitative interviews and a focus group were utilised alongside a quantitative, self-report record of activities that the deans engaged in during a five-day period: the dean's daily log (Appendix B). Additionally, school documents were collected to inform the results (Section 3.3). Justification for the use of each method of data collection is discussed at the beginning of the sub-sections 3.4.1: School documentation, 3.4.2: Interviews and focus group, and 3.4.3 Dean's daily log.

\footnotetext{
7 Research questions 1, 2 and 4 (Section 1.4).
} 
The perceptions of the interviewees and focus group participants were analysed concurrently with the results from the deans' activity logs to give a comparison of perception versus reality. The analysis of participant perceptions, as presented through interviews and a focus group plus dean activity reporting, will serve as triangulation (Section 3.8.1). The comparative nature of this analysis assisted in formulating the 'essence' of the experience and perceptions held by the participants involved in the study, and also highlight any difference that each of these groups may hold and sufficiently address the research questions (Johnson \& Christensen, 2012).

\subsection{Method Implementation}

This section outlines the process that was utilised in the empirical component of this study. It details aspects of the internal and external context of the study school in order to provide a fuller understanding of the case study context as discussed in Section 3.1.1. It will outline:

- the setting of the study including the selection of the study site (Section 3.2.1)

- the process of recruitment of participants (Section 3.2.2)

- the details of the participants of the study (Section 3.2.3).

\subsubsection{Setting}

This section outlines the characteristics, and the context of the school.

The rationale for the criteria for choosing the study site is presented in Table 1. The participating school, Northside College, met pre-determined criteria of: urban geographic location within the Wellington region, and because it is a state, coeducational secondary school offering five or more years of secondary schooling with a high priority on pastoral care. 
Table 1. Rationale for criteria for selection of study school

\begin{tabular}{|c|c|}
\hline Criteria & $\begin{array}{l}\text { Rationale } \\
\text { To ensure: }\end{array}$ \\
\hline $\begin{array}{l}\text { Urban geographic location within Wellington } \\
\text { region }\end{array}$ & $\begin{array}{l}\text { a large school population }(>800) \text { to } \\
\text { understand the pressures that deans } \\
\text { encounter, within the area that I live. }\end{array}$ \\
\hline State school & $\begin{array}{l}\text { a setting free from religious structures of } \\
\text { pastoral care or special character features } \\
\text { of private schools that may have impacted } \\
\text { on the pastoral care structure of the school. } \\
\text { State schools are also influenced by central } \\
\text { government policy and expectations of } \\
\text { other national bodies (e.g., ERO). }\end{array}$ \\
\hline Co-educational & $\begin{array}{l}\text { that care issues encountered by the dean } \\
\text { were not gender specific. }\end{array}$ \\
\hline Offers five or more years of schooling & $\begin{array}{l}\text { a number of deans from one school could } \\
\text { be included in the study }\end{array}$ \\
\hline High priority on pastoral care & $\begin{array}{l}\text { that deans would hold some responsibility } \\
\text { for the pastoral care of the students. }\end{array}$ \\
\hline
\end{tabular}

In line with case study research (Merriam, 1988), it is important to describe the study context in detail. Northside College is a decile $8^{8}$ school with a student population of over 1200. The latest ERO report states that the school places a priority on pastoral care and focuses on supporting students' transition to secondary school and general sense of well-being ${ }^{9}$. The school is divided by year level, with each year level under the care of a dean responsible for the pastoral care of those students, and senior managers responsible for one or two year levels within the school. The senior management team consists of the Principal, a Deputy Principal and three Assistant Principals. The Assistant and Deputy Principals hold their own area of responsibility. The Deputy Principal has responsibility for Year 11. The Assistant Principals hold positions of responsibility that include; Senior Manager Year 9 and 10, Senior Manager Year 12 and 13, and Senior Manager Operations. Each year level, therefore, has a designated dean (or two) and a designated senior manager who is responsible for the pastoral care of the students.

The dean assigned to the year level follows the year level through their secondary schooling so that the students have the same dean every year. At the end of the five-year cycle, deans can apply to begin the cycle again at Year 9. Year 9 had two deans

8 A school's decile rating indicates the extent to which it draws its students from low socio-economic communities. Decile 1 schools have the highest proportion of students from low socio-economic communities, whereas decile 10 schools have the lowest proportion of these students.

9 Reference withheld to protect the identity of the school. Please contact the researcher for enquiries regarding the source of this information. 
responsible for the year level and this structure was being introduced to Year 10 during the course of this study. The school has implemented various different pastoral structures throughout its time, including a vertical system. The current system has been in place for over 10 years.

The school employs over 80 teachers and also has two guidance counsellors onsite. Official roll numbers, as reported by the $\mathrm{MOE}^{10}$, detail the numbers for each year level as being between 160 and 270 as at July, 2012. These figures are outlined in Table 2 below and are rounded to the nearest ten.

Table 2. Number of students in each year level

\begin{tabular}{|c|c|}
\hline Year Level & $\begin{array}{c}\text { Number of students (rounded to the nearest } \\
\text { ten) }\end{array}$ \\
\hline 9 & 260 \\
\hline 10 & 260 \\
\hline 11 & 220 \\
\hline 12 & 190 \\
\hline 13 & 160 \\
\hline
\end{tabular}

The school experienced recent changes in their achievement data, showing a steady increase in their National Certificate of Educational Achievement (NCEA) attainment data with an increase of $20 \%$ of students gaining their Level 1, 2 and 3 NCEA qualification from $2009-2013^{10}$.

Northside College has a focus on restorative justice ${ }^{11}$ within the school. The staff are provided with professional development in implementing the processes involved with restorative justice and are encouraged to utilise these protocols in managing behaviour within the school. The school utilises their student management system KAMAR. KAMAR is an administrative software tool used to track, monitor, maintain records and therefore communicate with staff, parents and students about individual student progress.

10 Reference withheld to protect the identity of the school. Please contact researcher for enquiries regarding the source of this information.

11 Restorative justice is a strategy to address undesirable behaviour within the school and is described by the school as a focus more on accountability, healing and needs rather than on punitive responses that focus more on punishment. 


\subsubsection{Recruitment of participants}

A convenience, purposive sample was utilised. Along with ERO reports and publicly available school documentation, a personal contact was used to establish school interest and eligibility. I approached the school initially by phone call, this was followed by an email which included an information sheet and consent form for the Principal (Sample information and consent forms are attached as Appendices $\mathrm{C}$ and D). This led to a meeting with the Principal and consent for the school to participate was granted.

Senior managers were approached in person by me and invited to participate. I provided them with an information sheet and consent form along with a verbal explanation of the study and the extent of their involvement. All senior managers indicated an interest in participating.

Deans were invited to participate by an email from an administrative staff member of the College on my behalf that included an information and consent form. This was followed up by a one-on-one discussion with each dean, outlining the purpose of the study and inviting them to participate. During this time, I provided each dean with a hard copy of the information sheet and a consent form. Deans indicated their interest either verbally during the meeting or by email following the meeting. All deans indicated an interest in participating.

The teachers were invited to participate in a focus group during two different staff meetings. All teachers in attendance were provided with an information and consent form. A returns box was placed in the staff room. Eleven staff returned signed consent forms. All of these staff were invited to indicate a preferred time from three options for the focus group interview. Five teachers were available to make one time slot, with some unable to make any.

Students were invited to participate through two randomly selected form classes from each of Year 10 and Year 12.These two year levels were selected in order to represent the junior and senior sections of the school and limit the participant pool. All four classes were provided with information on the study on two occasions and invited to participate in order to enhance the response rate. After the first information session, only one student returned a consent form to express their interest. The second visits resulted in a further three students returning their forms indicating interest in 
participating. All students involved in the study were Year 12. No Year 10 students returned their consent forms.

Students had the option of participating in a one-on-one interview, or to bring a friend with them if they felt more comfortable (Howeison \& Semple, 2012). Students were able to indicate on their form which of their peers they would have liked to bring to the interview with them.

Students were offered the option of handing the consent forms to the office, to their form teacher, or to their dean. All students returned their consent forms to their form teacher.

\subsubsection{Participants}

The participants included the senior management team (the principal, deputy principal, and two assistant principals responsible for year levels), the six deans, a group of five teachers, and four students. To protect their identities, pseudonyms are used for all participants. The pseudonyms given are not associated with gender or ethnicity and are preceded with SM (senior manager), Dean, or Student to indicate their position within the school.

\section{Senior Managers}

All senior managers identified as NZ European/Pākehā. Of the senior managers who participated in this study, two were male and two female. All had over 18 years' experience in teaching.

Deans

All of the deans identified as NZ European/Pākehā. Five deans were male and one female. The deans had between 4 and 30 years' teaching experience.

\section{Teachers}

Five teachers with between 10 and 30 years' teaching experience participated (Table 3). Three teachers were female and two male. All teacher participants had held or currently held a position of responsibility in this school or another (Table 4). 
Table 3. Teacher participant responsibilities

\begin{tabular}{|l|l|}
\hline Pseudonym & Current or previous areas of responsibility \\
\hline Teacher Devon & Curriculum \\
\hline Teacher Sam & Curriculum and Pastoral \\
\hline Teacher Alex & Pastoral \\
\hline Teacher Taylor & Curriculum \\
\hline Teacher Cameron & Curriculum and Pastoral \\
\hline
\end{tabular}

\section{Students}

Four Year 12 students participated in one-on-one semi-structured interviews- three females and one male. Two of the students identified as NZ European, one as Chinese and one as Māori. All students attended Northside College from their first year of College, (Year 9). One student transferred to Northside College later in her first year of College.

\subsection{Data collection}

This section outlines the process through which the empirical data were collected.

The data collection process included:

\section{School documentation}

- School documents including: school charter, job description (Appendix G), staff handbook and the school's own restorative justice process pyramid.

\section{Individual interviews}

- Semi-structured interviews with the senior management personnel, each lasting 4560 minutes.

- Semi-structured interviews with the six deans, each lasting 30-45minutes (Appendix $\left.\mathrm{E}^{12}\right)$.

- Semi-structured interviews with four individual students, lasting 30 minutes each.

Focus group

- One semi-structured focus group lasting 60 minutes (Appendix F).

Deans' daily logs

- Self-report daily log completed by each dean on the nature of activities and length of time spent on them for five consecutive days (template in Appendix B).

12 Question schedules for each group were identical, for this reason a sample question schedule is attached. 
The senior manager interviews were followed by interviews with the deans, the teacher focus group, and students. The interviews of each group began at different times over the following three-week period. It was possible that the presentation of the log itself as a tool may have influenced the deans' perception of their role. To minimise any effects of this, each dean was asked to commence their log after their interview had been conducted. This was done so that the deans' perception of their role would not be distorted by being exposed to the information included in the log (Bogdan \& Biklan, 2007, p. 26).

The teacher focus group was held after 5 of the 6 interviews with deans were completed, and the final interview was with a dean because of the availability of staff. The student interviews commenced after the teacher focus group. The interviews and focus group were conducted in this order due to:

1. Practical time constraints. The dissemination of information and collection of consent forms was more time consuming for the larger participant pools of teachers and students than those for the senior managers and teachers. In contrast, interviews with the senior managers and deans were easier to organise as I had more one-on-one access with all of the willing participants in this group, making the arrangement of interviews quick and often immediate. School documentation that was easily available (e.g., the school charter and vision statements) on the school's website were examined initially, with further documentation being analysed upon its receipt.

2. Revealing context specific themes to explore further. From an ethnographic perspective, the concept of 'holism' assisted in determining the order of the interviews (Johnson \& Christensen, 2012), dictating that the "whole is greater than its parts" (p. 394) but also asserting that the parts need to be understood in order to understand the whole.

As discussed by Burns (2000), it became apparent that in order to understand the perspectives and experiences of the individual members of the school community, I first had to gain an understanding of the wider context. Interviewing the principal and senior management team first, along with reading the school documentation that was available on the school website, allowed me to gain an understanding of the beliefs and values of the school, as well as the function of the school as an organisation (p. 400). These interactions revealed certain aspects and values (e.g., 
restorative justice) belonging to the college which then prompted additional or modified questions in the later interviews with the different groups (Section 3.2.1).

3. Increasing the likelihood of a positive participant response. The order of the interviews allowed the leadership of the school to demonstrate their willingness to participate in the study. I believe this model led the deans and teachers to see that the leaders of the school were engaging with me as an outsider, creating a "halo effect" (Tolich \& Davidson, 1999, p. 94) and may have encouraged their active participation in the study by adding credibility to me as a researcher and validating my presence in the school (Tolich \& Davidson, 1999).

\subsection{Design, Procedure and Analysis}

This section outlines the design and procedure utilised in the empirical process of this study. It describes the development of the instruments used including interviews and focus groups, the deans' daily logs, and the school documentation. Included in each section is an explanation of how these tools were trialled and then utilised to collect data, and in turn, how the data were analysed. In order to distinguish between participating groups at different stages of this process, people involved in the development of the instruments (e.g., interview questions and deans' daily logs) will be described as 'volunteers'. People involved in the data collection, who are members of the study school community (Northside College), will remain as 'participants'.

The Section groups together each form of data collection in subsections, including:

\subsubsection{School documentation}

\subsubsection{Interviews and focus group}

3.4.3 Deans' daily logs.

The purpose of the development stages for the interview and focus group questions were twofold. Firstly, they served as an opportunity to refine the questions to ensure they elicited responses that would help to answer the research questions, and secondly, they provided me with the opportunity to practise the skills required for qualitative data collection such as "empathic neutrality" (Patton, 1990, p. 55), establishing rapport (Johnson \& Christensen, 2012), and dealing with a range of personalities within a group (Krueger, 1994). 
All data gathering tools were tested and refined before their use. I invited staff and students from a different college to volunteer to take part in an interview with me in order to test and refine my questions. These volunteers were actively recruited through personal contacts, and the testing and development of the research questions was conducted separately to any interaction with the study school (Northside College) concerned in this study. One senior manager, two deans, and three students were involved in the trialling of questions.

The practice interviews and focus group were run as they would have been in the study and audio recorded. During the interviews with volunteers, I also made notes on questions that I felt needed to be refined in order to clearly communicate my meaning.

\subsubsection{School documentation}

\section{Justification}

In order to inform the definition and intention of the role of the dean at Northside College, documents specific to this school and the role of the dean were examined. School strategy documents, policy around pastoral care and dean role descriptions were utilised in order to understand the school's intended role of the dean. These documents also provided an important comparison to analyse whether the perceptions of the groups involved aligned with the intended goals of the school.

Use

The following documents were provided by the school and analysed:

- The school's charter document

- The job descriptions of staff positions

- The staff manual

- The school's restorative justice pyramid.

\section{Analysis}

The school documents are the last to be described as they were the final aspect of data to be collected. The school's charter document was retrieved from the school website early in the data collection period. The remaining documents, however, were supplied to me near the end of data collection after attempts to gather the documents earlier.

School documentation was analysed by selecting relevant sections of the school charter, staff handbook and job description for statements pertaining to the role of the dean as 
determined by the researcher. The criterion that influenced my judgement on relevance was whether or not the document referred to the role of the dean.

The tasks described in the job description were allocated into three categories that aligned with those used to create items for the deans' daily logs (Section 3.4.2) and informed by Best's (1999) work on the aspects of pastoral care. These a priori categories were social, emotional, behavioural care; academic care; and administrative tasks. Some tasks fitted into more than one category. Where this co-occurrence happened (Johnson \& Christensen, 2012), the task was allocated to all appropriate categories (Section 3.2, Table 7).

\subsubsection{Interviews and focus group}

\section{Justification}

The interviews were intended to provide insight into the perception of the dean as to what challenges and affordances they faced in performing their role and insight into the nature of the role and the essence of the experience of care, one which only they can provide (Johnson \& Christensen, 2012). The use of interviews in this case is pragmatic in that the number of individual interviewees was manageable and appropriate to gain multiple perspectives from all deans and senior managers in order to address the central research question (Section 1.4) (Creswell, 2013, 2014). The consideration that there were fewer staff members in the roles of senior management and deans also meant that one-on-one interviews were more practical (Johnson \& Christensen, 2012).

A teacher focus group was utilised in order to promote and encourage discussion around the role of the dean (Creswell, 2011). The use of a focus group was selected for practical reasons, enabling me to garner a variety of perspectives in a short amount of time (Frey \& Fontana, 1991; Krueger, 1994; Patton, 2002). Part of the concern surrounding focus groups is the lack of anonymity and confidentiality. Considering that the study was not intended to investigate potentially sensitive areas for the teachers in particular, a focus group remained an appropriate choice of data collection. Frey and Fontana (1991) discuss the importance of recognising the different backgrounds and personalities of the members of the focus groups and how this may influence their perspectives. Whilst limitations exist within the use of focus groups, including the dominance of some participants over others and the possibility of participants not 
speaking up because of the group situation, for this study it was decided that the benefits outweighed the risks (Creswell, 2011).

\section{Instrument development}

\section{Pre-study instrument development}

At times, volunteers in the tool trialling asked for clarification regarding a question, which assisted in the development of the questions. For example, during tool trialling when I asked the question 'How often does the dean engage in the activity you have described?'. A volunteer student in the test interview asked for clarification around whether I meant in general or with her personally. I made a note of this query and utilised it as a probe in future interviews. This question from the volunteer student also prompted me to include probes in the deans' interviews surrounding the question 'How frequently do you have contact with the students in your care?', as I sought clarification around the interaction they had with the year level they were responsible for as a whole or the individuals in that year level.

Originally, there were ten questions for the teacher focus group. In trialling, I noted that the volunteer teachers often took longer than the deans to answer each question, and progressed through different ideas naturally without the need for as many questions. This observation, along with revisiting literature on focus groups (Johnson \& Christensen, 2012; Krueger, 1994), led me to the conclusion that limiting the focus group to five main questions would enable the participants to provide in-depth answers, and promote discussion amongst the group (Krueger, 1994), particularly in the anticipation of having a larger focus group in the study than in the trial. The trialling process led me to improve my skills in controlling my reactions (Patton, 1990).

\section{Adaptations throughout study}

Throughout the study itself, the questions were informed by previous interviews and my growing knowledge of the school. The concept of pastoral care and the role of the dean was a subjective question successfully eliciting a range of responses from participants. 'Question 1: What is the role of the dean in this school?', as detailed in Appendix E, revealed quite clearly how the deans perceived their responsibility. Questions 2, 5 and 10-13 are dependent on how the deans perceived their role. One participant in particular, clearly stated repetitively that they did not distinguish between behavioural and academic aspects of care and saw them as the same concept. This participant found it very difficult to distinguish between these two areas and for the 
purposes of that one interview, questions that separated the social, emotional, and behavioural aspects of care from the academic aspects of care were combined.

In my primary interviews with the senior management team it became apparent that the leaders of the school placed a large emphasis on their restorative justice process that they had developed specifically with their staff for their school (Section 3.2.1). The theme of the function of the dean in the junior section of the school differing from that in the senior school also became apparent in my interviews with the first two senior managers as specific to this school. Because of the emphasis placed on these two areas, they became an additional area of questioning informed by the context of the school as a case (Creswell, 2011; Tolich \& Davidson, 1999).

Use

A focus group was conducted with five teachers from the school. The focus group ran for 45 minutes and was completed during school hours on school grounds. The teachers were offered five guiding questions to highlight the focus of the discussion (Section 3.4.2.).

All interviews were recorded by digital voice recorder and participants were alerted to and agreed to this. I also took notes throughout the interviews. At the end of each interview I summarised the participants' points back to them verbally. Participants used this as an opportunity to clarify or comment on the raw data I had collected (Section 3.7.1) (Creswell, et al., 2007; Moustakas, 1994). The interviews were transcribed.

\section{Data Analysis}

The transcribed interviews and the focus group were segmented to identify "meaningful units" in the data that served in answering the research questions (Johnson \& Christensen, 2012, p. 520). Segments were then coded using straightforward category labels (Miles \& Huberman, 1994).

Inductive and deductive a priori coding were both used in a "hybrid approach" (Fereday \& Muir-Cochrane, 2006, p. 1) to coding. Fereday and Muir-Cochrane (2006) utilised this method in their study, ensuring their coding approach "complemented the research questions by allowing the tenets of social phenomenology to be integral to the process of deductive thematic analysis while allowing for themes to emerge direct from the data" (p. 4). Whilst in deductive coding, a template approach is utilised with 
predetermined themes dictated by the researcher after data collection. In this study, as in Fereday and Muir-Cochrane's (2006), the categories for coding were developed a priori. These were informed by the theoretical frameworks of pastoral care (Best, 1999; Section 1) and the research questions (Section 1.4) (Fereday \& Muir-Cochrane, 2006; Johnson \& Christensen, 12; Patton, 2002). These pre-determined codes included: proactive care $(\mathrm{P})$; reactive care $(\mathrm{R})$; addressing social, emotional, behavioural issues (SEB); and addressing academic issues (Acad) (Figure 1).
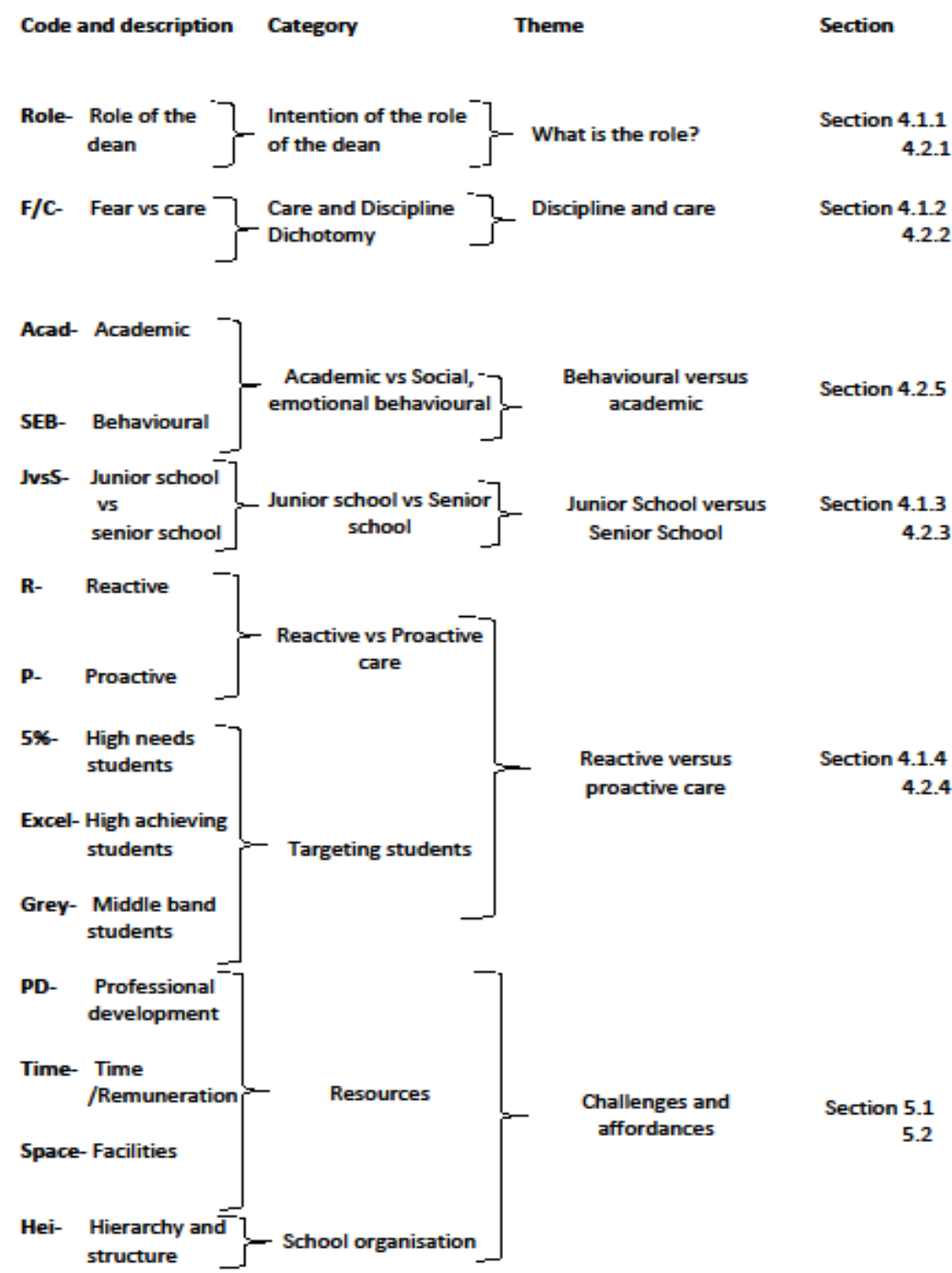

Figure 1. Codes, categories and themes utilised in data analysis 
Inductive codes were developed and added to a master list (Figure 1), for example; facilities (Space), professional development (PD), and difference between Junior school and senior school (JvsS). Some meaningful interview segments could have numerous codes applied to them (Johnson \& Christensen, 2012). Where this occurred the segments were allocated all appropriate codes and then some codes were combined (Patton, 2002) (Figure 1).

\subsubsection{Deans' daily logs}

\section{Justification}

A quantitative self-report log was utilised in the study in order to enable triangulation of data (Section 3.8.1) and address research question 3 (i.e., How are staff spending their time in their role as dean?). The log was influenced by Spillane, Camburn, and Pareja's (2007) work on examining the role and function of the school principal. They utilised an 'End of Day' self-report log to collect data on principals' daily activities.

The deans were asked to complete the log each day over five consecutive days, rather than weekly, in order to minimise reporting error associated with activity recall (Spillane et al., 2007). This period was decided in order to limit intrusion in the deans' day, capture variety in the activities completed, and to fit within the time frame suitable for data collection for this thesis (Section 7.3.1).

\section{Instrument development}

The deans' daily logs were developed with assistance from two volunteer senior managers from a different college who provided an extensive list of all of the activities that deans may encounter in their role. The combined list included over 50 activities ranging from running assemblies to following up truancy. Whilst the list was exhaustive, it proved challenging for me to formulate a user friendly template that would enable deans to record their work efficiently using so many categories.

Utilising the theoretical models of pastoral tasks presented by Best $(1999,2003)$ in combination with the definitions discussed in Hearn et al. (2006) I created descriptions of activities which provided a more general framework to encompass the listed tasks. 
Three main areas emerged:

- Social, emotional and behavioural matters

- Academic matters

- Administration and management matters (Appendix B).

Each category drew from three of the five pastoral tasks in the model developed by Best (1999) - reactive pastoral casework; proactive, preventive pastoral care; and the management and administration of pastoral care. For example, Figure 2 outlines the items used for 'reactive casework'. The log was intended to be categorical in order to make it a practical tool to measure different aspects of the dean's role based on the nature of the task (reactive case work) rather than the task itself (telling off a student about their incomplete homework).

Table 4. Example items developed to measure time spent on reactive casework

\begin{tabular}{|l|l|l|}
\hline \multicolumn{1}{|c|}{} & \multicolumn{1}{|c|}{$\begin{array}{c}\text { Social, emotional and behavioural } \\
\text { matters }\end{array}$} & \multicolumn{1}{c|}{ Academic matters } \\
\cline { 2 - 3 } & One-on-one problem solving with students & $\begin{array}{l}\text { One-on-one discussion with students } \\
\text { addressing problems with academic } \\
\text { progress }\end{array}$ \\
\cline { 2 - 3 } & Problem solving with a group of students & $\begin{array}{l}\text { Problem solving with teachers about an } \\
\text { individual student }\end{array}$ \\
\cline { 2 - 3 } & $\begin{array}{l}\text { Problem solving with teachers about an } \\
\text { individual student }\end{array}$ & $\begin{array}{l}\text { Problem solving with parents about } \\
\text { problems faced by an individual student }\end{array}$ \\
\cline { 2 - 3 } & $\begin{array}{l}\text { Problem solving with parents about } \\
\text { problems faced by an individual student }\end{array}$ & $\begin{array}{l}\text { Problem solving with an external agency } \\
\text { about an individual student }\end{array}$ \\
\cline { 2 - 3 } & $\begin{array}{l}\text { Problem solving with an external agency } \\
\text { about an individual student }\end{array}$ & \\
\hline
\end{tabular}

In the activity log, participants were given multiple time values for each item (0 minutes, 1 to 30minutes, 30 minutes to 1 hour, 1 hour to 2 hours, more than 3 hours) and asked to circle the amount of time that best described the period that they spent on this task during that day. The log was limited to 20 items to make it straightforward and quick to complete.

Once the draft log had been developed, it was given to the volunteer senior managers for feedback. One responded positively, outlining that she thought the log would be easy to use, and clearly outlined the major underlying tasks and activities involved in the role of the dean. The other volunteer senior manager sought feedback from all of the deans at their school on the log. She reported that the deans thought that the log was too 
basic and it did not reveal the complexity of the dean's role. She also indicated that the 'check box' form of the log was restrictive and too categorical. Whilst this feedback could be perceived as negative, this confirmed to me that the log had been designed in accordance with its intention, and also reinforced my decision to conduct qualitative interviews with members of the school community to further understand the complexity of the role. Hence, this confirmed that the log was fit for its intended purpose.

Use

Deans completed the log daily for five consecutive school days after participating in a semi-structured interview with me around their role as dean. The deans were briefed on the intention of the log and were given instructions on how to complete it, and were then given five copies of it. Colour printing enabled the activities to be separated into three clear categories: social, emotional, behavioural; academic; and administrative (Appendix B). Deans asked questions at this stage around what kind of activities go under each category, all clarified using the same examples, explaining which category each would go under and why. Each dean confirmed that they had a sound understanding of how to use the log.

As the log recording began after each interview, each dean started their log at a different time. All deans returned 5 completed $\log$ sheets to me at the end of their five-day period.

\section{Analysis and Assumptions}

The daily log was utilised in order to generate a general picture of how the deans' time was spent, and enabled simple comparisons to be made between types of activities. The data were not intended to be utilised for statistical tests of significance, rather to outline a general picture across the small sample of dean participants. The log was designed in order to reduce intrusion into the deans' busy schedules and, therefore, maximise the likelihood that the log would be completed.

It is assumed that the option of ' 0 to 30 minutes' is included in the lesser range (1-30 minutes) and the '30 minutes to 1 hour' range refers to 'at least 30 minutes'. Range 3 (30 minutes to 1 hour) has a minimum value of $>30$ minutes defined therefore as 31 to 60 minutes (Table 5). 
Table 5. Definition of ranges

\begin{tabular}{|l|l|l|l|}
\hline \multicolumn{1}{|c|}{ Range I.D. } & Presentation in log & Range (minutes) & Value (minutes) \\
\hline 1 & 0 minutes & 0 & 0 \\
\hline 2 & $0-30$ minutes & $1-30$ & 15.5 \\
\hline 3 & 30 minutes to 1 hour & $31-60$ & 45.5 \\
\hline 4 & 1 hour to 2 hours & $61-120$ & 90.5 \\
\hline 5 & 2 hours to 3 hours & $121-180$ & 150.5 \\
\hline 6 & More than 3 hours & $181-240$ & 210.5 \\
\hline
\end{tabular}

Range 6 (more than 3 hours) is unique due to the range being open-ended. There was only one instance of this range being chosen and for the purposes of statistical analysis it was defined as 181 to 240 minutes.

For the purposes of this study, the value used to define the range was calculated at half of the difference between the minimum and maximum times of the range detailed in the log (Table 5).

value

$$
=((\max -\min ) / 2)+\min
$$

For example:

value(range 3, 31-60 minutes) $\quad=((60-31) / 2)+31$

$$
=45.5 \text { minutes }
$$

The data were processed to calculate the percentage of each dean's time spent on particular activities. Each dean's time spent (in minutes as defined by the value) was calculated for each item (e.g., 'one-on-one problem solving with a student') by applying the above calculation to their selection of time spent. The time values within two predetermined comparative categories were calculated. The categories were:

1. Proactive care versus reactive care.

2. Social, emotional, behavioural care versus academic mentoring and monitoring.

The categories for each individual dean were then combined to compare them between deans. A comparison of time spent on tasks between junior and senior school deans was also conducted. Quantitative data were then compared to the qualitative data. 


\subsection{Ethics}

This research was approved by the Faculty of Education Human Ethics Sub-committee under delegated authority from the Victoria University Human Ethics Committee. The study adhered to the New Zealand Association of Research in Education (NZARE) Ethical Guidelines (2010). Coercive pressure may have decreased for staff and students as I was an outsider of the school community (Burns, 2000; Johnson \& Christensen, 2012). The voluntary nature of the study was outlined to all participants.

All participants were invited to participate, issued with information sheets and engaged in a discussion around the nature of the study, the extent of their involvement in the study and how their responses would be represented in the study. They were informed that: what they said would not be attributed to them in any way through the reporting process, pseudonyms would be used, and official job titles would be excluded.

All participants were required to sign the consent form before participating in the study. Student participants were also required to return a signed parental consent form indicating that their parent or caregiver had read the information sheet and agreed to their child participating in the study.

A significant ethical consideration for this study was that the nature of deans' work can often be sensitive in nature. The questions asked in the interview were designed in order to elicit responses that focused on the generality of the aspects of the role of the dean rather than specific instances or interactions with specific students. During interviews, participants did, at times, name specific students or staff in the process of providing examples to support their points. These names were treated confidentially.

The questions asked of the students were also designed to ameliorate the likelihood of students needing to divulge sensitive or personal information. It remained a risk that the students "might reveal sensitive information that was not part of the goal of the study" (Johnson \& Christensen, 2012, p. 105). During the interviews with students, I maintained awareness of this possibility. I did not encounter any ethical issues with the information that the students provided to me throughout the course of my interviews. 


\subsection{Reflexivity}

My orientation to this research is as an investigator interested in exploring the phenomenon of how we care for our students in New Zealand secondary schools. The topic for this study was borne out of my experiences as a secondary school teacher in New Zealand and my interactions with students (Section 1). It was my belief that the role of the dean was not an effective one because, in my experience, students who were experiencing difficulties outside of curriculum concerns, often approached a trusted teacher or friend rather than a dean.

Upon examining my own preconceived ideas about the role of the dean and upon examining the literature on qualitative phenomological studies, I came to realise that my position and prior knowledge would influence my understanding of the lived experiences of others (Boylorn, 2008). I addressed my preconceived ideas around what the role of the dean in a secondary school should be by acknowledging that the role varies within each school and therefore the intention of the role, and the perception of the intention of the role, should be ascertained from the participants involved in the study (Tolich \& Davidson, 1999). My perception of the necessary requirements of the role of the dean changed throughout the initial literature review and design process, allowing me to conduct this study with an open-mind and an understanding that you “cannot entirely anticipate what you will find” (Morse, 2010, p. 349; Moustakas, 1994).

Siraj-Blatchford's (1997) work also enlightened me to the idea that "if we wish to describe what someone is doing we must first understand what it is that they think they are doing" (p. 236). This concept of hermeneutics was important to acknowledge through my research design in order to address the alternative perspectives of the role of the dean within the school, but also to address my position as an outsider.

As an outsider to the school community of Northside College it became apparent during some of my initial conversations with the participants, particularly those who held positions of responsibility, that there was some confusion over the intention of my study. Some participants began to speak in a way that communicated their deep belief in the importance of pastoral care in schools and described to me how they fulfilled their job expectations. Whilst this was encouraging to hear, I took time to mention that I had chosen the school because it fitted my criterion of having a priority on pastoral care (Section 3.2.1). This assurance seemed to allay any concerns that I was there to assess 
the staff on their ability to provide adequate care to their students as this was not the intention of the study.

Some participants were wary of me as an outsider and the tasks I was conducting within the study. Some deans in particular became self-aware when I discussed that I would be interviewing students for their perspectives. In order to address this, I explained that the discussion with students was around the role of the dean in a general sense rather than the performance of any particular dean. This appeared to address any concerns around my study acting as a critique of a particular dean within the school, which again, was not the intention of the study.

\subsection{Validity}

A convergent parallel mixed-methods design was used in which the quantitative data and the qualitative data were analysed separately and then compared to see if the findings confirmed or disconfirmed each other (Creswell, 2014). This research design was utilised in an attempt to establish quantitative validity and qualitative validity for each database (Creswell, 2014).

\subsubsection{Qualitative validity strategies}

\section{Triangulation}

As recommended by Creswell (2014), different sources were used throughout the study (Section 3.3) in order to establish several converging sources. Different groups from Northside College were interviewed for their perspective on the role of the dean in order to ascertain the "essence" of the phenomenon (Johnson \& Christensen, 2012, p. 385) and highlight any differences in perspective. The school documentation was collected and analysed to establish whether the perspective of participants in the school community reflected the original intention for the role, as outlined in the official school documentation.

The deans' daily logs were used to compare and contrast the difference between perception and reality. This data source provided another database for comparison to assist me in further understanding how the role of the dean was functioning on a day-today level and whether what the deans were doing varied in any way from what they thought they were doing (Siraj-Blatchford, 1997). 


\section{Member Checking}

Member checking was utilised throughout the interviews and focus groups. I summarised the participants' responses at the end of each interview to give them the opportunity to clarify or comment on what I had recorded and interpreted (Carson, 2010; Creswell, et al., 2007; Tracey, 2010). During this time, all participants either added a comment or corrected a statement I had made from my notes based on the raw data they had provided (Creswell \& Miller, 2000). I also summarised some of the themes that I had interpreted in what they had said and provided them with the opportunity to comment (Creswell, 2014).

\section{Bias}

Retaining self-awareness of my previous experience and knowledge assisted me towards conducting the interviews in an empathetic yet neutral manner in order to avoid leading the participants. The pilot interviews conducted (Section 3.4.1) also provided me with the opportunity to practise my interview skills in order to improve my “empathic neutrality" (Patton, 1990, p.55).

As a purposive, convenience sample was used (Section 3.2.2), there is the potential for participant bias within this study. The possibility that participants who volunteered to participate (e.g., students and teachers) may have done so with the intention of portraying a particular message. The use of multiple data collection methods for triangulation was employed in an attempt to counter this bias; however, it remains evident that the sample for this study may not be representative of the population and therefore generalisation of results should be made so cautiously (Johnson \& Christensen, 2012). 


\section{Chapter 4: The role of the dean}

This chapter provides evidence to assist in answering research questions 1-4 relating to the role of dean (Section 1.5). Section 4.1 presents the results pertaining to the first four research questions, highlighting key themes of:

- the role of the dean (Section 4.1.1),

- the relationship between discipline and care (Section 4.1.2),

- a distinction in the role between the junior and senior schools (Section 4.1.3), and

- $\quad$ engaging in the provision of reactive and proactive care (Section 4.1.4).

Section 4.2 then discusses the findings in relation to existing literature, following the same themes as in Section 4.1 with the addition of a discussion on the distinction between academic and behavioural care (Section 4.2.5). This additional theme is introduced to discuss findings in relation to existing literature, utilising data integrated across the four original themes.

\subsection{Results}

The job descriptions of the dean, head of department, and form teacher were the only documents provided by the school that contained information relevant to this study. This is analysed along with participant perspectives and log data.

\subsubsection{The role of the dean}

\section{School documentation}

The job description for the dean (Appendix G) is universal across all year levels. It outlines areas of accountability and 14 key tasks. In the school's job description for the dean, the responsibility of the dean is for "all students in the year level".

Lines of authority are not clearly stated across the job descriptions (Table 5). The 'responsible to' and 'responsible for' sections do not correspond with one another. For example, form teachers are described as being responsible to the deans, but the deans are only responsible for the students in the year level and not the form teachers. This discrepancy shows inconsistency across the documents which indicates that confusion may exist over the intention of the role of the dean. Also, the form teacher is described as 
being responsible for pastoral tasks such as: "setting standards, pastoral care, promotion of a pro-achievement culture", whereas the dean is not.

Table 6. Lines of authority from job descriptions of dean, head of department, and form teacher

\begin{tabular}{|c|c|c|c|}
\hline & Dean & Head of Department & Form Teacher \\
\hline $\begin{array}{l}\text { Responsible } \\
\text { to }\end{array}$ & $\begin{array}{l}\text { - Principal and senior } \\
\text { management }\end{array}$ & - Principal & $\begin{array}{l}\text { - Principal and senior } \\
\text { management } \\
\text { - Deans }\end{array}$ \\
\hline $\begin{array}{l}\text { Responsible } \\
\text { for }\end{array}$ & $\begin{array}{l}\text { - All students in the year } \\
\text { level }\end{array}$ & $\begin{array}{l}\text { - All staff teaching in } \\
\text { the department }\end{array}$ & $\begin{array}{l}\text { - All pupils [sic] in the } \\
\text { form class } \\
\text { - Setting standards } \\
\text { - Pastoral care } \\
\text { - Promotion of a pro- } \\
\text { achievement culture }\end{array}$ \\
\hline Liaises with & $\begin{array}{l}\text { - Principal and senior } \\
\text { management } \\
\text { - Form Teachers } \\
\text { - Truancy officer/RTLB } \\
\text { - Parents }\end{array}$ & $\begin{array}{l}\text { - SMT } \\
\text { - Other HODs }{ }^{13} \\
\text { - Deans } \\
\text { - NZQA Principal's } \\
\text { Nominee } \\
\text { - Report co-ordinator } \\
\text { - Finance Officer } \\
\text { - Parents } \\
\text { - Contributing primary } \\
\text { schools }\end{array}$ & $\begin{array}{l}\text { - Principal and senior } \\
\text { management } \\
\text { - Deans } \\
\text { - Parents }\end{array}$ \\
\hline
\end{tabular}

The rest of the job description (Appendix G) details specific tasks including: administrative and communicative tasks, behaviour management, and the support of academic endeavours and achievements (Section 3.4.3) (Table 6). The administrative and communicative tasks of the role include planning, resourcing, monitoring, evaluating, and otherwise facilitating the care of all of the students in their year level and disseminating information to students and staff members. Behaviour management tasks include monitoring individual students' behaviour and providing support for staff members as they implement the school behaviour management systems. The enforcement of school policy is explicitly mentioned in several tasks detailed in the job description. Deans are expected to reinforce and communicate policy to students and staff members. Enforcement of school policy was categorised under behaviour management.

13 Head of Department 
Table 7. Deans' tasks as detailed in job description and their nature using identified categories informed by Best (1999)

\begin{tabular}{|c|c|c|c|}
\hline Task & $\begin{array}{l}\text { Administrative/ } \\
\text { communicative }\end{array}$ & $\begin{array}{l}\text { Behavioural, } \\
\text { social and } \\
\text { emotional } \\
\text { management }\end{array}$ & $\begin{array}{l}\text { Academic } \\
\text { concerns }\end{array}$ \\
\hline $\begin{array}{l}\text { 1. Set up a system where the aim is to meet } \\
\text { with as many of the students in your } \\
\text { charge as possible. }\end{array}$ & & & \\
\hline $\begin{array}{l}\text { 2. Hold regular assemblies with the aim of } \\
\text { informing, accenting positive } \\
\text { achievements and attitudes and } \\
\text { reinforcing school routines and policy. }\end{array}$ & & & \\
\hline $\begin{array}{l}\text { 3. Monitor your students' learning and } \\
\text { behaviour through the use of KAMAR. }\end{array}$ & & & \\
\hline $\begin{array}{l}\text { 4. Support form teachers in the contacting } \\
\text { of parents when a student has been } \\
\text { absent for three days without warning or } \\
\text { explanation, or if an absence note seems } \\
\text { suspect. }\end{array}$ & & & \\
\hline $\begin{array}{l}\text { 5. Enrol new students; allocate them to a } \\
\text { form class and to subject classes; update } \\
\text { lists as required. }\end{array}$ & & & \\
\hline $\begin{array}{l}\text { 6. Back form teachers up as they work to } \\
\text { enforce policy relating to uniform, } \\
\text { absences, student diaries, and sustained } \\
\text { silent reading. }\end{array}$ & & & \\
\hline 7. Oversee the use of Student Diaries. & & & \\
\hline $\begin{array}{l}\text { 8. Proof read reports and write dean's } \\
\text { comments if required. }\end{array}$ & & & \\
\hline $\begin{array}{l}\text { 9. Organise the Course Selection process } \\
\text { and meetings designed to inform students } \\
\text { and parents about course options for the } \\
\text { coming year. }\end{array}$ & & & \\
\hline $\begin{array}{l}\text { 10. Communicate student-related matters to } \\
\text { the } \mathrm{SMT}^{14} \text { at weekly meeting with deans. }\end{array}$ & & & \\
\hline $\begin{array}{l}\text { 11. Provide restorative behavioural backup } \\
\text { for the subject teachers, form teacher and } \\
\text { HOD, in accordance with the_Behaviour } \\
\text { Management System. }\end{array}$ & & & \\
\hline $\begin{array}{l}\text { 12. From time to time meet with form and } \\
\text { subject teachers for the purpose of } \\
\text { sharing information, communicating } \\
\text { policy, and getting a comprehensive feel } \\
\text { for what is happening at each level. }\end{array}$ & & & \\
\hline $\begin{array}{l}\text { 13. Ensure that information gathered from } \\
\text { primary school is made available to form } \\
\text { and subject teachers and that student } \\
\text { profiles are updated twice a year by form } \\
\text { teachers. }\end{array}$ & & & \\
\hline
\end{tabular}

14 Senior Management Team 


\begin{tabular}{|c|c|c|c|}
\hline Task & Administrative/ \\
communicative & $\begin{array}{c}\text { Behavioural, } \\
\text { social and } \\
\text { emotional } \\
\text { management }\end{array}$ & $\begin{array}{c}\text { Academic } \\
\text { concerns }\end{array}$ \\
\hline $\begin{array}{c}\text { 14. Communicate with parents on matters of } \\
\text { concern. Sometimes this will involve } \\
\text { setting up a meeting at school between } \\
\text { parents and one or more staff in addition } \\
\text { to yourself. }\end{array}$ & & & \\
\hline Total & 11 & 8 & 3 \\
\hline
\end{tabular}

I have interpreted "positive achievements" (Task 2) to include those of an academic, sporting, or creative nature. "Student learning" (Task 3) and "matters of concern" (Task 14) have been interpreted to include academic achievement and progress. The support of academic endeavours is not specifically mentioned in the job description tasks. Task $6^{15}$ and task $11^{16}$ in the job description detail the deans' position as one of 'backup' for the form teachers and subject teachers implying that the subject teachers and form teachers are the first line of interaction for students.

Based on my outsider's understanding of the school and the documents that the school provided to me, there were no clear and measurable goals for the provision of pastoral care within the school. Item $2^{17}$ is the only item in the job description that details an explicit aim. It is apparent that the school does not have an explicit pastoral care policy or goals, or if they do, they were not made available for me to include in this study.

\section{Participant perspectives}

Participants often found it difficult to explain the role of the dean succinctly, at times, taking several minutes to do so. Their interviews revealed that the role is complex and multifarious in nature, because they detailed specific tasks to be completed by the dean that were similar to those presented in the job description.

Most of the responses were focused on the social, emotional, behavioural, and academic aspects of the role; however, staff members discussed the administrative and communicative aspects of the dean's role. Participants from all groups commonly stated

15 "Back form teachers up as they work to enforce policy relating to uniform, absences, student diaries, and sustained silent reading."

16 "Provide restorative behavioural backup for the subject teachers, form teacher and HOD, in accordance with the Behaviour Management System"

17 "Hold regular assemblies with the aim of informing, accenting positive achievements and attitudes and reinforcing school routines and policy" 
in their interview responses that the main activity of the dean was to have an overview of the year level and their pastoral needs. They described the main activity of the dean:

Overview of the needs of the kids, there are lots of points. (Dean Tui)

The job we do is so varied and often time consuming that I don't really think there is one main role. (Dean Casey)

...to overlook the year level and keep people in line. (Student George)

All participants, mentioned in some way that the dean acted as a person to go to. This included students and staff members reportedly using the deans to actively solve problems as shown by the excerpts below:

I reckon they have someone who is not directly dealing with them every single day, so someone who is one step removed and it is also someone who is an impartial support person because it will also go to the Dean if they think they have been treated unfairly. (Teacher focus group)

If I was having issues with a class or something then I could go to the Dean and talk to them about that class and see if there is an alternative. (Student Rory)

Senior managers discussed the role of the dean as complex and multi-faceted, and consisting of many different aspects of care and discipline:

Often the kids will come and say I will need to see you I am being bullied or I have a relationship issue with this friend or some of my friends have got relationship issues or whatever. So they will come down and ask for help and that happens quite a lot. (SM Jordan)

Deans identified numerous tasks that they were responsible for as compounding:

You are the dumping ground for stuff that anyone else thinks is too hard or that doesn't naturally fit into a nice clean tidy box. (Dean Kennedy)

The students spoke more generally about the role of the dean as being a problem solving role:

I think they are just there to make sure everyone is doing well in their classes, like if they are getting on well and to be there when the student has problems. (Student Rangi)

I guess when people need help they sort it out, if they need extra help and stuff like that. (Student George)

Students went on to explain that the types of problems they went to see the dean about were academic or administrative in nature (rather than behavioural, social, or emotional) 
(Best, 1999; Section 1.1). They mentioned other support systems such as the guidance counsellor, form teacher or friends as people they would go to with issues of a social or emotional manner. The dean was the main person within the school that students would go to if they were facing an academic or administrative problem that they could not solve themselves:

If I was having class issues...then I would go and see the Dean about the class and see if I could schedule or re-work the timetable. (Student Rory)

If I was really struggling in one of my subjects or just some problems with teachers or other people. (Student Rangi)

I was off school for a week and she talked to my teachers and got me extensions on the tests I was going to miss and that was helpful. (Student George)

Participants reported difficulty with lines of authority between curriculum staffing and pastoral staffing as challenging and inconsistent at times:

Structurally schools have said 'this is the hierarchy' and it has been predominantly academic based...The HoDs should be responsible for the academic success of students in their own discipline but unfortunately as the curriculum shifted holistically, the Dean's role has become much more important... HoDs don't have to deal with disciplinary issues as much as deans. (Dean Kennedy)

At the same time, you have no clearly defined authority in that the Head of department is structured in really clear lines of communication or authority. In the pastoral network, those lines of authority don't exist so I have ten form teachers that are in theory responsible to me but some of those form teachers are quite senior members of staff so heads of major departments or deputy heads so the lines of authority become very muddled. (Dean Jessie)

This perceived tension is reflected in the job descriptions of these positions where the lines of authority as dictated in the documents are incongruent.

\section{Deans' daily $\log s$}

Based on the mid-point calculation (Section 3.5), the deans reported spending between an estimated 6 hours and 23 hours per week on deaning activities. The dean who recorded the lowest estimated time and the dean who recorded the highest estimated time were both responsible for a year level from the junior school. 


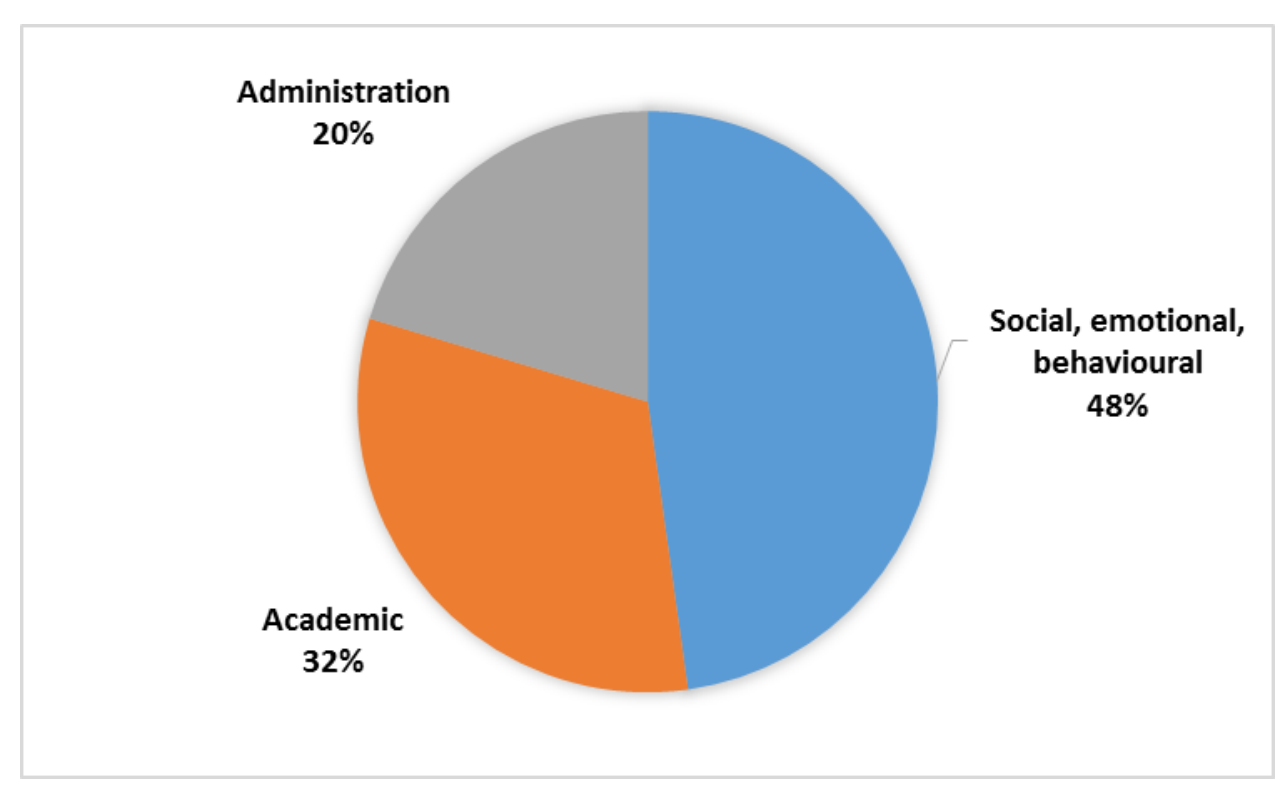

Figure 2. Percentage of time deans spend on different aspects of care

Deans reported spending $20 \%$ of their total time on administrative tasks but a higher percentage was spent on either social, emotional, behavioural, or academic issues (Figure 3). The results from the deans' daily logs show that in the total time reported by all deans, $48 \%$ is spent dealing with issues of a social, emotional or behavioural nature compared to $32 \%$ on academic issues.

\subsubsection{Discipline and care}

The role of disciplinarian was discussed by members of all participant groups at some point in the interviews and was accompanied by descriptions of the dean as an authoritarian figure. Two participants referred specifically to the students' sense of fear or being scared of the deans. Participants often contradicted themselves with descriptions of a non-intimidating, caring role. This was more frequently done by staff members and is represented in Table 9. 
Table 8. Statements describing the contrasting roles of the dean

\begin{tabular}{|l|l|l|}
\hline Traditional disciplinarian perspective & \multicolumn{1}{|c|}{ Caring perspective } & \\
\hline $\begin{array}{l}\text { "If they get called to the dean they will } \\
\text { wonder if they are in trouble" }\end{array}$ & $\begin{array}{l}\text { "I don't think the students are scared } \\
\text { of the deans and they don't see them } \\
\text { as people who will be punishing } \\
\text { them" }\end{array}$ & SM Jordan \\
\hline $\begin{array}{l}\text { "You have to let the kids know that they } \\
\text { have gone beyond classroom level and } \\
\text { you are now at the Dean's level and that } \\
\text { is not good." }\end{array}$ & $\begin{array}{l}\text { "I think the office provides security } \\
\text { for students to perhaps open up a } \\
\text { little bit ...that is definitely one side } \\
\text { of it, the sharing, caring type role that } \\
\text { we play." }\end{array}$ & Dean Casey \\
\hline $\begin{array}{l}\text { "As a junior dean, you walk into a } \\
\text { classroom and ask to talk to such and } \\
\text { such a kid and their immediate response } \\
\text { is they are in trouble." }\end{array}$ & $\begin{array}{l}\text { "When somebody takes the time to } \\
\text { actually sit down with them and talk } \\
\text { with them about their issues and help } \\
\text { them work through the barriers, they } \\
\text { can be resolved and that leads to best } \\
\text { success for that student." }\end{array}$ & $\begin{array}{l}\text { Kean } \\
\text { Kennedy }\end{array}$ \\
\hline $\begin{array}{l}\text { "In the junior school you've got to be a } \\
\text { bit scary... One of the teachers...thanked } \\
\text { me for having that effect on a school of } \\
\text { fish that a white shark would have. An } \\
\text { intake of breath when you walk in the } \\
\text { room and an audible sigh of relief when I } \\
\text { walk out...I think the kids think I am that } \\
\text { scary." }\end{array}$ & $\begin{array}{l}\text { have issues with a specific teacher } \\
\text { and they know they can come to me } \\
\text { and I can help them to try and sort it } \\
\text { out." }\end{array}$ & Dean Tui \\
$\begin{array}{l}\text { "Juniors are scared witless. There is an } \\
\text { element of fear until they get to 5 } 5^{\text {th }} \text { and } 6^{\text {th }} \\
\text { form and then they don't care...this is the } \\
\text { authority figure and they don't see the } \\
\text { dean as a teacher." }\end{array}$ & $\begin{array}{l}\text { "It's more like instead of being } \\
\text { hierarchical it is very collegial... } \\
\text { very approachable which hasn't } \\
\text { always been the case in our school." }\end{array}$ & $\begin{array}{l}\text { Teacher } \\
\text { focus group }\end{array}$ \\
\hline
\end{tabular}

These contradictions could be interpreted as role conflict. It is more likely, however, that this is an example of the different kinds of roles the deans utilise in order to perform their job effectively. The statements demonstrate a difference in the perception of the role in the junior school to that in the senior school, and this is further discussed in Section 4.2.3.

In addition to reactive care, Best's (1999) model includes "proactive, preventive pastoral care" (p. 57) that is intended to anticipate critical events in students' lives in order to prevent the need for reactive care (Section 1.4.1). Managing assemblies is an example of deans using proactive care. When asked about the topic of assemblies, some deans mentioned that they were usually about current issues concerning the year level, indicating a complex relationship between proactive and reactive care that is further discussed in Section 6.1. The deans' reaction to a small group of students facing an issue was to hold an assembly to discuss the issue with the year group and anticipate any 
potential issues for them. This use of assemblies can therefore be seen as both reactive and proactive:

I am able to deal with a lot more cyber bullying, texting and facebooking and all that, that takes up a very large part of what we do here now actually and it is only increasing so in assembly we are always sending out messages of just how dangerous technology can be in the ways they are used... (Dean Casey)

Tasks concerning the academic progress and the pastoral care of students were discussed as entities that could be addressed separately from one another by at least one participant from each of the senior management, teacher focus group, and deans. However, all participants explained that both the academic and pastoral tasks that they described were included as responsibilities of the dean:

To me it is big, I think you need to be thinking it is about the wellbeing of the student but it is also about the academic progress of the student, this is how we do it. (SM Rangi)

The role of the Dean to me is to oversee the pastoral care in terms of social development as well as academic development of all students in their year group. (Dean Jessie)

So that whole bench-marking process...I think that is a huge part of the Dean's role... But what takes up a lot of their time is the firefighting ${ }^{18}$ isn't it. (Teacher focus group)

The aspects that deans reported spending most time on were the social, emotional, behavioural aspects of their role, generally engaging in individual casework (Section 1.1), described above by the teacher focus group as "firefighting":

I guess in terms of hours spent it would be the disciplinary side of it. But in saying that, often you scratch the surface and it turns very quickly into a more pastoral care type situation and kids come with behavioural issues or are behaving inappropriately in class... (Dean Casey)

\subsubsection{A distinction between the junior and senior schools}

All participants explained that there was a difference in the role of the dean between the junior school and the senior school. This difference was explained as being due to two main reasons: the administration of an assessment programme, and the different developmental stages of the students.

18 Fire-fighting, in this context, is the process of dealing with problems as they arise rather than planning strategically to avoid them. 
In addition to the provision of pastoral care, deans discussed the administration of discipline as part of their role. All junior school deans described the role of the dean as twofold, explaining the discipline of students and the care of students as separate tasks:

I think there are two main purposes, it is definitely pastoral care... The more traditional role is the more disciplinary approach so that when teachers have issues that are either minor or on-going or serious enough as a one off offence that they can send them over to us. (Junior School Dean ${ }^{19}$ )

The purpose of the role of the Dean at this school is two part, in the junior school it is very much focussed on discipline and integration into the school... At the end of year 10 and start of year 11 it becomes very much more academically focussed so it is about that academic coaching. (Junior School Dean ${ }^{19}$ )

The purpose of the Dean is to provide pastoral care primarily in the junior school, we are moving towards the academic mentoring as well... (SM Jordan)

The seniors I think it is a lot of academic stuff and juniors is sort of like smaller stuff, uniform and that kind of thing. (Student Rangi)

The difference in the roles between junior and senior school was mainly attributed to the senior school focus on attaining qualifications and the institution of the national qualification, NCEA, in this part of the school making data more readily available. The senior school students receive academic conferencing, meeting with a staff member about their academic progress, based on their NCEA results. Juniors are not subject to this activity:

I think it is because the data is much more readily available on academic achievement within the senior school. (SM Jamie)

I think the systems starting at Year 11 and going into the senior school are focussed a lot more around academic conferencing and the holistic mentoring and interventions that come out of those academic conferences are a lot more focussed on the students' wellbeing, whereas at the junior school, I feel like the model is still focussed on making kids behave. (Dean Kennedy)

This concept of "making kids behave" in the junior school compared with the "holistic mentoring" (Dean Kennedy) of the senior school provides a stark contrast between views of the role of the dean in the junior school and the senior school. The comment on making students behave in the junior school links to participants' views that the students in this part of the school are more fearful of the dean than the students in the senior school and can associate this position with being in trouble (Table 9).

19 In order to preserve anonymity, the pseudonym is withheld here to prevent any dean being identified as working in the junior or senior school. 
There was also a difference between results of the junior school and senior school deans in the use of their time as reported in the deans' daily logs (Figure 4). There are three deans in each part of the school and the collation of their hours demonstrates that for deans in the senior school, their time was reported as being almost evenly divided between the two aspects of social, emotional, and behavioural care $(51 \%)$ and the aspect of academic care (49\%). Comparatively, junior school deans reported spending a much higher percentage of their time - 69\% - dealing with issues of a social, emotional or behavioural nature than those of an academic nature.

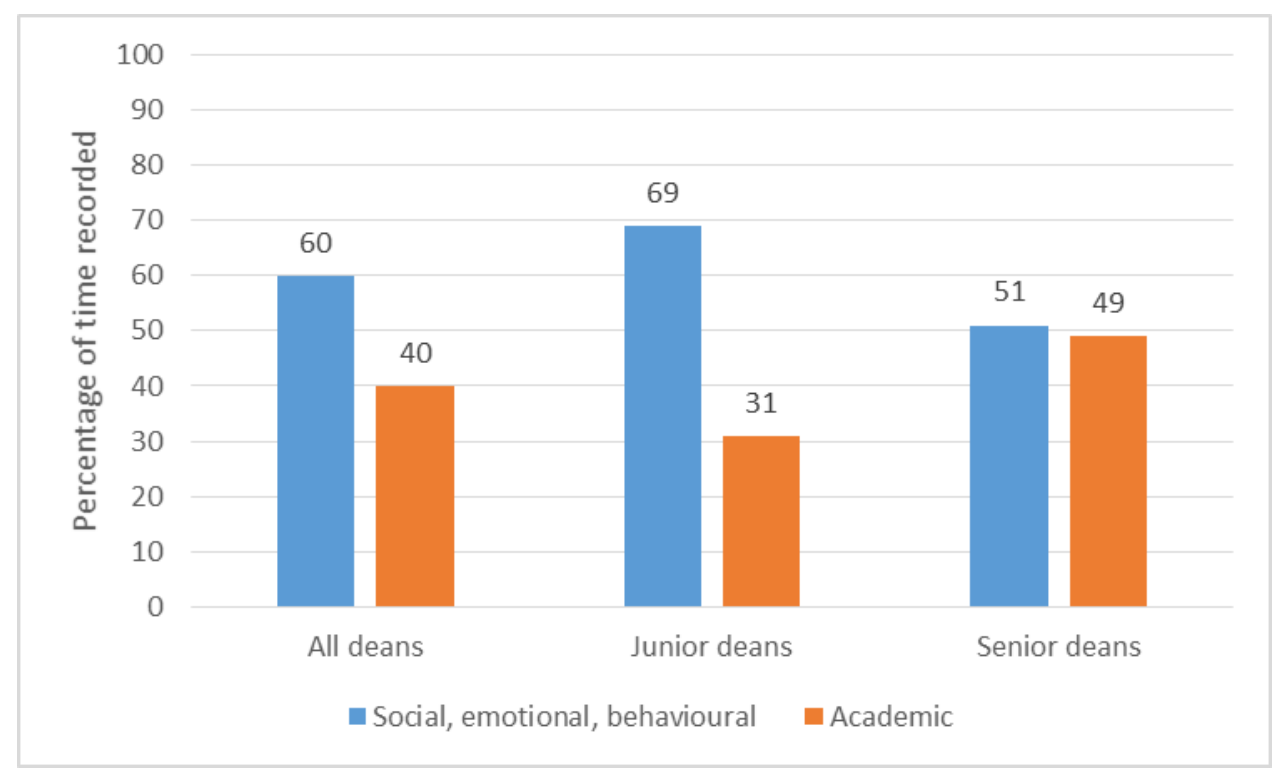

\section{Figure 3. Percentage of time spent on tasks associated with social, emotional, and behavioural issues compared to academic issues.}

The teacher focus group, along with some of the deans, mentioned that perhaps "adolescent psychology" and student lack of experience within the secondary system could explain the perceived focus on behavioural issues in the junior school:

[the dean is] like the Principal, they are there to be the boss... [it's] pretty normal in terms of adolescent psychology...it's fun to cultivate...they grow in confidence. (Teacher focus group)

I think they see it as a punitive system, certainly in the junior school...I think in the senior school it carries slightly less stigma. By the time you get to Year 11 they are kind of learning their way out of that habit. (Dean Kennedy)

Senior managers, deans and teachers all reported an awareness of the difference between the role in junior and senior schools. In order to enhance the focus of junior deans on academic matters in the role of the dean between the junior and senior schools, a graduation system based on 'points' has been introduced to the junior school. 
It is just another way of marking, I think the graduation thing is the thing that will get them thinking about it...it is in its infancy at the moment with the graduation system so we are going to start looking at having those interviews with parents of kids who are especially not achieving. (SM Jordan)

The teacher focus group outlined their opinion on the relationship between academic care and social, emotional and behavioural care. They explained that, across both the junior and senior school deans, academic care and social, emotional, behavioural care are inextricably linked:

When you start having fires happening, when kids start to erupt, it is generally affecting their academic progress anyway and quite often a way of getting them on board to do something about whatever issues they are having is looking at where they are going academically. (Teacher focus group)

\subsubsection{Reactive versus proactive care}

The following quotes are representative of the large number of statements that were made about the reactive care the deans provide, showing that the dean's role, and in particular the role of the dean in the junior school, is perceived as a predominantly reactive role:

I would say in the junior school it is almost exclusively fighting fires, reacting. (SM Jaime)

The junior school systems are set up to be quite reactive rather than proactive... (Dean Kennedy)

I guess when people need help they sort it out, if they need extra help and stuff like that. (Student George)

The teacher focus group also raised the issue of time spent "firefighting" by the dean, addressing the complex relationship between proactive and reactive care.

All deans reported spending more time on reactive work than proactive work through the deans' daily logs. Each activity in the log, whilst categorised into social, emotional and behavioural, academic, and administrative tasks, was also able to be categorised into proactive or reactive tasks. 


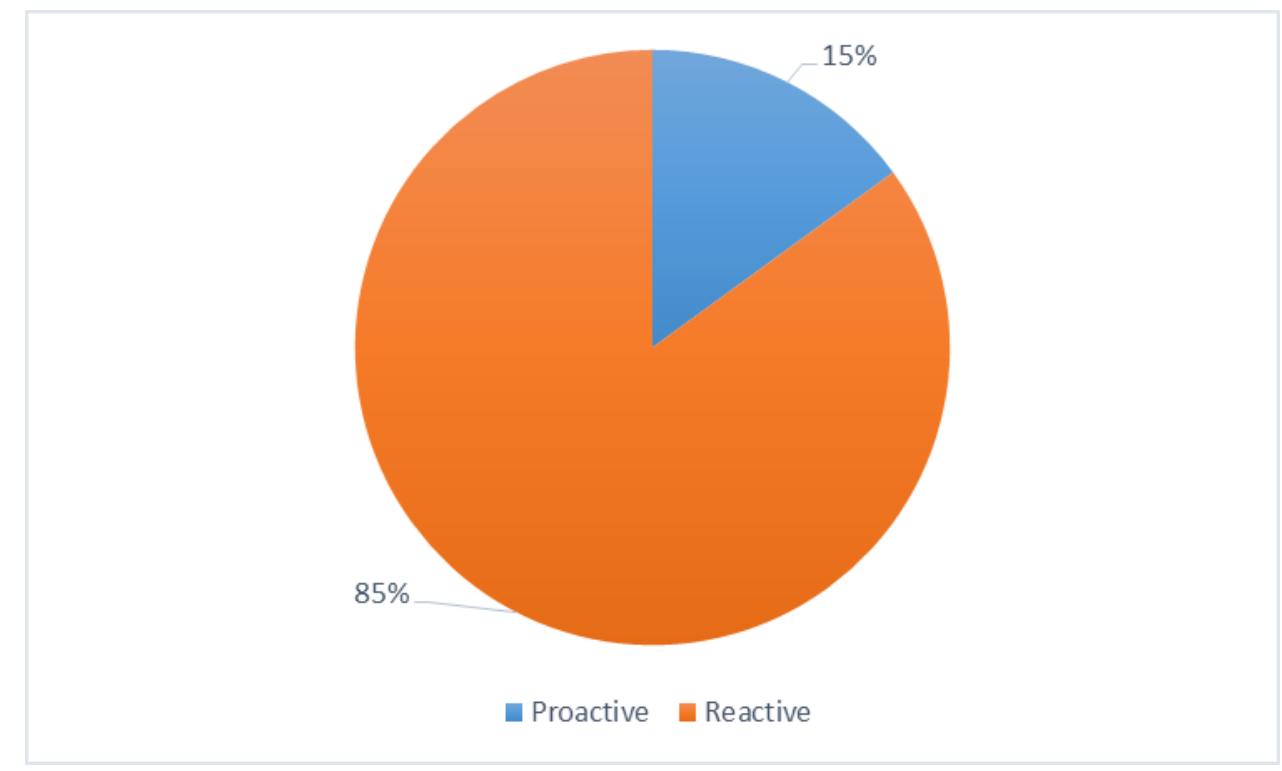

Figure 4. Percentage of time spent on tasks categorised as reactive or proactive tasks

Both junior and senior school deans indicated that they spent much more time on reactive tasks than proactive tasks. The senior school deans reported spending a larger percentage of time on proactive care than deans from the junior school (Figure 6).

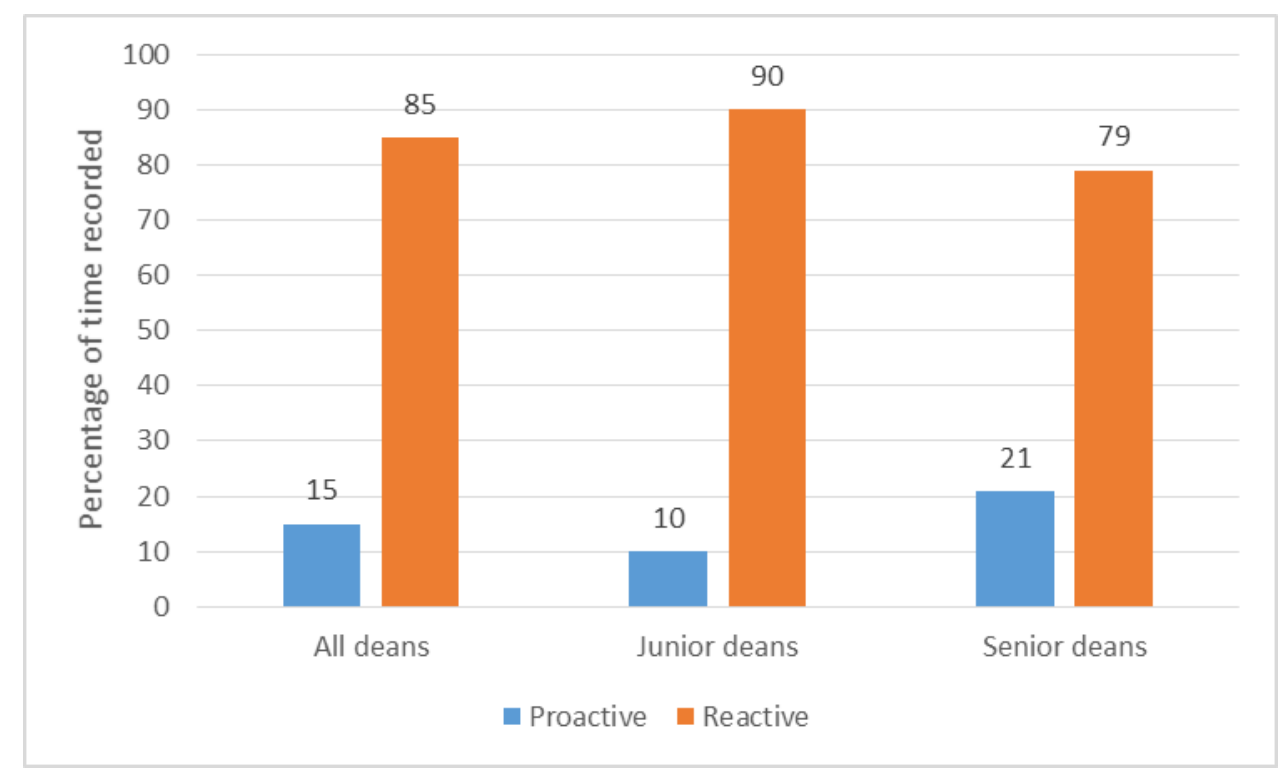

Figure 5. Dean engagement in proactive and reactive tasks

Deans used academic records to establish both high achieving groups and 'high risk' (low achieving) groups. 
The high risk students were identified using benchmarking ${ }^{20}$, a reactive process based on existing records and low achievement levels. Each student in this group is identified as high risk by their academic record. The students in this group are then monitored regularly by the dean for academic progress in order to proactively monitor and encourage the students:

...benchmarking, that's the academic progress for the kids that are at the bottom basically that we feel are at risk of not achieving unless they are reminded to chase re-submissions or finish assessments. (Dean Tui)

Workshops are organised for high-achieving students who are identified by the dean as having the potential to achieve an endorsement on their qualification. The reactive process of identifying students based on their academic record is followed up by the proactive action of the ongoing workshops:

What we have identified is students who have a certain percentage, are on a trajectory to get Excellence Endorsement Level One...he is going to talk to them about how well they are doing and discuss some strategies to make sure that happens. (Dean Jessie)

Benchmarking, the identification of high achieving students, and any interactions with these groups of students is not identified in the job description of the dean. All participants explained that the deans mainly work with a small number of 'at risk' students and a small number of students who are achieving higher academic results:

The students that the Deans deal with are the ones that are causing issues in a number of classes and they are often at risk academically. (SM Jamie)

I feel like I am only dealing with the naughty kids at the moment and I don't feel like I am getting enough time to actually go and see the top kids and give them some ideas on how to keep on top. (Dean Tui)

What I thought a dean was before I got here was someone who looked over the whole year and knew everyone which it sort of is...[It's more] making sure the naughty kids stop doing whatever they are doing. (Student George)

There would be two main groups that they should be concentrating on in a year and they would be those who are going places and those who aren't. I guess I am somewhere in the middle. (Student Rory)

20 Benchmarking is a process used at the school to identify students who are 'at-risk' of not achieving their qualifications based on their academic performance in the previous year. This group is 'academically mentored' throughout the year by either a Senior Manager (for the most 'at-risk') or the year level dean. 
These descriptions of the deans spending most of their time with a smaller group of students is in contrast to initial reports by participants, and to the role descriptions, that state the role of the dean is to provide care to all the students in the year level. Dean Kennedy and Dean Ashton explained that dealing with this targeted group not only helped the higher needs students, but was also important in helping all students. One dean's words explain the perspective that while it may appear that only a few are receiving help from the dean, in fact, many more students would benefit from this targeted work:

$5 \%$ of my students take up $95 \%$ of my time as dean but they are also the 5\% that have the potential to do the most harm and be the most disruptive to other people's educational and social experience. (Dean Kennedy)

Participants also acknowledged that this focus on higher needs students leaves a middle band of students who did not receive direct attention from the dean. The responsibility for these students was described as lying ideally with the form teachers. It was suggested by one dean that sharing the pastoral responsibility by making form teachers more accountable for student care would decrease the load on the dean. This middle band was mentioned by participants from all groups and is represented by the following comments:

I need my form teachers to be working with students who are at risk but not at severe enough risk that they warrant my intervention...unfortunately that does leave a middle band which doesn't get a huge amount of support but they get there. (Dean Jessie)

I feel like there is a lot of untapped potential that isn't being recognised or isn't being nurtured at the moment. (Dean Kennedy)

That's what worries me about dismissing the grey kids ${ }^{21}$ as 'ok they'll be fine'. Those are the kids that won't achieve their potential because they are the ones that will sit there and get Achieved for the rest of their lives when they could be getting Merits. (Teacher focus group)

Two senior managers, four deans and the teacher focus group explained that this middle band did not need a relationship with the dean and could get along "just fine" (teacher focus group). All four student participants identified themselves as belonging to the middle band without prompting and noted that they would like some improvement in the support they received whilst also acknowledging the difficulty the deans would face in doing this:

21 'the grey kids' was a term used by staff to describe students who sat in the middle band of achievement and behaviour or 'the grey area'. 
It could be better looking onto everyone, it would be hard because there are a hundred or whatever people in our year but knowing who people are a bit more and not just the kids who mess around...I have sort of just been in the middle, I haven't had that much trouble with school so it hasn't really affected me. (Student George)

It would be more beneficial for the entire year group if it were equal maintenance for all. (Student Rory)

\subsection{Discussion}

\subsubsection{What is the role of dean?}

Participants agree that the dean is responsible for all of the students in their year level. This aligns with the job description. Student perceptions of the current role of the dean indicated some discrepancies between their ideas and the deans' ideas on the intention of the role, most notably on the presence of the dean, with students wanting the dean to be more visible and accessible. This result is similar to the findings of Howeison and Semple (1996, 2000), who identified a similar discrepancy between students and teachers.

The job descriptions indicate some inconsistencies in the lines of authority across different positions within the school. This finding is consistent with Marland's theory on the difficulty of deans moving from being responsible for students to responsible for staff (1988, as cited in Marland, 2001). The concept of deans having some responsibility for adults, in this case the form teachers, was not discussed by most participants and was not present in the quantitative data. The dean participants who did discuss being responsible for the form teachers indicated some confusion around the lines of authority, similar to findings from analysis of the job description, which is also consistent with some theory (e.g., Carnell \& Lodge, 2002). The deans discussed the expectation that the form teachers would be taking on responsibility for the care of students in their form class. Whilst this was reported as the ideal, it is unclear how much responsibility the form teachers take for the provision of care to students as this was outside the bounds of this study.

The lack of pastoral goals in the job description and other school documentation, and lack of a shared vision for the intention of the role of the dean is consistent with literature that details this as a challenge that staff with pastoral care responsibilities face (Calvert \& Henderson, 1998; Carnell \& Lodge, 2002). The resulting confusion over the intention of the role of the dean manifests itself in the cumbersome number of tasks required of the dean, limiting their ability to provide (or facilitate the provision of) care to students. The 
lack of clarity within the dean's role reflects one of the difficulties faced by deans and form teachers in that job descriptions do not reflect the role and purpose of the job, instead detailing an extensive list of tasks and responsibilities (Calvert \& Henderson, 1998; Carnell \& Lodge, 2002).

The inconsistencies in the job descriptions, as well as the reported confusion over lines of authority, align with existing literature that asserts that the implementation of guidelines on responsibility and roles within the school hierarchy can improve the staff perception of their role and minimise confusion (Howeison \& Semple, 2000). Additionally, Hoy and Sweetland's (2001) work that emphasises the value of a well implemented hierarchy, where staff are aware of their own responsibilities but can work collaboratively with their colleagues to problem solve, justifies further examination of the alignment of job descriptions at Northside College. The individual reactive casework and benchmarking (Section 4.1.4) is not explicit in the job description, indicating that deans spending most of their time on this area of care is not the official intention of the role. This discrepancy may contribute to the confusion reported by the staff participants (Hoy \& Sweetland, 2001). These implications are further discussed in Chapter 6.

\subsubsection{Discipline and care}

The potential for intra-role conflict was apparent when deans were discussing their roles as disciplinarians. Participants referred to the role of the dean as including elements of discipline, and care. There was a clear distinction made between what participants described as the traditional role of the dean (discipline) and the aspects of the role that dealt with caring, listening and helping students to solve problems. This double, dichotomous role was described by two senior managers, all deans, the teacher focus group, and students (Table 9).

The deans themselves appeared relaxed and accepting of these seemingly contrasting aspects of their role, describing the care and the fear as necessary and normal. I found this description puzzling as it was repeatedly discussed by a number of participants. In my experience, fear has never been necessary in order to be an authoritative teacher with clear boundaries. It seemed to be spoken about with a sense of pride, that this fear was important and cultivated (Section 4.1.2). There appears a stark conflict between being a caring figure and support person whilst simultaneously being associated with fear. It is to 
be hoped that the fear the participants explained to me was being mistaken for a sense of arresting presence that comes with being higher up the hierarchy.

Participants did not mention any confusion or challenge in their role as carer while also being a disciplinarian which was in contrast to the literature (Averill, 2009; Brenton, 1989; Howeison \& Semple, 2000). Students did not report any difficulty in dealing with the multiple perspectives of the dean which contrasts with Howeison and Semple's (2000) findings. Some participants in Howeison and Semple's study (2000), however, spoke of a required level of discipline and control as part of the provision of an effective care programme which is a finding in common with this thesis.

\subsubsection{Junior school versus senior school}

Participants from all groups mentioned that they thought that the deans responsible for junior year levels dealt with more social, emotional, and behavioural issues than academic issues. This difference was reflected in the data reported through the deans' daily logs. Participants perceived the deans working in the senior school dealt with more academic issues than social, emotional or behavioural issues. However, this perspective from the participants is not reflected in the data from the deans' daily logs (Figure 4).

The distinction between the senior and junior schools is not represented in any available literature. Rose and Pelleschi (1998) have presented a finding that indicated a discrepancy between the perspectives of staff from the senior school and the junior school on a change to the pastoral care system. The account reported staff in the senior school being dissatisfied with the amount of support provided during the induction of pupils, whereas the junior school staff perceived that there was sufficient support for students who transitioned to the school. The nature of the discrepancy between the two parts of the school is in conflict with the nature of the difference at Northside College. However, it supports the concept found in this study that within one school, members of the junior and the senior school can experience phenomena differently.

\subsubsection{Reactive versus proactive care}

During interviews, participants from all groups referred to reactive pastoral care as the main aspect of the dean's role within the school, a finding that is consistent with existing literature (Carnell \& Lodge, 2002). This is further supported by studies that indicate the role of the dean to be someone in the school community to whom students of a particular group, often year level, can go to for help (e.g., Farrand et al., 2007; Swinson, 2010; 
Tucker, 2013). The concept of 'fire-fighting' was discussed as taking up a large amount of deans' time, particularly in the junior school. This compensatory view of pastoral care, which was further reflected in the discussion of the restorative justice model as part of pastoral care at Northside College, is consistent with existing literature (Carnell \& Lodge, 2002).

The findings of this thesis suggest that the main perception of pastoral care within the secondary school is that it is reactive in nature. Best's (1999; Section 1.1.1) model details five different types of pastoral care, with individual reactive casework only one of them. It may be that deans are aware of other ways of providing care to students (e.g., proactive, preventative care) but due to the overwhelming nature of providing reactive care, these are outside of the deans' capability.

An alternative explanation is that deans do not consider proactive care to be part of their position. Deans' daily logs indicated that some time is spent on proactive care; however, this was notably less than reactive care (Figure 5). Interviews revealed that participants found it difficult to distinguish proactive tasks from reactive tasks. This was because proactive action from the dean was often informed by an incident(s) or existing issue. The implications of this complex relationship between reactive and proactive care are further discussed in Chapter 6.

\subsubsection{Behavioural versus academic focus}

The existence of a dichotomy in the role of the dean (as a pastoral carer or subject teacher) (Clark, 2008; Griffiths, 1995; Power, 1996) was not evident; however, a separation in the level of responsibility for pastoral care between staff was apparent. Staff members with specific responsibility for the care of students (deans and form teachers) were reported as having more responsibility for the provision of care for students than subject teachers, including heads of departments. Participants did not report perceiving pastoral care as having a lower status than curriculum matters as has been discussed by some literature (Calvert \& Henderson, 1998; Carnell \& Lodge, 2002).

The monitoring of students was an aspect of pastoral care that featured prominently in qualitative interviews, including the benchmarking of students to identify those at risk of not achieving. Deans working in the senior school addressed this issue through regular academic conferencing with the most at-risk students, with the remaining students being 
monitored by the form teachers. The school was attempting to address the difference in focus of the dean between the junior school and the senior school by introducing a graduation system (based on points) in the junior school to motivate students in their academic achievement. Whether or not the points system will alone motivate students remains to be seen. The senior school utilises a student-form teacher conferencing programme to set and monitor student progress. Staff participants reported difficulty with introducing conferencing into the timetable due to timetabling restrictions.

The participant responses concerning the academic focus in the senior school and the literature examining the use of academic mentoring programmes (Reading, 1999; Rose \& Pelleschi, 1998) and student goal setting (Robinson et al., 2009) creates an interesting case for introducing regular student mentoring in addition to monitoring. However, findings from Darling and Hamilton (1996) suggest that, in general, synthesised mentoring relationships can be ineffective if the quality of the mentoring is not high. This implies that the quality of mentoring would need to be monitored and that staff acting as mentors may benefit from professional development in how to build meaningful relationships with students in order to support their learning (Bishop et al., 2014; Darling \& Hamilton, 1996; Howeison \& Semple, 1996). 


\section{Chapter 5: Challenges and affordances of the role of the dean}

This chapter aims to address research question 5 by outlining the challenges and affordances reported by the deans in their role. The chapter outlines an overview of the challenges and affordances that the deans encounter (Section 5.1.1), then presents an examination of common issues that the deans reported; the provision of professional development (Section 5.1.1), school facilities (Section 5.1.2), time and remuneration pertaining to the role (Section 5.1.3) and the structure of the school (Section 5.1.4). The chapter concludes with a discussion of the results, relating them to the existing literature (Section 5.2).

\subsection{Results}

Deans reported encountering a range of issues that made their job more difficult and a number of factors that enabled them to enact their responsibilities with greater confidence. These factors mainly focus on resources - detailed in this section as professional development, facilities, time and remuneration, and the structure of the school.

\subsubsection{Challenges and affordances}

When asked about what made their jobs difficult, deans, senior managers and teachers reported administrative tasks or issues with other adults (staff and parents) were the most challenging issues in the role of the dean. Deans consistently discussed their responsibility for the student reporting process as challenging. Dean Tui provided the example of colleagues repeatedly making the same errors in student reports year after year as an example of staff within the school making the job more cumbersome:

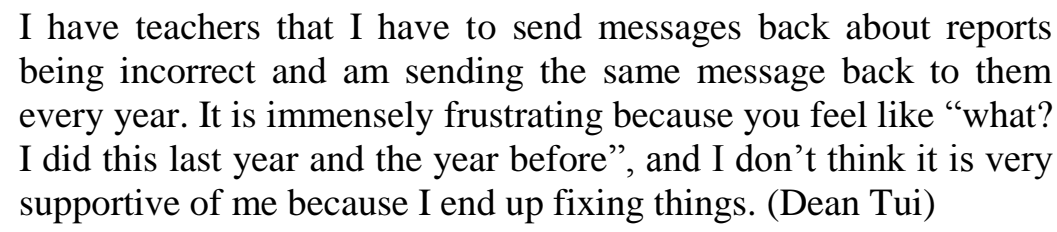

The teacher focus group reported an awareness of some staff members making the dean's role more difficult due to a lack of a collaborative approach to care and discipline: 
Some colleagues just don't want to compromise. (Teacher focus group)

All six deans identified the senior management structure as effective and supportive:

We get plenty of support from senior management. (Dean Aubrey)

[Senior management] is really good with providing me with guidance on how to sort these kids out. (Dean Ashton)

However, two deans identified lines of communication and of responsibility as challenging areas in the senior manager-dean relationship. Dean Jessie discussed the importance of power, referring to the hierarchy of authority that exists within the school:

Sometimes a process that I see as being appropriate can be overruled by the powers above me which kind of takes the power out of my hands and depowers me as a dean...sometimes I am open to the fact that my methods don't always work but it is hard to take on the chin. (Dean Jessie)

Sometimes communication [is difficult']. [The senior manager and I] communicate like that, it's tough at the moment although we have set aside a period to do that, often we don't do it then, we might do it last thing Friday afternoon. (Dean Tui)

The structure of the staffing outside of the senior management proved to be a recurring theme in participant responses (4.1.1).

\subsubsection{Professional Development}

Deans identified senior management as a key resource for their learning and development. Teachers and deans spoke positively about the senior staff structure of the school, praising the approachability and experience of the senior management team. These relationships assist the deans in furthering their skills and knowledge:

The senior management in this school are very approachable, they don't see themselves as being all high and mighty. They are willing to teach you along the way with various issues and they just make very clear decisions and they will take responsibility for those decisions. (Dean Casey)

Deans identified formal professional development as an area they would like more opportunities in due to a lack of formal learning opportunities:

Perhaps offer courses on furthering ourselves like if we are looking at senior management positions or Assistant Principal positions, I am not sure but I think HoDs are afforded luxuries but it would be quite nice to be made aware of courses that are coming up. (Dean Casey)

There is no pastoral training at Teacher's College level...it is carried on by schools as well because we get PD time dedicated to 
digital learning, or to the NZ Curriculum but there is never any form teacher training or pastoral care and that sort of stuff. (Dean Kennedy)

The focus is not only on the lack of professional development focused on pastoral care but also in other areas pertaining to a dean's career progression. This could be transferred to include particular skills that are involved in pastoral care such as staff management skills and problem solving, areas that deans have highlighted they find challenging at times in their role.

\subsubsection{Facilities}

\section{Physical Space}

All staff participant groups discussed the physical facilities as an issue. The participants raised the issue of limited office space and lack of interview rooms as a challenge and the benefits of the current proximity to each other in which they work as an affordance in the execution of their roles. Deans, senior managers and teachers all discussed the positive aspects of having an area where the deans and senior managers functioned together to facilitate collegiality and team work amongst the deans:

That is one of the things that I really like about being a dean in this school is the fact that it is a really collegial environment, it's a shared office situation but the junior deans and the senior deans, the offices are next door to each other and we take the pressure off each other. (Dean Kennedy)

All staff members identified the need for a space that could be used to interview students privately. The reasons given were categorised into three areas:

- To provide a private space for students to feel comfortable to speak openly:

You need a space where you can interview a student privately, where people aren't going to overhear what you are talking about. (Teacher focus group)

- To ensure that deans can provide their undivided attention to students in need and not be called upon for other duties or be interrupted by colleagues or students:

I think the physical resourcing is not good actually, you can't have private conversations with kids, they tend to bring them in here, it makes it very hard for them to work if they have to sit while other people are interviewing kids. (SM Jordan)

- To ensure that deans are not prevented from using their office space when required:

A better working space, there are [a number] of us in here and I have to interview students. Yesterday afternoon I lost an hour of my time because all my stuff is in here and another Dean was using the office to interview a student and I couldn't get in. (Dean Tui) 


\section{Technology}

All deans and senior managers commented on the school's student management system KAMAR as an effective and useful system that is used regularly. Deans and teachers utilise the system to communicate about pastoral incidents. In addition, deans utilise the system during conversations with students to discuss current academic achievement and progress. The programme is also being developed to further inform parents:

The technology allows deans to be interested much more in academic achievement now more than they ever were before. (SM Jamie)

I think it is great, and the kids often come into class now and ask if you can bring KAMAR up and show them how many credits they have got. (Dean Tui).

Through the KAMAR system and the school portal, if I write an incident up on KAMAR, if parents are checking the portal they will actually see what has happened. (Dean Jessie)

Participants reported the system increased communication across staff and made monitoring student progress more practical. The potential for KAMAR to be utilised as a communication and reporting tool with parents is powerful. One dean outlined the need for a tool to monitor results from the whole year group "to look at patterns that are emerging and be able to intervene...to make sure the students are having the opportunities to achieve" (Dean Ashton). This would enable deans to identify particular groups of students or particular classes where further assistance would benefit students.

\subsubsection{Time and remuneration}

All staff participants identified the limitations of time as a hindrance in the role of the dean with senior managers acknowledging that this restriction contributes to added pressure on the deans' subject teaching workload as well. This highlights that it is not just the deans' ability to provide pastoral care to all the students in the year level that is challenged, but also their ability to perform at their best as subject teachers. Deans appeared generally accepting of the current state of the time allocation, however dissatisfied:

A standard teacher would have about 20 hours a week, a dean does 16 so they only get four hours but the reality is that every dean has non-contacts that go to deaning, they don't have non-contacts to do marking and preparation and all those kinds of things. (SM Jamie)

Time commitments...given that as a dean we are given three noncontacts to do our deaning work is unrealistic but we know that going into it as well, and we know that going into the teaching profession that it's not a 9-3 job...it's part and parcel. (Dean Casey) 
I can quite confidently say...I will not be a dean again. Not without some other allowance, two lines of the timetable would be better because one line is not enough. (Dean Tui)

However, two deans contributed that they did not want more time allowance dedicated to deaning as they enjoyed their time in the classroom, with one explaining that being a dean was not being a 'teacher' in the traditional sense:

The reality of being a dean is that this could be the dean and that is all they did. Ironically enough, it is not a job I want because I trained to be a teacher because I love teaching so it is one of those things where it is a fine line. (Dean Kennedy)

More time but then that means less class room time and I like classroom teaching as well. (Dean Tui)

The deans above identified their conflict over having more time for carrying out their role and students also identified this as an issue. Two students (Student Harry and Student Rangi) identified having two deans at one year level as a good idea. Participants from all groups identified having two deans for each year level as a positive move by the school and wanted to see this at every year level. Teachers identified this move as positive because it shared the workload. Students, however, indicated that this was positive because it gave students a choice in whom to approach with concerns:

If you don't like one dean there is another one to go to and just more eyes on everyone, they could have different strategies they could work together with. (Student Harry)

All of the students had opinions on the role of the dean, whereas staff participants were generally of the opinion that the students "don't care" (Dean Tui) about the role of the dean. All students identified a need for deans to be more visible and accessible:

...maybe if they made a few more appearances, more deans' assemblies just to update everyone. I can't remember the last time we had a deans' assembly. Make themselves actually there and they are not just about bad stuff but the good as well. (Student Harry)

Two deans and one senior manager identified remuneration as an area for improvement stating that this may be an area that would improve job satisfaction or increase the deans' sense of value in the school:

I know it is not all about money but I think they need to get paid more for their job. (SM Ryan)

I think there are other roles in the school that get monetary appreciation that is greater than what a dean does so again, I don't know if we are fully valued. (Dean Jessie) 
I am probably working for about 5 cents an hour. I like doing it but it is burning me out. (Dean Tui)

Dean Jessie refers to "other roles in the school" and is likely referring to the other middle management positions in the school which are those of heads of department. This conflict regarding pastoral care versus curriculum matters was also discussed in Section 4.2.5.

\subsubsection{Structure}

The school allocates a dean to a year level, specifically, Year 9. This dean then follows the cohort through to Year 13. All participants talked about this system structure positively, citing the main benefit as building strong relationships with students and parents:

We have a thing where the deans go with the kids. (SM Jamie)

When you follow them through you get to know them very, very well and they get to know you very well so it is also kind of like a safety net for the kids and parents as well because by the end of it you know the parents really well. (Teacher focus group)

I think [the dean going through with you] is good because the dean will know the students and you know the dean and you are comfortable with each other. (Student Harry)

The staff mentioned that the school had trialled different school structures in the past, including a vertical system but had decided that a horizontal system where the dean progresses with the cohort was the most appropriate for this school. Participants reported that the way the system is set up is positive, enabling stronger relationships between the dean and the students in their year level.

\subsection{Discussion}

Participants reported that the deans were well supported by senior managers and other colleagues in their role. This support reflects literature (Calvert \& Henderson, 1998; Carnell \& Lodge, 2002) that indicates that a lack of support from the school leadership team can be a challenge in the deans completing their roles. In this case, the opposite was found to be true with the support of senior managers identified as an affordance for deans. However, communication between the two positions was cited as a challenge for the deans at times, highlighting a possible area of improvement for schools.

Providing the deans and the form teachers with professional development around the skills required to effectively deliver pastoral care for all students may improve the 
effectiveness of the pastoral care delivered by the staff working in these areas. This is an example of where professional development for form teachers and deans may enable staff to get students to open up and genuinely engage in the conversation using highlevel interviewing skills (Howeison \& Semple, 1996). The provision of professional development does not have to focus on pastoral care as a separate provision to the skills required to ensure the provision of care for all teachers, such as building and maintaining relationships (Bishop et al., 2014).

Participants all discussed a need for a private room to discuss confidential matters, address student needs uninterrupted, and free up communal work spaces for the other deans. Providing such spaces could be a change that would have an impact on the delivery of care, easing some pressure on deans and also increasing the perceived emphasis placed on pastoral care within the school. Findings from this thesis are consistent with Howeison and Semple's (1996) study where students mentioned the lack of a private space as impacting their willingness to engage with their dean about serious issues. It was not necessarily the space but the privacy that it afforded that appealed to students (Howeison \& Semple, 1996; Nelson \& While, 2002).

Time was reported as a major limitation for deans being able to carry out their role by all participants involved in the study. However, there did not seem to be a straightforward resolution to this. Staff participants reported that the deans spent a lot of their time on deaning tasks, leaving little for their work on subject specific teaching tasks, despite all retaining subject teacher roles. This, in combination with the students' reported desire to see their deans more frequently in classrooms and one-on-one, outlines a lack of provision of resources to this role. Some deans, however, reported not wanting to relinquish their subject teacher positions, being unwilling to decrease their time spent teaching.

These findings are consistent with results in studies by Howeison and Semple (1996, 2000) that found participants in the role of guidance teacher found lack of time to be a major challenge in the performance of their role. Students reported wanting their guidance teacher to be more accessible, indicating that the effects of time restraints are part of the essence of the role. Other literature also states that a lack of time acted as a constraint for deans in the delivery of effective pastoral care (Carnell \& Lodge, 2002; Nelson \& While, 2002; Swinson, 2010). 
The structure of the school aligns with existing literature reflecting the common organisation of the school into horizontal year groupings (Arnott, 1994; Best, 1999; Galassi et al., 1997). Whilst some literature advocates the vertical groupings for establishing strong links with students and parents (ERO, 2012), Northside College has addressed this by implementing a rotating dean (Bulman, 1987). The participant reports support claims from literature that it enables strong relationships between the dean and students and increases familiarity (George \& Alexander, 1993; Galassi, et al., 1997). The implications of these findings for schools, parents, and policy makers is further discussed in Chapter 6. 


\section{Chapter 6: Conclusion}

This concluding chapter revisits the research questions posed in Chapter 2 and summarises the key findings relating to the sub questions, which in turn, address the central research question of this study. Reflections and limitations of the study are considered (Section 6.2) followed by a discussion of the implications of the main findings in relation to existing literature (Section 6.3).

\section{Summary of study}

This study explored the role of the dean and its function in a New Zealand secondary school. After examining existing literature, this study utilised perspectives from within a school community to draw out the essence of the participants' experience of the role. A phenomenological case study paradigm was utilised, informing the mixed-methods design of this study. Participants included four members of the senior management team, six deans, a group of five teachers, and four students.

Qualitative interviews, a focus group, school documents, and a quantitative measure (an activity $\log$ ) completed by the deans were utilised to collect data. The qualitative data were analysed through relevant segment selection. Inductive and deductive approaches were used during coding. In order to generate a general understanding of how deans in this school were spending their time in their role as a dean, the self-report deans' daily logs were processed and analysed to reveal what aspects of care deans reported spending their time on.

Findings from the various data sources were compared in order to ascertain an understanding of the essence of the role of the dean and how it functions within this school. These findings were then discussed in relation to existing literature.

\subsection{Addressing the research questions}

This section revisits the research questions that guided this study to provide an understanding of the role of the dean as it operates at Northside College.

Each sub-question is discussed summarily in turn and then the central research question is addressed: 
1. What is the role of the dean as perceived by members of the different groups in the school community including, the senior managers, the dean themselves, teachers, and students?

When asked about their view on the role of the dean, participants directly answered that the role was responsible for the whole year level, for keeping students in line, and for being there when they had a problem. This description reveals two things about the essence of the role. The first is that the perception of the role is one that is responsible for the whole year level, and the other is that the role is reactive in nature (Section 4.2.4). The deans considered the academic progress and achievement of students as at least equal in importance as matters of a social, emotional or behavioural nature even if they considered that they spent more time on the behavioural matters that students were dealing with (Section 4.2.5). There may be some connection between the amount of individual reactive casework and the number of social, emotional and behavioural issues that the deans deal with, or, the connection may be between the lack of proactive, preventative care provided to the students and the amount of individual reactive casework the deans engage in.

Participants explained the cause of the difference between the role in the junior and senior schools as the presence of NCEA as a system of monitoring and measurement, the use of academic conferencing, and generally students in the senior school being more mature than those in the junior school (Section 4.2.3). There are several other possible explanations that were overlooked, including that the rotating deans become more experienced in their role as they progress through to the senior school position, or students may have worked with their dean for a number of years upon reaching the senior school, building a strong relationship with them.

2. What is the role of the dean as defined by documentation designed to inform the management of the school, including staff role descriptions, school policy and strategy documentation?

The school documentation describes the dean as being responsible for all the students in the year level. The documentation describes a number of tasks that deans should complete with a large number of these able to be categorised as administrative or communicative in nature. Tasks that concern student behaviour far outnumber those that concern the academic progress and achievement of students. 
The job description does not include explicit reference to the individual reactive casework of deans. The job descriptions of the dean, the head of departments, and the form teachers highlight discrepancies between the lines of authority within the school (Section 4.2.1).

3. How are staff spending their time in their role as dean?

Deans reported spending a much larger amount of time on reactive care tasks than on proactive care tasks through the deans' daily logs (Section 4.2.4). There was a notable difference in the types of tasks being addressed by deans who work in the junior school and those who work in the senior school. Senior school deans reported spending a relatively even amount of time on social, emotional, and behavioural tasks, and those that concern the academic tasks. Junior school deans recorded spending a larger amount of time dealing with tasks that concern social, emotional and behavioural issues than those that concern academic tasks (Section 4.2.3).

Deans are allocated 4 hours a week in which to complete their deaning tasks (of which, one hour is spent with a truancy officer for deans working in the junior school). It is a sobering thought to consider that deans are spending up to 23 hours a week completing their deaning tasks, on top of their subject specific teaching load.

4. How do perceptions and documents concerning the role of the dean and the deans' practice compare in evaluating the aspects of pastoral care addressed by the dean?

The list of tasks referred to in the job description and the tasks described by the deans align. Whilst deans did not refer specifically to their job description, a lot of the tasks described in the job description were also discussed by the participants and recorded by the log. The deans did not report completing administrative work as considerably as I had expected based on the job description. This log may not reflect the seasonal nature of the deans' job with a flurry of activity happening around specific times, for example, report writing or enrolment (Section 3.4.3). Alternatively, it may indicate that the deans are managing the administrative requirements of the job without issue. Whilst this may be the case, the completion of administrative tasks - such as report proofreading - was reported as a time consuming and frustrating task, other administrative tasks (e.g., recording students' progress for monitoring and communicative purposes) were seen as necessary. 
5. What challenges and affordances do deans experience in relation to addressing aspects of pastoral care, and therefore promoting student well-being?

The challenges that the deans face in delivering pastoral care are numerous and varied. Primarily, resources were reported to be a hindrance to deans in the performance of their role. The precious resource of teachers' time in teaching is not a new issue. This study was designed to have minimal impact on teachers' time in order to increase the likelihood of voluntary participation. Northside College was attempting to address the issue of time by introducing two deans at each year level (beginning at Year 9), a change that staff and students alike were welcoming. Notably, the two deans at Year 9 did not report spending less time on their deaning tasks. In fact, one of the deans who had shared responsibility for the Year 9 cohort reported spending the most time of all the deans on deaning tasks in the week (the upper range of 23 hours, Section 4.2.1). Staff reported that strong collegial relations within the staff and senior management team acted as an affordance in the functioning of their role as dean.

Some participants discussed professional development, facilities, staff relations and structure as other challenges in their role. I propose that lack of school policy and guidelines on pastoral care may also have an impact on the deans' ability to do their job in that the introduction of clear pastoral aims, alongside clear, school-wide behavioural expectations and values that are enforced by all staff members and reflected in school documentation, may aid in improving the ease with which deans engage in their role. A more collective responsibility for the care of students across staff may also help (Chapter 4.2.1).

\subsubsection{The central research question:}

What aspects of pastoral care are evident in the role of the dean as intended by school policy and documentation, as enacted by the deans and as received by the students?

Qualitative and quantitative data highlight the role of the dean as complex and varied. The role of the dean is one of responsibility for the provision of care to every student within the year level. The role consists mainly of individual reactive casework, which sees the dean dealing with a small number of high needs students throughout the year. Frequently engaging in this aspect of the role has positive and negative effects. Students with the highest needs get individualised attention and other students benefit because of the contribution to their positive learning environment that is consequential to the 
effective management of potentially disruptive students. However, some students feel they miss out on care from their dean because the dean is too busy dealing with high needs students. In addition, deans are loaded with many tasks, making their time management difficult. Proactive aspects of the role, which could assist in reducing the number of reactive cases that need attendance, are not addressed (or considered) because, currently, other aspects of the role require the deans' immediate attention. Some arbitrary tasks that do not appear to require the specialist skills of the dean become their duty adding to their workload (e.g., proofreading and correcting all subject reports for all students within their year level).

In order to further address this question, the definition used in Section 1 will be used as a guide to identify which aspects of pastoral care are, and are not, evident in the role of the dean. The definition identified several key aspects of pastoral care (Table 7).

Table 9. Key aspects of pastoral care evident in the role of the dean as informed by the definition pastoral care (Section 1.2)

\begin{tabular}{|l|l|l|}
\hline $\begin{array}{l}\text { Aspect of pastoral } \\
\text { care }\end{array}$ & $\begin{array}{l}\text { Evident in the role of the dean } \\
\text { at Northside College }\end{array}$ & $\begin{array}{l}\text { Absent from the role of the dean } \\
\text { At Northside College }\end{array}$ \\
\hline $\begin{array}{l}\text { The quality of } \\
\text { teaching and } \\
\text { learning }\end{array}$ & $\begin{array}{l}\text { Quality of learning could be an } \\
\text { indirect outcome of some aspects } \\
\text { of the role of the dean. }\end{array}$ & $\begin{array}{l}\text { Quality of teaching and learning is } \\
\text { not explicitly addressed within the } \\
\text { role. The main interaction within } \\
\text { the role is between student and } \\
\text { dean }\end{array}$ \\
\hline $\begin{array}{l}\text { The nature of } \\
\text { relationships }\end{array}$ & $\begin{array}{l}\text { Primarily provides conflict } \\
\text { resolution for students in various } \\
\text { relationships including peer-peer, } \\
\text { teacher-peer. }\end{array}$ & $\begin{array}{l}\text { The fostering of positive } \\
\text { relationships through the promotion } \\
\text { of preventative pastoral care } \\
\text { strategies is absent. }\end{array}$ \\
\hline $\begin{array}{l}\text { Arrangements for } \\
\text { monitoring pupils } \\
\text { overall progress }\end{array}$ & $\begin{array}{l}\text { Monitoring of academic progress } \\
\text { in the form of academic } \\
\text { benchmarking based on NCEA } \\
\text { achievement data in the senior } \\
\text { school and new points-based } \\
\text { system in the junior school. There } \\
\text { is some discrepancy between } \\
\text { deans working in the junior school } \\
\text { and those in the senior school. }\end{array}$ & $\begin{array}{l}\text { Monitoring of pupils' personal and } \\
\text { social development is not explicitly } \\
\text { or officially monitored by the dean. }\end{array}$ \\
\hline $\begin{array}{l}\text { Specific pastoral } \\
\text { support systems }\end{array}$ & $\begin{array}{l}\text { There are some systems and } \\
\text { procedures in place for the delivery } \\
\text { of pastoral care. The systems } \\
\text { present as more reactive than } \\
\text { proactive in nature, particularly in } \\
\text { the junior school. }\end{array}$ & $\begin{array}{l}\text { There are some aspects of the } \\
\text { system that appear to be lacking, } \\
\text { including a focus on learning (over } \\
\text { achievement) and the promotion of } \\
\text { student social, emotional and } \\
\text { behavioural development. }\end{array}$ \\
\hline
\end{tabular}




\begin{tabular}{|l|l|l|}
\hline $\begin{array}{c}\text { Aspect of pastoral } \\
\text { care }\end{array}$ & $\begin{array}{c}\text { Evident in the role of the dean } \\
\text { at Northside College }\end{array}$ & $\begin{array}{c}\text { Absent from the role of the dean } \\
\text { At Northside College }\end{array}$ \\
\hline $\begin{array}{l}\text { Extracurricular } \\
\text { activities and the } \\
\text { school ethos }\end{array}$ & $\begin{array}{l}\text { Deans intend to monitor student } \\
\text { involvement in extra-curricular } \\
\text { activities and encourage student } \\
\text { participation, particularly in the } \\
\text { junior school. }\end{array}$ & \\
\hline $\begin{array}{l}\text { Address the } \\
\text { particular } \\
\text { difficulties some } \\
\text { individual pupils } \\
\text { may be } \\
\text { experiencing }\end{array}$ & $\begin{array}{l}\text { This aspect is a large part of the } \\
\text { dean's role. }\end{array}$ & \\
\hline
\end{tabular}

Note: Aspects of care are taken from the definition of pastoral care from the UK's Department of Education and Science (1989).

The deans' roles appear to function as a 'dumping ground' for challenging tasks, completing a range of tasks such as supplying students with missing parts of uniform to visiting primary schools. The actual tasks performed within the role are numerous but listing them does not accurately represent the intention or the purpose of the role (Calvert \& Henderson, 1998; Carnell \& Lodge, 2002). Attempting to describe the role through a list of tasks may underestimate and limit the role of the dean, reflecting one dean's opinion that any task that did not fit into someone else's job description became part of theirs. The amount of weighting given by the school community to the actual job description of the dean was not measured; therefore, it is difficult to ascertain whether or not this job description is a valued document that is thoroughly utilised by the staff at Northside College. The task of being responsible for the whole year level as well as completing all of the other tasks detailed within the job description could be overwhelming, even to the most capable of deans.

The role at Northside College does not appear to have a realistic, achievable purpose attached to it. The general understanding is that the dean is responsible for the year level; however, it is difficult to ascertain what this much responsibility actually looks like. Alternatively, the expectation that deans will provide pastoral care to the students in the year level seems unrealistic with the current pressures on the role and the restrictive way of working.

Best's (1999, 2003) work on pastoral care highlights reactive casework, proactive, preventative care, and the promotion and maintenance of an orderly and supportive environment as three separate pastoral tasks. In examining the tasks of pastoral care as 
outlined in the literature, and applying them to this study, I have learnt that it is increasingly difficult to completely separate these tasks. They are interrelated and interdependent (e.g., Figure 6). It becomes difficult to categorise aspects of the dean's role as only reactive or proactive within a system that is focused on improving student outcomes as the reactive so often informs the proactive (Section 4.2.4).

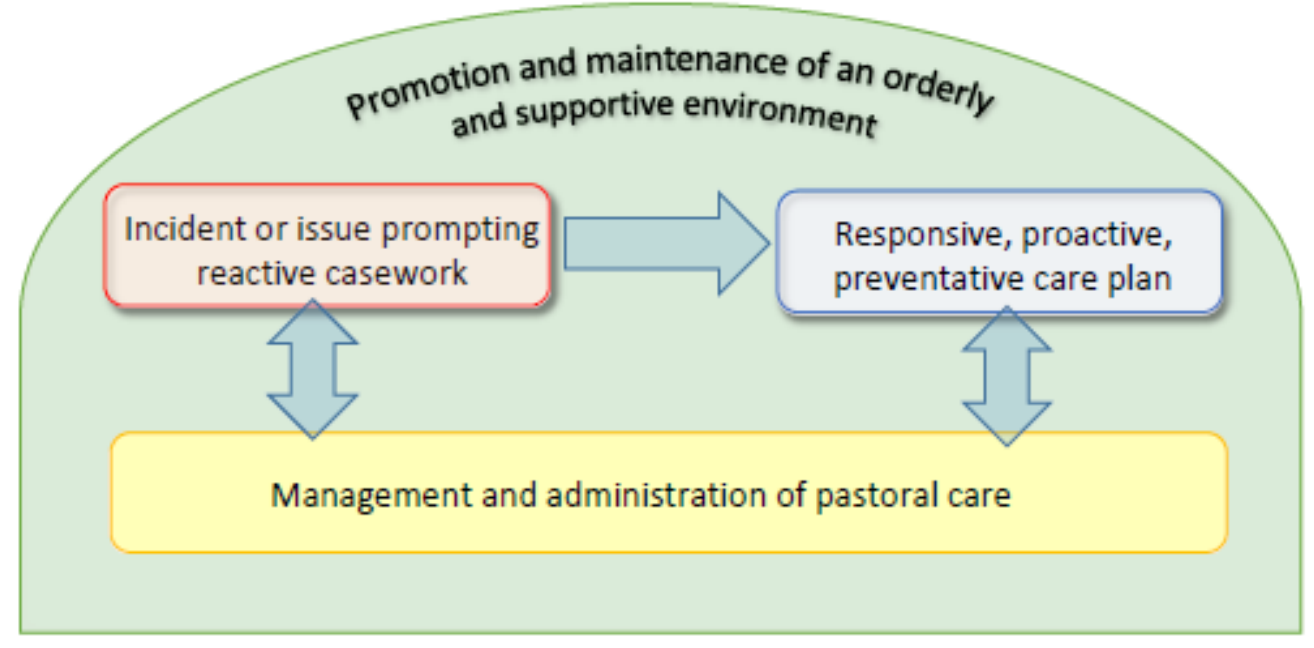

Figure 6. Interpretation of the interrelationship between Best's (1999) pastoral tasks

Howeison and Semple (2000) also found some discrepancies between students' and deans' perspectives, highlighting the student desire for deans to be more present and available but the staff in these positions being reluctant to sacrifice any subject specific classroom time. This discrepancy raises the issue of how a system is modelled. Should the system reflect student need or cater to teacher needs? The consideration of both perspectives when developing policy and goals in this area would be valuable. Balancing these perspectives when there is a discrepancy would remain a challenge for decision makers.

\subsection{Reflections and limitations}

The use of Moustakas's (1994) philosophical concepts in informing the use of multiple perspectives of the role of the dean proved useful. The different accounts from the varied groups provided a range of perspectives. This enabled me to identify common themes that the participants agreed upon, assisting me to understand the 'essence' of the phenomenon (Johnson \& Christensen, 2012) and also identify areas of incongruence, where the different perspectives of the participants may lead to a new understanding of the role of the dean. The sample size enabled me to collect an amount of data that was able to be managed effectively. This sample size, dictated by the decision to conduct a 
case study, also creates a limitation regarding findings from this thesis being generalised beyond the context of this thesis. However, based on literature (Chapter 2), along with my experience within the schooling system in New Zealand, the structure and function of the role of the dean at Northside College is typical of other schools and pastoral care structures in New Zealand. Whilst the findings of this case study should only be generalised with caution, they could be used contextually to provide indications across New Zealand secondary schools.

The use of the mixed-methods approach proved useful when comparing participant perspectives on the role of the dean, how they utilise their time, and what the deans recorded in terms of their daily deaning activity. In order to limit intrusion in the deans' already busy activities, the log was created so that deans could quickly select the approximate amount of time they spent on a task by circling a time range. This contributed towards all deans completing every log, every day. However, a limitation of creating the log this way was that the time indications gathered were difficult to process statistically. The use of ranges meant that the times recorded were a rough indication of what deans spent their time doing.

This tool was a self-report account for which I relied upon the deans to complete the log daily and honestly. Further research may consider documenting what the deans actually spend their time doing in order to gain more insight into the function of this role. If I were to repeat the study for this thesis, the daily log would be the one area that I would focus on improving. I would make the time ranges smaller or alternatively, ask deans to record the amount of time themselves in order to provide more specific accounts.

In my initial proposal, I intended to include the parent perspective as part of this thesis. The voice of the wider community as represented by the parent or caregiver can be valuable in informing and improving the practice of schools (Epstein, 2001; Gamage, 1993; Pekrul \& Levin, 2007; Rose \& Pelleschi, 2003). Practical restraints as well as a lack of parent volunteers limited my ability to get willing parents to participate in the research for this thesis. Similarly, I intended to interview students from two year levels. I received four signed information and consent forms from students indicating interest in the study for this thesis. All of these forms were from Year 12 students. This enabled me to gain an understanding of the role of the dean from a student perspective. However, further investigation on perspectives from the student body may have shed 
more light on some of the themes that emerged from the data, in particular, the difference in the role of the dean between the junior and senior schools.

My role as an outsider from the school community may have impacted the number of participants who volunteered. The teacher participants in this study all volunteered by returning their information letters. The teachers who participated were all experienced teachers who had some responsibility, whether it be pastoral or curriculum within the school. This experience may have impacted the data as, at times, the focus groups discussed what they thought the pastoral care system was like $\mathrm{x}$ number of years ago which was an area of investigation not relevant to this study. However, I am reminded again of Moustakas' (1994) philosophy on the varied state of perception between time, people and interpretation and conclude that even if the whole school community was involved in the collection of their perceptions to inform this study, there would still be other times and other meanings that existed. In order to limit the data of the study, a small sample size proved practical.

\subsection{Implications}

\section{For policy makers}

The lack of guidance, research and development surrounding the provision of pastoral care in New Zealand schools requires further attention from central government. I am hesitant to recommend that government impose regulations or requirements around the provision of pastoral care, due to the varied and unique nature of schools and their student populations in New Zealand. However, with the increasing expectation on schools to be responsible for the well-being of students (Parata, 2012) and the Better Public Service Targets of improving NCEA qualification attainment (MOE, 2014), it may benefit schools to have guidance around evaluating and improving their pastoral care systems. This study does not conclude what the guidance should be because the findings of this study do not allow for conclusive statements to be made about what does and does not work in pastoral care in schools. However, setting some overarching, broad guidelines as to what the purpose of pastoral care is in schools for all students and staff, or indicating to schools that they should include pastoral care in their policy documents and school aims, would align policy guidelines with government expectations. This would allow for interpretation and application of goals at school level whilst providing the school with some guidance. Guidance on the need for evaluation and planning in schools would create an awareness in schools of the need to 
investigate what the state of their current pastoral care system is, the intended aims for this aspect of the school, and how they plan to achieve those aims.

\section{For schools}

The responsibility of the dean for all the students in the year requires further clarification. Utilising student voice in this process could prove valuable. How deans are meant to fulfil the responsibility of caring for all students in a year level requires thought from school communities, both in the instance of Northside College and all New Zealand secondary schools. Involving members of the schools' communities, including the students, can increase ownership of school-wide goals for pastoral care and the same could be said for defining staff positions to address student needs (Howeison \& Semple, 2000; Lodge, 2006; Robinson et al., 2009).

The examination of the literature along with the findings of the study reveals some shortcomings of the current system and highlights some possible practical changes that could be made to ease the pressure on deans and increase the possibility of more students receiving care. Schools may need to consider the issues associated with implementing a completely private room for discussion with students and problem solve around how best to address these issues to meet student needs. Directives such as improving facilities and providing some professional development for staff may compensate for seemingly unachievable higher remuneration for deans and recognise their reported passionate commitment to these positions.

The perception of dean as caring for all whilst also functioning in an overwhelmingly reactive fashion creates somewhat of an anti-thesis. It is more accurate to describe the role by saying, if a student were in the dean's year level and needed care that was unable to be provided by a form or classroom teacher, then the dean would provide care for that student. In my opinion, it is not likely that a dean can actively care for all students in their year level at the same time. This poses the question of, if the dean is responsible for all of the students in the year level, what are they actually responsible for? If the answer is the pastoral care of those students, as some participants responded in this study, then the function of the dean needs some adjustment in order to ensure that the students in that year level are in fact receiving care from someone. I propose that that person could be the form teacher, supported and mentored by the dean (Section 4.2.1). 
The concept of shared responsibility requires deans to become more responsible for other adults who provide pastoral care for students, delegating responsibility and mentoring of students. This shift may demand different skills from deans that require them to upskill for this position. This issue aligns with literature that outlines the challenges of staff being appointed to roles of pastoral care responsibility without the necessary skills and in the absence of ongoing professional development (Calvert \& Henderson, 1998; Carnell \& Lodge, 2002; Lodge, 2006; Murphy, 2011; Reading, 1999). Additionally, it may be that the whole staff, in particular the form teachers, would benefit from some professional development on skills related to delivering effective pastoral care, should schools decide that all staff are responsible for the provision of pastoral care.

One of the major questions to arise from the study is 'What is the intention of the role of the dean within each specific school?'. Because of the self-governing nature of schools, this question will be context specific and should be framed within a set of wider goals for the provision of pastoral care. The description of the role as being responsible for the care of the designated year level is insufficient and needs further consideration by the schools. In this instance, the job descriptions of the dean, the head of department and the form teacher do not correlate to provide a clear picture of responsibility, an observation that is akin to the sentiment expressed by the participants in this study.

Utilising the results from this study and the existing job description from Northside College, an amended job description is attached (Appendix $\mathrm{H}$ ) that includes statements intended to reflect Northside College's unique context. However, upon establishing school-wide pastoral care goals, this job description should be reviewed to ensure that it will facilitate progress towards achieving them. In addition, each individual school should consider utilising the key headings proposed in the job description but adjusting the items to reflect their own context and goals.

Some literature examined in this thesis proposes major staff structural changes or complete re-definition of the role of the dean (Lodge, 1999, 2006; Reading, 1999; Rose \& Pelleschi, 1998; Swinson, 2010). Some of the empirical studies that examine such major changes are practice-based narratives from one person's perspective and hence should be utilised cautiously (Reading, 1999; Rose \& Pelleschi, 1998). These studies reveal some interesting ideas about the role of the dean, but more importantly, they 
demonstrate a careful process of evaluation and planning that schools undergo in order to address their students' pastoral care needs. It is this method of self-examination that I would recommend to schools, ensuring that the context of their school is understood and the needs of their students and community are met through consultation and reevaluation. It may be that the alternative to the current system proposed in this thesis of a shared responsibility for pastoral care aligns with schools' needs and goals and would therefore be practical for schools to develop.

\section{A proposed job description}

Based on the findings from this study and the literature that informed it, I have developed a tentative framework for a dean's job description (Appendix H). The job description outlines the purpose of the role of the dean with some indicative goals for the role. The general goals encourage deans to:

- Promote quality teaching and learning

- Promote positive relationships within the school community

- Arrange monitoring for pupils' overall progress

- Contribute to and take a leadership role in a collaborative, school-wide pastoral support system

- Promote extra-curricular activities and school ethos

- Address the particular issues some individual pupils may be experiencing.

Under each goal are some possible tasks that the deans may engage in, in order to achieve the goals. For example, in order to promote quality teaching and learning, deans could:

- Implement and monitor a mentoring programme where the form teacher mentors students in their form class on matters of learning, achievement, and social, emotional, and behavioural development.

The job description is indicative. It is important that schools consider the purpose of the pastoral care system within their school and the relationship of the role of the dean to other roles within the school, and ensure that the job description accurately represents those factors that are specific to the school. 
The description of goals and tasks created within the proposed job description gives an indication of the complexity of the role. These particular tasks detail a potential shift in the role away from being primarily an individual caseworker. The role, instead, provides support and strategies for staff to assist in the collaborative delivery of care to students. Form teachers are supported primarily by deans and empowered to problem solve and set goals with individual students. Form teachers may be alarmed at an increase in their work load and this could be addressed in a number of ways. Form teachers can be assisted by deans and senior managers to ensure that form time occurs regularly, that the size of the form class is manageable, and where the size of the class cannot be reduced, associate form teachers could be utilised (typically in New Zealand, not all teachers are form teachers).

The functioning of the system discussed by some deans in this thesis, where form teachers are responsible for the pastoral care of students, outlines an ideal that was found to be effective in studies by Farrand et al. (2007), Reading (1999), Swinson (2010), and Rose and Pelleschi (1998). These studies indicated that some level of increased responsibility for the subject or form teachers increased the quality of care for students, and the efficiency of the pastoral care system. The desire to see form teachers as the primary providers of care is consistent with findings from Farrand et al. (2007) that found that students were more likely to turn to form teachers than deans as a person to help them in a number of pre-defined circumstances. This shared responsibility for the provision of pastoral care also supports a finding that New Zealand schools that are more successful in the provision of care to transient students had higher levels of cooperation and collaboration across staff (Mutch et al., 2011). However, these studies do not consider constraints that may impact schools such as a shortage or reluctance of teachers, and lack of specialist pastoral training (Nelson \& While, 2002).

The role of reactive caseworker is not absent from the redesigned job description of the dean. This aspect of the role is spread across the school staff, reflecting the collaborative approach and shared responsibility of pastoral care. The dean remains the figurehead of the year level, addressing issues that need to be escalated, but placing increased emphasis on supporting other staff members to take responsibility for the students in their care. 
I assumed initially that the dean should be providing more proactive care. I have come to realise that reactive care is an important part of the job and that students come from diverse backgrounds and are diverse people. Some may require extra assistance and it is wise to appoint an appropriate person to address these issues, and in doing so, not only help the individual student but ensure that the year level continues to operate without disruption to other's learning. Streamlining the system so that minor issues such as disciplinary, behavioural and academic matters can be dealt with by the form teacher without the dean's intervention, may capacitate the dean to attend to tasks that would assist them towards providing effective care for all of the students in the year level.

It is worth noting that there are several tasks that I have left off this description. That is not to say the tasks are not important in the promotion of an orderly environment, nor that the school benefits from such tasks; however, I aim to highlight whether or not such tasks need to be completed by the dean. If the enforcement of school regulations, such as uniform discrepancies, are important to the school then these issues should be addressed in some way. Likewise, I see the value in issuing students and parents with grammatically correct, accurately punctuated school reports. I suggest that schools reconsider whether or not these tasks need to be carried out by an over-burdened dean (Brenton, 1989).

There is no easy solution to these issues but some jobs being allocated to deans are, at times, done so because they do not fit anywhere else. However, with some creative problem solving and collaborative responsibility across the staff, reallocation of these jobs may relieve some pressure on the deans and enable them to engage in some proactive care strategies with the intention of reducing their reactive casework load (Farrand et al., 2007; Griffiths, 1995; Reading, 1999; Rose \& Pelleschi, 1998; Tucker, 2013). Whilst the elimination of reactive casework is not the end goal, a reduction in students requiring an intervention from the dean would be positive (Best, 1999), if influenced by stronger relationships, positive school ethos, a mentoring programme, and a collaborative approach to student pastoral care (Best, 1999; Bishop et al., 2014; Carnell \& Lodge, 2002; Cemalcilar, 2010; Department for Education and Science United Kingdom, 1989; Eby et al., 2009; Hearn et al., 2006). 


\section{For future research}

The study has shed some light on the role of the dean and indicated some changes that could be made to improve the efficiency and effectiveness of the role. Further research on these suggested changes is needed to investigate their appropriateness for the school setting, whether or not they would make a difference for student social, emotional, and behavioural outcomes, and their academic achievement and progress. Further investigation on how to implement a successful mentoring programme effectively would be needed to ensure the programme achieved its desired outcomes and alignment with pastoral care goals (Reading, 1999). In addition, an investigation into how students are being cared for in a range of New Zealand schools would be valuable.

The role of the form teacher, its relationship to the dean, and its impact on student connectedness, well-being, achievement, and referrals for reactive care from the dean, is an area for future study. Questions that could be considered for future study include: What efficiencies can be made to maximise the effect of the provision of pastoral care for students and minimise the potential burden of the role of the dean for staff? Is the role of the dean, as it is, effective? Would the proposed changes make this role more effective in improving outcomes for students?

The literature examined suggests that a dichotomy exists within the role of the teacher, with teachers viewing themselves as either subject teachers or pastoral carers (Clark, 2008; Power, 1996). The responsibility of all teachers as providers of pastoral care reflects values included specifically in New Zealand theoretical models and programmes, highlighting the importance of relationship building and educating the whole child (Bishop et al., 2014; Durie, 1985). How the values and ideas that have been identified as improving student outcomes can be effectively incorporated into, or even enhanced by, our current pastoral care systems and organisation in schools is an area for further research.

The effectiveness of our current pastoral care systems in English-medium schools and in Māori-medium schools through a cultural lens is an area for future research. An investigation into this area was outside of the bounds of this study but would be useful because the purpose of pastoral care can closely align with key theories and findings in New Zealand literature that can improve the outcomes of Māori students and students from other minority groups (Bishop et al., 2014). 
Based on the perception of the school community on the role of the dean and the literature included in this thesis, the following areas could be further investigated to further increase the efficiency of this role and the provision of pastoral care within this school:

a. The collective responsibility of staff to provide pastoral care to all students

b. The re-distribution of any tasks that are currently allocated to the deans that do not require their specific skills

c. The empowerment of form teachers to act as academic mentors in the junior school and to strengthen this system for form teachers in the senior school

d. A re-examination of the dean's job description in accordance with the form teacher and head of department job descriptions to ensure coherence and consistency

e. The opportunity for professional development for all staff in areas that would improve the pastoral care of students that would include building positive relationships, high level interview skills, promotion of positive behaviour and school values, and continued and regular development in the use of the school's restorative justice programme

f. The perception of other staff members on taking a more collaborative approach to the provision of pastoral care for students.

\subsection{Summary}

The participants were generally very positive around the impact of the role of the dean and most major aspects of the role were agreed upon by members of the participant pool. The role of the dean is an integral part of many pastoral care systems in secondary schools (Carnell \& Lodge, 2002). It is a unique and complex role that is context specific, being influenced by the school that it is operating within. This study illuminated some of the practices that the deans most commonly engage in as well as highlighting some issues within the role. The findings of the study support the literature (Calvert, 2009; Marland, 2001; Lodge, 1999, 2006) in that the role was found to consist of predominantly reactive casework. Deans at Northside College are dealing with student issues that concern a range of matters and include social, emotional, and behavioural issues as well as those of an academic nature. The academic issues are not 
restricted to monitoring and now include academic conferencing, a form of mentoring used in the senior school. This reflects the progressive blurring of the perceived dichotomy between the academic and pastoral issues, a divide that has previously limited the consideration of the student as a whole, influenced by the organisation of staff within the school (Clark, 2008; Lang, 1995; Power, 1996).

The potential staff divide, because of an existing, traditional management structure, appears to have limited influence at Northside College, making it difficult to challenge the hierarchy where pastoral care is concerned. In order to address this challenge, along with challenges of limited time in which to help all of the students in the year level, several solutions could be considered. The literature examined in this thesis has seen studies re-structure staff or rename and redefine the role of the year level dean (Reading, 1999; Rose \& Pelleschi, 1998). However, the traditional hierarchy is so entrenched in the school organisation (Watkins, 1999) that to try and restructure it in an attempt to reach ideals of a school based on care (Noddings, 1992) could be a dramatic and challenging solution. Considering Hoy and Sweetland's (2000) theory on enabling hierarchies, even if dramatic changes were made to the school, the changes may not positively impact how the staff functions for the betterment of the student if the same issues exist within the new school hierarchy. Hoy and Sweetland propose that flexibility within and between roles in order to assist problem solving is needed if a hierarchy promotes positive gains. This reflects the proposed shift to a collective responsibility for the care of students with a focus on improving student outcomes (Mutch et al., 2011; Robinson, 2009).

As a preliminary step, instituting small changes could have an impact on the efficiency of pastoral care. Evaluating current systems for schools through utilising perceptions from the school community could inform areas of need for change and highlight areas of strength (Bishop et al., 2014; Epstein, 2001; Gamage, 1993; Robinson, et al., 2009; Rose \& Shevlin, 2004). At Northside College, the collegiality between staff, the perception that the academic and social, emotional, and behavioural aspects of student progress are interrelated, and the value that the school places on pastoral care are the school's areas of strength. Their use of achievement data and academic conferencing with their senior students promotes a 'pro-achievement' culture in this part of the school and is a tool they are investigating to incorporate into the junior school. 
Implementing a pastoral care system can improve student achievement by building a strong connection with the school, setting and monitoring achievable goals, and developing their personal and academic skills (Battistich et al., 2004; Birch \& Ladd, 1998; Hamre \& Pianta, 2001). An efficient pastoral care system in New Zealand schools is worthy of investigation and improvement. New Zealand can utilise international research to inform the next steps and can also learn from current practices here. It is important to ensure that the way we care for students in New Zealand secondary schools is effective, and that we continually strive to better the outcomes for the young people in the care of New Zealand schools. 


\section{References}

Arnott, R. (1994). A whole school approach to pastoral care- A New Zealand perspective. In P. Lang, R. Best, \& A. Lichtenberg (Eds.), Caring for children: International perspectives on pastoral care and PSE. London: Continuum International.

Averill, R. (2009). Teacher-student relationships in diverse New Zealand year 10 classrooms: Teacher care (PhD thesis). Victoria University of Wellington, New Zealand.

Battistich, V., Schaps, E., \& Wilson, N. (2004). Effects of an elementary school intervention on students' “connectedness" to school and social adjustment during middle school. Journal of Primary Prevention, 24(3), 243-262. doi:0.1023/B:JOPP.0000018048.38517.cd

Best, R. (1995). Concepts in pastoral care and PSE. In R. Best, P. Lang, C. Lodge, \& C. Watkins (Eds.), Pastoral Care and Personal-Social Education (pp. 3-18). London: Continuum.

Best, R. (1999). The impact on pastoral care of structural, organisational and statutory changes in schooling: Some empirical evidence and a discussion. British Journal of Guidance and Counselling, 27(1), 55-70.

Best, R. (2003). Citizenship and pastoral care. In L. Gearon (Ed.), Learning to teach citizenship in the secondary school (pp. 54-65). London: RoutledgeFalmer.

Best, R., Ribbins, J., \& Jarvis, C. (1977). Pastoral care: Concept and process. British Journal of Educational Studies, 5(2), 124-135.

Birch, S. H., \& Ladd, G. W. (1998). Children's interpersonal behaviors and the teacher-child relationship. Developmental Psychology, 34(5), 934-946. doi:http://dx.doi.org/10.1037/0012-1649.34.5.934

Bishop, R., Berryman, M., \& Wearmouth, J. (2014). Te Kotahitanga: Towards effective reform for indigenous and other minoritised students. Wellington: NZCER Press.

Bogdan, R., \& Biklen, S. K. (2007). Qualitative research for education: An introduction to theories and methods. Boston, MA: Pearson Education.

Booker, C. B. (2006). School belonging and the African American adolescent: What do we know and where should we go? The High School Journal, 89(4), 1-7. doi:10.1353/hsj.2006.0005 
Boylorn, R. M. (2008). Lived experience. In L. M. Given (Ed.), The SAGE encyclopaedia of qualitative research methods. Thousand Oaks, CA: SAGE.

Brenton, J. (1989). Administering a year group: An insight into the lives of year heads.

Pastoral Care in Education, 7(3), 19-25. doi:10.1080/02643948909470671

Bulman, L. (1987). Heads of year: Rotating or static. Pastoral Care in Education, 5(1), 48-

51. doi:10.1080/02643948709470570

Burns, R. (2000). Introduction to research methods. London: SAGE.

Bryman, A. (2012). Social research methods. New York, NY: Oxford University Press.

Calvert, M. (2009). From 'pastoral care' to 'care': Meanings and practices. Pastoral Care in Education, 27(4), 267-277.

Calvert, M., \& Henderson, J. (1998). Managing pastoral care. London: A\&C Black.

Carnell, E., \& Lodge, C. (2002). Supporting effective learning: London: SAGE.

Cemalcilar, Z. (2010). Schools as socialisation contexts: Understanding the impact of school climate factors on students' sense of school belonging. Applied Psychology, 59(2), 243-272.

Chittenden, A. H. R. (2002). A Pastoral Care Teacher's Theory of Action, Interactive Thinking and Effective Teaching Practice. Pastoral Care in Education, 20(1), 3-10. doi: http://dx.doi.org/10.1111/1468-0122.00214

Clark, K. E. (2008). The pastoral academic divide: Impacts and implications for pastoral care (Masters of Education). Murdoch University, Perth.

Collins, Ú. M., \& McNiff, J. (1999). Rethinking pastoral care: London: Routledge.

Creswell, J. W. (2011). Educational research: Planning conducting and evaluating quantitative and qualitative research. Boston, MA: Peasron Education.

Creswell, J. W. (2013a). Qualitative inquiry and research design: Choosing among five approaches. Los Angeles, CA: SAGE.

Creswell, J. W. (2014). Research design: Qualitative, quantitative, and mixed method approaches. Los Angeles, CA: SAGE.

Creswell, J. W., Clark, V. L. P., Gutmann, M. L., \& Hanson, W. E. (2003). An expanded typology for classifying mixed methods research into designs. In A. Tashakkori \& C. Teddlie (Eds.), Handbook of mixed methods in social and behavioural research (pp. 209-240). Thousand Oaks, CA: SAGE.

Creswell, J. W., \& Miller, D. L. (2000). Determining validity in qualitative inquiry. Theory in Practice, 39(3), 124-130. 
Creswell, J. W, Hanson, W. E., Clark Plano, V. E., \& Morales, A. (2007). Qualitative research designs: Selection and implementation. The Counseling Psychologist, 35(2), 236-264.

http://vuw.summon.serialssolutions.com/link/0/eLvHCXMwY2BQMEiySLQ0BaaW NHMDS4Mkc1PTVPM0w0TztEQzCwvDVNDGZPcIE1cvc79QUzek0txNiIEpNUUQcrNNcTZQ7estDweOoYRDzq1HJgdDMUYeBNBK7_zSsA7xFLEGVjTgNGUK g4qOsWBxogzcERYGgX5RVgGQLhCMK5eMXgbk15hiTiwpAbHsq6hnikAEjEqa $\mathrm{W}$

Darling, N., \& Hamilton, S. F. (1996). Mentors in adolescents' lives. In K. Hurrelmann \& S. F. Hamilton (Eds.), Social problems and social contexts in adolescence: Perspectives across boundaries. New York, NY: Transaction.

Denscombe, M. (2007). The good research guide for small scale research projects. Berkshire: Open University Press.

Department for Education and Science United Kingdom. (1989). Pastoral care in secondary schools: An inspection of some aspects of pastoral care in 1987-8. London.

Department for Education United Kingdom. (2012). The National College for Teaching and Leadership. National Occupational Standards for Supporting Teaching and Learning: Pastoral and welfare. Retrieved March 24, 2014, from http://www.education.gov.uk/nctl/traininganddevelopment/staff/standards/b00203854 /nos-for-stl/units-for-particular-jobs/pastoral

Department of Education Northern Ireland. (2008). Evaluating pastoral care. Retrieved May 3, 2013, from http://www.etini.gov.uk/evaluating-pastoral-care.pdf.

Department of Education Western Australia. (12 January 2010). Behaviour and wellbeing: Providing practical resources to our teachers and staff. Retrieved March 2, 2014, from http://det.wa.edu.au/studentsupport/behaviourandwellbeing/detcms/schoolsupport-programs/behaviour-and-wellbeing/wellbeing/pc/pastoralcare.en?oid=MultiPartArticle-id-5046226

Durie, M. H. (1985). A Maori perspective of health. Social Science \& Medicine, 20(5), 483486. doi:http://dx.doi.org/10.1016/0277-9536(85)90363-6

Eby, L. T., Allen, T. D., Evans, S. C., Ng, T., \& DuBois, D. (2009). Does mentoring matter? A multidisciplinary meta-analysis comparing mentored and non-mentored individuals. Journal of Vocational Behaviour, 72(2), 254-267. doi:10.1016/j.jvb.2007.04.005 
Education Review Office. (2012). Awatapu College Education Review. Retrieved December 2013, from http://www.ero.govt.nz/Early-Childhood-School-Reports/SchoolReports/Awatapu-College-21-11-2012

Education Act 1989. (2014). No 80. Retrieved 1 July, 2014, from http://www.legislation.govt.nz/act/public/1989/0080/latest/DLM175959.html

Education Reform Act 1988 (Commencement No. 3). Retrieved 27 November, 2013, from http://www.legislation.gov.uk/ukpga/1988/40/contents

Epstein, J. (2001). School, family, and community partnerships: Preparing educators and improving schools. Boulder, CO: Westview Press.

Farrand, P., Parker, M., \& Lee, C. (2007). Intention of adolescents to seek professional help for emotional and behavioural difficulties. Health \& Social Care in the Community, 15(5), 464-473. doi:10.1111/j.1365-2524.2007.00705.x

Fereday, J., \& Muir-Cochrane, E. (2006). Demonstrating rigor using thematic analysis: A hybrid approach of inductive and deductive coding and theme development. International Journal of Qualitative Methods, 5(1), 1-11.

Fincham, D. (1991). Horizontal or vertical? Integrating pastoral and academic concerns. School Organisation, 11(2), 241-251. doi:10.1080/13632434.1991.10384452

Fleming, P. (2012). Becoming a secondary school teacher: How to make a success of your initial teacher training: London: Routledge.

Frey, J. H., \& Fontana, A. (1991). The group interview in social research. The Social Science Journal, 28(2), 175-187. doi:10.1016/0362-3319(91)90003-M

Frydenberg, E., Freeman, E., \& Chan, E. (2009). Interrelationships between coping, school connectedness and wellbeing. Australian Journal of Education, 53(3), 261-276.

Galassi, J. P., Gulledge, S. A., \& Cox, N. D. (1997). Middle school advisories: Retrospect and prospect. Review of Educational Research, 67(3), 301-338. doi:10.2307/1170567

Gamage, D. (1993). A review of community participation in school governance: Emerging culture in Australian education. British Journal of Educational Studies, 41(2), 134149.

George, P., \& Alexander, W. (1993). Grouping students in the middle school. The exemplary middle school (2nd ed., pp. 299-330). Orlando, FL: Harcourt Brace College Publishers.

Griffiths, P. (1995). Guidance and tutoring. In R. Best, P. Lang, C. Lodge, \& C. Watkins (Eds.), Pastoral care and personal-social education: Entitlement and provision. London: Continuum. 
Gysbers, N. C. (1994). Developmental counselling and guidance programmes in the schools: Developments in the USA. In P. Lang, R. Best, \& A. Lichtenberg (Eds.), Caring for children: International perspectives on pastoral care and PSE (pp. 55-65). London: Cassell.

Gurwitsch, A. (1966). Studies in phenomenology and psychology. Evanston, IL: Northwestern University Press.

Hakanen, J., Bakker, A. B., \& Schaufeli, W. B. (2006). Burnout and work engagement among teachers. The Journal of School Psychology, 4(3), 495-513.

Hamre, B., \& Pianta, R. (2001). Early teacher-child relationships and the trajectory of children's school outcomes through eighth grade. Child Development, 72, 625-638.

Hearn, L., Campbell-Pope, R., House, J., \& Cross, D. (2006). Pastoral care in education. Perth: Child Health Promotion Unit, Edith Cowan University.

Howeison, C., \& Semple, S. (1996). Guidance in secondary schools. Edinburgh: Centre for Educational Sociology, University of Edinburgh.

Howeison, C., \& Semple, S. (2000). The evaluation of guidance: Listening to pupils' views. British Journal of Guidance and Counselling, 28(3), 373-387.

Hoy, W. K., \& Sweetland, S. R. (2000). School bureaucracies that work: Enabling not coercive. Journal of School Leadership, 10(6), 525.

Hoy, W. K., \& Sweetland, S. R. (2001). Designing better schools: The meaning and measure of enabling school structures. Educational Administration Quarterly, 37(3), 296-321.

Husserl, E. (1982). Cartesian meditations: An introduction to phenomenology. (Dorion Cairns, Trans.). Boston: Nijhoff. (Original published 1960).

Johnson, B., \& Christensen, L. (2012). Educational research. Thousand Oaks: SAGE.

Jose, P. E., \& Pryor, J. (2010). New Zealand youth benefit from benefit from being connected to their family, school, peer group and community. Youth Studies Australia, 29(4), 3037.

Joyce, S. (2013). Everything to everybody': The profile and challenges of pastoral care middle leadership in New Zealand secondary schools. Auckland: Unitec Institute of Technology.

Karcher, M. J. (2005). The effects of developmental mentoring and high school mentors' attendance on their younger mentees' self-esteem, social skills, and connectedness. Psychology in the Schools, 42(1), 65-77.

Kidger, J., Gunnell, D., Biddle, L., Campbell, R., \& Donovan, J. (2010). Part and parcel of teaching? Secondary school staff's views on supporting student emotional health and 
well-being. British Educational Research Journal, 36(6), 919-935.

doi:10.1080/01411920903249308

King, K. A., Vidourek, R. A., Davis, B., \& McClellan, W. (2002). Increasing self-esteem and school connectedness through a multidimensional mentoring program. Journal of School Health, 72(7), 294-299. doi:10.1111/j.1746-1561.2002.tb01336.x

Krueger, R. A. (1994). Focus groups: A practical guide for applied research $\left(2^{\text {nd }}\right.$ ed.). Thousand Oaks, CA: SAGE.

Lang, P. (1983). Book Review [Review of the book Perspectives on pastoral care by R. Best, C. Jarvis \& P. Ribbins). Pastoral Care in Education, 1(1), 61-68.

Lang, P. (1995). Preparing teachers for pastoral care and personal social education: To train or educate? Pastoral Care in Education, 14(4), 18-23. doi:

10.1080/02643949509470939Peter Lang

Lang, P., Best, R., \& Lichtenberg, A. (1994). Caring for children: International perspectives on pastoral care and PSE. Michigan, MI: Cassels.

Lodge, C. (1999). From head of year to year curriculum coordinator and back again? Pastoral Care in Education, 17(4), 11.

Lodge, C. (2006). Beyond the head of year. Pastoral Care in Education, 24(1), 4-9. doi:10.1111/j.1468-0122.2005.00355.x

Marland, M. (2001). School management and pupil care. Pastoral Care in Education, 19(4), 25-34. doi:10.1111/1468-0122.00209

McNeely, C. A., Nonnemaker, J. M., \& Blum, R. W. (2002). Promoting school connectedness: Evidence from the National Longitudinal Study of Adolescent Health. Journal of School Health, 72(4), 138-146. doi:10.1111/j.1746-1561.2002.tb06533.x

Merchant, J. (1988). The pastoral care/discipline conjunction and its relation to social control. Pastoral Care in Education, 6(3), 9-14. doi:10.1080/02643948809470623

Merriam, S. B. (1988). Case study research in education: A qualitative approach. Michigan, MI: Jossey-Bass.

Miles, M. B., Huberman, A. M. (1994). Qualitative data analysis: an expanded sourcebook. London: SAGE.

Ministry of Education. (2004). The national education goals. Education Legislation. Retrieved May 20, 2013, from http://www.minedu.govt.nz/theMinistry/EducationInNewZealand/EducationLegislatio $\mathrm{n} /$ TheNationalEducationGoalsNEGs.aspx

Ministry of Education. (2007). The New Zealand curriculum: For English-medium teaching and learning in years 1-13. Wellington: Learning Media. 
Ministry of Education. (2013). The national administration guidelines. Education Legislation. Retrieved November 27, 2013, from

http://www.minedu.govt.nz/theMinistry/EducationInNewZealand/EducationLegislatio $\mathrm{n} /$ TheNationalAdministrationGuidelinesNAGs.aspx

Ministry of Education. (2014). Better public services: More young people with NCEA level 2. Retrieved April 30, 2014, from http://www.minedu.govt.nz/theMinistry/BetterPublicServices/More18YearOldsWith NCEALevel2.aspx

Morse, J. (2010). Procedures and practice of mixed method design: Maintaining control, rigour, and complexity In Tashakkori, A., \& Teddlie, C. (Eds), SAGE Handbook of Mixed Methods in Social \& Behavioural Research (pp. 339-352). Los Angeles, CA: SAGE.

Mowat, J. G. (2010) 'He comes to talk to me about things': supporting pupils experiencing social and emotional behavioural difficulties - a focus upon interpersonal relationships. Pastoral Care in Education, 28:3, 163-180. doi:10.1080/02643944.2010.504218

Moustakas, C. (1994). Phenomenological research methods. Phenomenological research methods. SAGE. Retrieved from http://psycnet.apa.org/psycinfo/1996-97117-000\#toc doi: http://dx.doi.org/10.4135/9781412995658

Murphy, K. (2011). The complexity of pastoral care middle leadership in New Zealand secondary schools (Master's Thesis). Unitec Institute of Technology, Auckland, New Zealand.

Murray, C., \& Pianta, R. C. (2007). The importance of teacher-student relationships for adolescents with high incidence disabilities. Theory Into Practice, 46(2), 105-112.

Mutch, C. A., Rarere, V., \& Stratford, R. (2011). 'When you looked at me, you didn't judge me': Supporting transient students and their families in New Zealand primary schools. Pastoral Care in Education, 29:4, 231-245. doi: 10.1080/02643944.2011.626065

Nadge, A. J. (2005). Academic care: Building resilience, building futures. Pastoral Care in Education, 23(1), 28-33. doi:10.1111/j.0264-3944.2005.00319.x

Nelson, E., \& While, D. (2002). Constraints to pastoral care for distressed children: Opinions of head teachers. Pastoral Care in Education, 20(3), 21-28. doi:10.1111/14680122.00233

New Zealand Council of Educational Research. (Producer). (9 March 2013). Wellbeing@School. Retrieved from http://www.wellbeingatschool.org.nz/ 
New Zealand Educational Institute, Te Riu Roa. (Producer). (2006). Guidelines: Physical contact with children. Wellington.

New Zealand Qualifications Authority. (2013). Code of Practice for the Pastoral Care of International Students. Retrieved 1 January, 2014, from http://www.nzqa.govt.nz/providers-partners/caring-for-international-students/

New Zealand Teachers Council. (2009). Registered teacher criteria. Available at http://www.teacherscouncil.govt.nz/rtc/rtc.pdf

Noddings, N. (1992). The challenge to care in schools: An alternative approach to education. New York: Teachers College Press.

Pandey, S. K., \& Gordon, A. K. (2000). Examining red tape in public and private organizations: Alternative explanations from a social psychological model. Journal of Public Administration Research and Theory: J-PART, 10(4), 779-799. doi:10.2307/3525765

Parata, H. (2012). NZ National Party. Paper presented at the Tackling mental health in schools. Available at http://www.national.org.nz/Article.aspx?articleId=38250

Patton, M. Q. (1990). Qualitative evaluation and research methods. Newbury Park, CA: SAGE.

Patton, M. Q. (2002). Qualitative research and evaluation methods. London: SAGE

Power, S. (1996). The pastoral and the academic: Conflict and contradiction in the curriculum. London:Continuum.

Purdy, N. (2013). Pastoral care 11-16: A critical introduction. London:Bloomsbury Academic.

Reading, M. (1999). The cross-curriculum manager: Maximizing the potential of learners. Pastoral Care in Education, 17(4), 23.

Rimm-Kaufman, S. (Producer). (2012). Improving students' relationships with teachers to provide essential supports for learning. American Psychological Association. Retrieved from http://www.apa.org/education/k12/relationships.aspx

Robinson, V., Hohepa, M., \& Lloyd, C. (2009). School leadership and student outcomes: Identifying what works and why best evidence synthesis. Wellington: Ministry of Education.

Rose, D., \& Pelleschi, A. (1998). Re-engineering the horizontally challenged pastoral system. Pastoral Care in Education, 16(4), 27-34. doi:10.1111/1468-0122.00107 
Rose, R., \& Shevlin, M. (2004). Encouraging voices: Listening to young people who have been marginalised. Support for Learning, 19(4), 155-161. doi:10.1111/j.02682141.2004.00341.x

Rowe, F., Stewart, D., \& Patterson, C. (2007). Promoting school connectednass through whole school approaches. Health Education, 107(6), 524-542. doi:10.1108/09654280710827920

Siraj- Blatchford, I. (1997). Reflexivity, social justice and educational research. Cambridge Journal of Education, 27(2), 235-249.

Spillane, J., Camburn, E., \& Pareja, A. (2007). Taking a distributed perspective to the school principal's work day. Leadership and Policy in Schools, 6:1, 103-125. doi: : http://dx.doi.org/10.1080/15700760601091200

Stark, S., \& Torrance, H. (2005). Case study research methods in social sciences (pp. 33-40). London: SAGE.

Swinson, J. (2010). Working with a secondary school to improve social relationships, pupil behaviour, motivation and learning. Pastoral Care in Education, 28(3), 181-194. doi:10.1080/02643944.2010.504221

Timperley, H., Wilson, A., Barrar, H., \& Fung, I. (2007). Teacher professional learning and development best evidence synthesis. New Zealand: Ministry of Education.

Tolich, M., \& Davidson, C. (1999). Starting fieldwork: An introduction to qualitative research in New Zealand. Melbourne: Oxford University Press.

Tracey, S. J. (2010). Qualitative quality: Eight 'big-tent' criteria for excellent qualitative research. Qualitative Inquiry, 16(10), 837-851.

Tucker, S. (2013). Pupil vulnerability and school exclusion: Developing responsive pastoral policies and practices in secondary education in the UK. Pastoral Care in Education, 31(4), 279-291. doi:10.1080/02643944.2013.842312

Turliuc, M. N., \& Marici, M. (2013). Teacher-student relationship through the lens of parental authoritative features. International Journal of Education and Psychology in the Community, 3(1), 43-53.

Walker, J. M. T. (2009). Authoritative classroom management: How control and nurturance work together. Theory Into Practice, 48(2), 122-129. doi:10.1080/00405840902776392

Waters, S., Cross, D., \& Shaw, T. (2010). Does the nature of schools matter? An exploration of selected school ecology factors on adolescent perceptions of school connectedness. 
British Journal of Educational Psychology, 80(3), 381-402. doi:10.1348/000709909X484479

Watkins, C. (1985). Does pastoral care = Personal and social education? Pastoral Care in Education, 3(3), 179-183. doi: 10.1080/02643948509470513

Watkins, C. (1999). Personal-social education: Beyond the national curriculum. British Journal of Guidance \& Counselling, 27(1), 71-84. 
APPENDICES 
Appendix A: Table of studies

\begin{tabular}{|c|c|c|c|c|c|}
\hline Study & Year & Location & Title & Description of method & Participants \\
\hline Averill & 2009 & $\begin{array}{l}\text { New } \\
\text { Zealand }\end{array}$ & $\begin{array}{l}\text { Teacher-student relationships in diverse New } \\
\text { Zealand Year } 10 \text { classrooms: Teacher care }\end{array}$ & $\begin{array}{l}\text { Mixed methods research, utilising } \\
\text { interviews and classroom observations }\end{array}$ & 161 students and 6 teachers from 3 schools. \\
\hline Best & $1999 \mathrm{a}$ & UK & $\begin{array}{l}\text { The impact on pastoral care of structural, } \\
\text { organisational and statutory changes in schooling: } \\
\text { some empirical evidence and a discussion }\end{array}$ & 5 page questionnaire issued at conference & $\begin{array}{l}159 \text { member of the National Association for } \\
\text { Pastoral Care in Education. }\end{array}$ \\
\hline Chittenden & 2010 & Australia & $\begin{array}{l}\text { A Pastoral Care Teacher's Theory of Action, } \\
\text { Interactive Thinking and Effective Teaching } \\
\text { Practice }\end{array}$ & $\begin{array}{l}\text { Action research. A hybrid } \\
\text { research model blending concept mapping } \\
\text { and stimulated recall methodologies }\end{array}$ & $\begin{array}{l}1 \text { teacher and } 19 \text { students from her form } \\
\text { class. }\end{array}$ \\
\hline Clark & 2008 & Australia & $\begin{array}{l}\text { The pastoral academic divide: Impacts and } \\
\text { implications for pastoral care }\end{array}$ & $\begin{array}{l}\text { Qualitative interviews from teachers, } \\
\text { students and senior managers }\end{array}$ & $\begin{array}{l}4 \text { students and } 13 \text { staff members including; } 3 \\
\text { senior managers; } 6 \text { middle managers; and } 4 \\
\text { teachers. } 4\end{array}$ \\
\hline $\begin{array}{l}\text { Farrand, Parker } \\
\& \text { Lee }\end{array}$ & 2007 & UK & $\begin{array}{l}\text { Intention of adolescents to seek professional help } \\
\text { for emotional and behavioural difficulties }\end{array}$ & Self-report questionnaire & 968 students in Year 9 and Year 11 \\
\hline Fincham & 1991 & UK & $\begin{array}{l}\text { Horizontal or Vertical? Integrating Pastoral and } \\
\text { Academic Concerns }\end{array}$ & Practice-based report with survey & 1 school \\
\hline $\begin{array}{l}\text { Howeison \& } \\
\text { Semple }\end{array}$ & 1996 & UK & Guidance in Secondary Schools & $\begin{array}{l}\text { Mixed-methods- qualitative interviews, } \\
\text { survey and focus groups }\end{array}$ & $\begin{array}{l}193 \text { students from } 6 \text { schools, parents, and } \\
\text { guidance staff. }\end{array}$ \\
\hline $\begin{array}{l}\text { Howeison \& } \\
\text { Semple }\end{array}$ & 2000 & UK & $\begin{array}{l}\text { The evaluation of guidance: listening to pupils' } \\
\text { views }\end{array}$ & $\begin{array}{l}\text { Mixed-methods- qualitative interviews, } \\
\text { survey and focus groups }\end{array}$ & 193 students from 6 schools \\
\hline $\begin{array}{l}\text { Kidger, } \\
\text { Gunnell, Biddle, } \\
\text { Campbell \& } \\
\text { Donovan }\end{array}$ & 2009 & UK & $\begin{array}{l}\text { Part and parcel of teaching? Secondary school } \\
\text { staff's views on supporting student emotional } \\
\text { health and wellbeing }\end{array}$ & Qualitative, semi-structured interviews & $\begin{array}{l}\text { School staff at eight secondary schools in } \\
\text { England. }\end{array}$ \\
\hline Lodge & 2006 & UK & Beyond the Head of Year & $\begin{array}{l}\text { Qualitative report on a practice-based } \\
\text { development process involving five } \\
\text { schools and one facilitator in order to } \\
\text { document the process of the schools in } \\
\text { their process to redefine the role of head of } \\
\text { year. }\end{array}$ & $\begin{array}{l}5 \text { head teachers plus their selected nominee } \\
\text { meet } 5 \text { times to discuss. }\end{array}$ \\
\hline
\end{tabular}




\begin{tabular}{|c|c|c|c|c|c|}
\hline Study & Year & Location & Title & Description of method & Participants \\
\hline $\begin{array}{l}\text { Mutch, Rarere } \\
\& \text { Strtaford }\end{array}$ & 2011 & $\begin{array}{l}\text { New } \\
\text { Zealand }\end{array}$ & $\begin{array}{l}\text { 'When you looked at me, you didn't judge me': } \\
\text { supporting transient students and their families in } \\
\text { New Zealand primary schools }\end{array}$ & $\begin{array}{l}\text { Case study evaluations utilising mixed- } \\
\text { methods (e.g., assessment data, interviews, } \\
\text { and school documents) }\end{array}$ & 11 primary schools \\
\hline Nadge & 2005 & Australia & $\begin{array}{l}\text { Academic Care: Building resilience, building } \\
\text { futures }\end{array}$ & $\begin{array}{l}\text { Practice-based report on the first phase of } \\
\text { work involved in the 'Community change } \\
\text { project'- promoting academic care which } \\
\text { utilised surveys and focus groups }\end{array}$ & 300 students from 4 schools. \\
\hline Nelson \& While & 2010 & UK & $\begin{array}{l}\text { Constraints to Pastoral Care for Distressed } \\
\text { Children: } \\
\text { Opinions of Head Teachers }\end{array}$ & Qual- semi-structured interviews & $\begin{array}{l}\text { Families recruited from oncology centres- } 19 \\
\text { schools ( } 10 \text { primary, } 9 \text { secondary). Head } \\
\text { teachers from } 35 \text { primary schools, pastoral } \\
\text { heads from } 46 \text { secondary schools. } 81 \\
\text { participants in total. }\end{array}$ \\
\hline Reading & 1999 & UK & $\begin{array}{l}\text { The Cross-Curriculum Manager: Maximising the } \\
\text { Potential of Learners }\end{array}$ & $\begin{array}{l}\text { Personal account of a practice-based } \\
\text { development of the role of Head of Year } \\
\text { to cross-curriculum manager }\end{array}$ & 3 secondary schools \\
\hline $\begin{array}{l}\text { Rose \& } \\
\text { Pelleschi }\end{array}$ & 1998 & UK & $\begin{array}{l}\text { Re-engineering the horizontally challenged pastoral } \\
\text { system }\end{array}$ & $\begin{array}{l}\text { Personal account of a practice-based re- } \\
\text { engineering of its pastoral system from a } \\
\text { horizontal, year based system to a semi- } \\
\text { vertical 'family' system }\end{array}$ & 1 secondary school \\
\hline Swinson, J & 2010 & UK & $\begin{array}{l}\text { Working with a secondary school to improve social } \\
\text { relationships, pupil behaviour, motivation and } \\
\text { learning }\end{array}$ & $\begin{array}{l}3 \text { phase study: consult, design and } \\
\text { implement, evaluate. } \\
\text { Interviews conducted with participants }\end{array}$ & $\begin{array}{l}\text { Students, parents and teachers from } 1 \\
\text { secondary school }\end{array}$ \\
\hline Tucker, S & 2013 & UK & $\begin{array}{l}\text { Pupil vulnerability and school exclusion: } \\
\text { developing responsive pastoral policies and } \\
\text { practices in secondary education in the UK }\end{array}$ & $\begin{array}{l}\text { Case study: qualitative data from semi- } \\
\text { structured interviews }\end{array}$ & $\begin{array}{l}49 \text { Year } 9 \text { pupils, } 8 \text { behaviour coordinators } \\
\text { across } 7 \text { secondary schools, and } 3 \text { school } \\
\text { managers. }\end{array}$ \\
\hline
\end{tabular}




\section{Appendix B: Deans' daily logs}

\section{Instructions:}

- Complete one log per day.

- Complete this log for 5 consecutive days. Only record times for activities that you performed in your role as dean.

- For each activity, circle the TOTAL amount of time that you spent on this activity for this day.

- If you spent no time on a particular activity, circle 0 minutes.

\section{DATE:}

\begin{tabular}{|c|c|c|c|c|c|c|}
\hline \multicolumn{7}{|l|}{ Solving social, emotional or behavioural } \\
\hline One on one problem solving with students & 0 mins & 1-30mins & 30 mins- 1 hour & $1-2$ hours & $2-3$ hours & More than 3 hours \\
\hline Problem solving with a group of students & 0 mins & $1-30 \mathrm{mins}$ & 30 mins -1 hour & $1-2$ hours & $2-3$ hours & More than 3 hours \\
\hline $\begin{array}{l}\text { Problem solving with teachers about an } \\
\text { individual student }\end{array}$ & 0 mins & $1-30 \mathrm{mins}$ & 30 mins- 1 hour & 1.2 hours & $2-3$ hours & More than 3 hours \\
\hline $\begin{array}{l}\text { Problem solving with parents about problems } \\
\text { faced by an individual student }\end{array}$ & 0 mins & 1-30mins & 30 mins- 1 hour & $1-2$ hours & $2-3$ hours & More than 3 hours \\
\hline $\begin{array}{l}\text { Problem solving with an external agency about } \\
\text { an individual student }\end{array}$ & 0 mins & 1-30mins & 30 mins- 1 hour & $1-2$ hours & $2-3$ hours & More than 3 hours \\
\hline $\begin{array}{l}\text { Personally delivering information or running an } \\
\text { activity for students intended to increase the } \\
\text { likelihood of good decision making (eg an } \\
\text { assembly on drugs education) }\end{array}$ & 0 mins & 1-30mins & 30 mins-1 hour & $1-2$ hours & $2-3$ hours & More than 3 hours \\
\hline $\begin{array}{l}\text { Organising another person or group to deliver } \\
\text { information or run an activity for students to } \\
\text { intended to increase the likelihood of good } \\
\text { decision making (eg organising a guest speaker to } \\
\text { discuss mental health) }\end{array}$ & 0 mins & $1-30 \mathrm{mins}$ & 30 mins-1 hour & $1-2$ hours & $2-3$ hours & More than 3 hours \\
\hline $\begin{array}{l}\text { Organising the delivery of information or an } \\
\text { educational activity to the wider school } \\
\text { community about social, emotional or } \\
\text { behavioural issues. }\end{array}$ & 0 mins & $1-30 \mathrm{mins}$ & 30 mins-1 hour & $1-2$ hours & $2-3$ hours & More than 3 hours \\
\hline Other (please detail): & 0 mins & 1-30mins & 30mins-1 hour & $1-2$ hours & 2-3 hours & More than 3 hours \\
\hline
\end{tabular}




\begin{tabular}{|c|c|c|c|c|c|c|}
\hline \multicolumn{7}{|l|}{ Academic } \\
\hline $\begin{array}{l}\text { Tracking individual student academic progress (eg } \\
\text { examining mark-books, emailing subject teachers) }\end{array}$ & 0 mins & 1-30mins & 30 mins- 1 hour & $1-2$ hours & $2-3$ hours & More than 3 hours \\
\hline $\begin{array}{l}\text { One on one discussion with students addressing } \\
\text { problems with academic progress }\end{array}$ & $0 \mathrm{mins}$ & 1-30mins & 30 mins- 1 hour & $1-2$ hours & $2-3$ hours & More than 3 hours \\
\hline $\begin{array}{l}\text { One on one discussion with students about study } \\
\text { skills and learning, not prompted by an academic } \\
\text { problem or concern. }\end{array}$ & 0 mins & 1-30mins & 30 mins- 1 hour & $1-2$ hours & $2-3$ hours & More than 3 hours \\
\hline $\begin{array}{l}\text { Problem solving with teachers about an } \\
\text { individual student }\end{array}$ & 0 mins & 1-30mins & 30 mins- 1 hour & $1-2$ hours & 2-3 hours & More than 3 hours \\
\hline $\begin{array}{l}\text { Problem solving with parents about problems } \\
\text { faced by an individual student }\end{array}$ & 0 mins & 1-30mins & 30 mins-1 hour & $1-2$ hours & $2-3$ hours & More than 3 hours \\
\hline $\begin{array}{l}\text { Problem solving with an external agency about } \\
\text { an individual student }\end{array}$ & 0 mins & 1-30mins & $30 \mathrm{mins}-1$ hour & 1.2 hours & $2-3$ hours & More than 3 hours \\
\hline $\begin{array}{l}\text { Problem solving with teachers about an } \\
\text { individual student }\end{array}$ & $0 \mathrm{mins}$ & 1-30mins & $30 \mathrm{mins}-1$ hour & $1-2$ hours & $2-3$ hours & More than 3 hours \\
\hline $\begin{array}{l}\text { Personally delivering information or running an } \\
\text { activity for students intended to increase the } \\
\text { likelihood of good decision making (eg how to } \\
\text { study for exams) }\end{array}$ & 0 mins & 1-30mins & 30 mins-1 hour & $1-2$ hours & 2-3 hours & More than 3 hours \\
\hline $\begin{array}{l}\text { Organising another person or group to deliver } \\
\text { information or run an activity for students to } \\
\text { intended to increase the likelihood of good } \\
\text { decision making (eg inviting a guest speaker to } \\
\text { discuss plagiarism) }\end{array}$ & $0 \mathrm{mins}$ & $1-30 \mathrm{mins}$ & 30 mins- 1 hour & $1-2$ hours & $2-3$ hours & More than 3 hours \\
\hline $\begin{array}{l}\text { Organising the delivery of information or an } \\
\text { educational activity to the wider school } \\
\text { community about academic issues. }\end{array}$ & $0 \mathrm{mins}$ & 1-30mins & 30 mins -1 hour & $1-2$ hours & $2-3$ hours & More than 3 hours \\
\hline \multicolumn{7}{|l|}{ Administration and management } \\
\hline $\begin{array}{l}\text { Planning, resourcing, monitoring, evaluating, and } \\
\text { otherwise facilitating all of the above }\end{array}$ & 0 mins & $1-30 \mathrm{mins}$ & 30 mins -1 hour & $1-2$ hours & 2-3 hours & More than 3 hours \\
\hline
\end{tabular}




\section{Appendix C: Sample Information Letter}

The role of the dean in the promotion of student well-being in a New Zealand secondary $\underline{\text { school }}$

Information for deans

\section{Kia Ora,}

Thank you for your interest in participating in my research into the role of the dean in New Zealand secondary schools. My name is Jennifer Fraser and I am a Masters student at the Faculty of Education, Victoria University of Wellington and am currently completing this research a part of my Masters of Education.

Project description and invitation

The aim of this project is to understand what aspects of pastoral care deans carry out in their day to day activities. Pastoral care is the promotion of students' personal and social development and includes social well-being and academic progress. This study will consider multiple perspectives from the school community on the role of the dean, along with documentation that describes the intended role of the dean specific to your school.

Your participation is voluntary and I would like to invite you to participate in this study. Your participation would include:

- A one-on-one, audio recorded interview with me to discuss your perspective on your role as dean.

- A daily log kept by you on a provided template to note the nature of your activities as dean and the time you spend doing them. This will take approximately 5 minutes to complete and needs to be completed for 5 consecutive days

This research has been approved by the Faculty of Education Human Ethics Sub-committee under delegated authority from the Victoria University Human Ethics Committee.

If you have any ethical concerns about the research, you should contact Dr. Allison Kirkman, Chair of the Victoria University of Wellington Human Ethics Committee: Alison.kirkman@vuw.ac.nz

Participant identification and project procedures 
Audio recording will be used during the interviews. These will also be transcribed. Documents and files will be stored securely and accessed only by myself and my supervisor. You will not be identified by name in any report or presentation.

At the end of the interview, I will summarise the main points that you have outlined for you to check

Participation is voluntary and if you choose to participate, you can pull out at any time before the end of data collection, and don't have to provide a reason.

Dissemination of results

The findings of this study will be published in my thesis and may also be used to make presentations at conferences of educators, and write papers for publication in academic journals. You will not be identified by name in any such presentation or report. I will not utilise the audio recordings at any such presentation. The name of your school will not be identified by name in any presentation or report.

If you are willing to participate in this research, please complete the attached consent form and return it to me.

Should you wish to receive a copy of the main findings, please check the appropriate box on the consent form to indicate this.

If you have any further question you can contact me via email at LloydJenn@myvuw.ac.nz. My supervisor is Dr Robin Averill and her email address is Robin.Averill@vuw.ac.nz should you wish to contact her.

Kind Regards,

Jennifer Lloyd 


\section{Appendix D: Sample Consent Form}

The role of the dean in the promotion of student well-being in a New Zealand secondary $\underline{\text { school }}$

Consent to Participate- Dean

I have read the Information Sheet and I understand what is involved in this study.

I agree to participate in a one-on-one interview that will be audio recorded.

I agree to complete a daily log based using the provided template about my activities and time spent completing these in my role as year level dean for 5 consecutive days.

I understand that all data will be stored in password protected digital folders and will be destroyed 5 years after the completion of the research.

I understand that my responses may be used in papers or presentations that are concerned with pastoral care or the role of the dean.

I understand that I may withdraw from this study at any time.

I understand that if I withdraw from the project, any data I have provided will be returned to me or destroyed

I understand that any information or opinions I provide will be kept confidential and reported only in a non-attributable form.

I consent that any information that could be used to identify me, other members of the school community or students will be kept confidential to the researcher, her supervisor and the person who transcribes the interview recordings.

If you wish to receive a summary of the results by email, please check this box

I agree to participate in this research

I do not agree to participate in this research

Email Address:

Signature:

Date:

Full name printed: 


\section{Appendix E: Sample Question Schedule}

\section{Questions for deans:}

1. What is your main role as the dean in this school?

2. How often do you engage in this aspect of your role?

3. What do you think is the most important part of your role as dean?

4. Why is this important?

5. How often do you engage in this activity?

6. How is this similar/different from the role in the senior/junior school?

Student interaction:

7. What do you do for the students in your care?

8. How do you communicate with students (for example, one-one meetings, assemblies, phone calls)

9. How frequently do you have contact with the students in your care?

10. What is the contact usually concerning?

11. How does having a dean make the student's life at school easier?

12. What do you do to improve the students' sense of well-being at school?

13. What else would you like to do to improve students' sense of well-being at school?

14. What do you think the students think of the dean system in this school?

Challenges and affordances:

15. What is difficult about your role as dean?

16. What is easy about your role as dean?

17. What would you change about your role as dean in this school?

18. How does the restorative justice model function within the school 


\section{Appendix F: Question schedule for focus group}

- What do you think is the purpose of having a dean?

- What do you think is the most important part of a dean's role here?

- How do you think having a Dean makes the students' life at school easier?

- As a teacher, form or classroom teacher, why would you seek out contact with the dean?

- What makes the dean's role easier or more difficult? 


\section{Appendix G: Job Description of the Dean at Northside College}

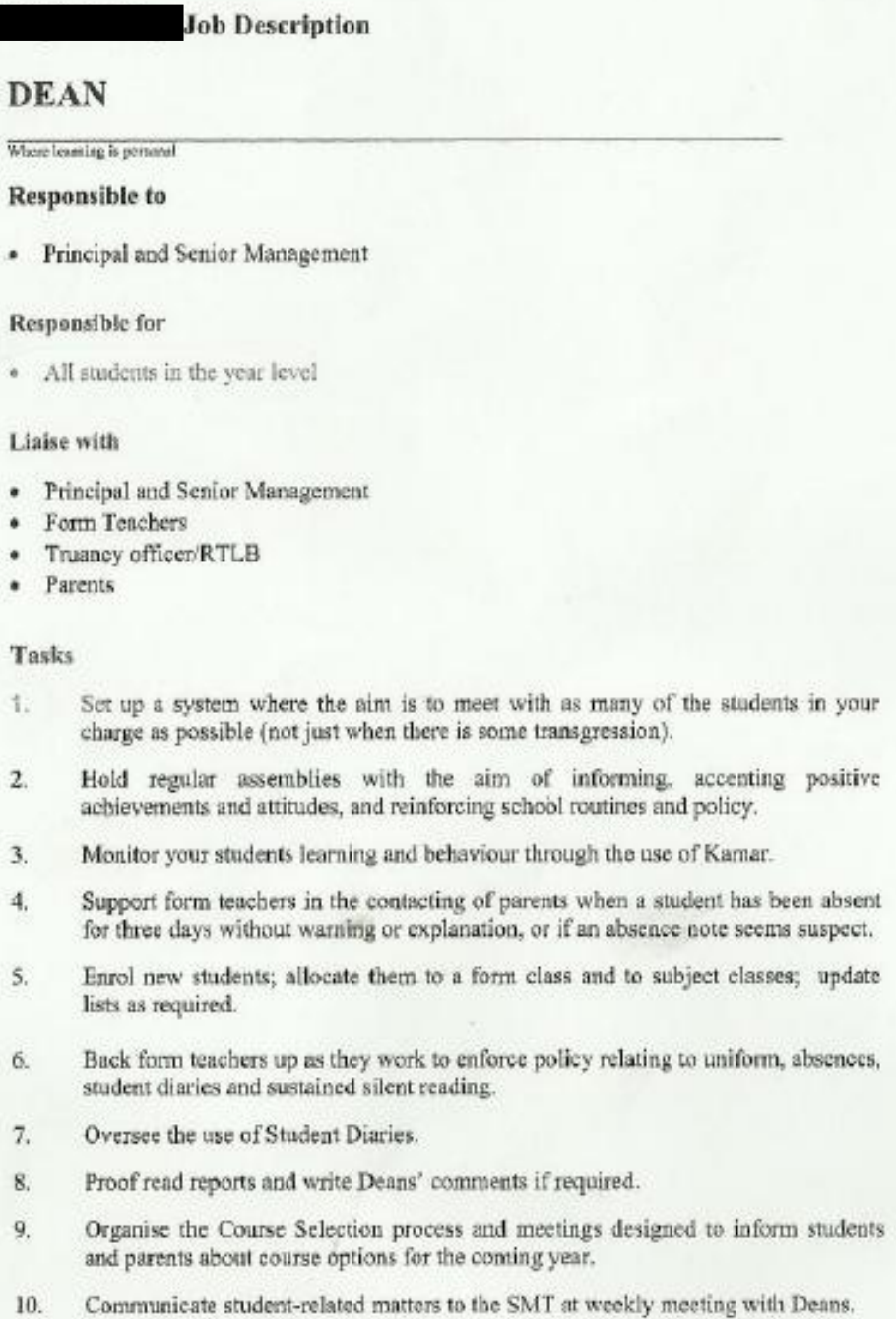

11. Provide restorative behavioural backup for the subject teacher, form teacher and HOD, in aceordance with the Belasviour Mnnacement.System.

12. From time to time meet with form and subject teachers for the purpose of sharing information, comnutucuting policy, and getting a comprehensive feel for what is happening at each level.

13. Ensure that informstion gathered fiom primaty school is made available to form and subjeet teachers and that student profiles are undated twice a year by form teachers.

14. Communicate with parents on matters of concern. Sometimes this will involve seting up meetings at sehool between parents and one or more staff in addition to yourself

Specific Delegations

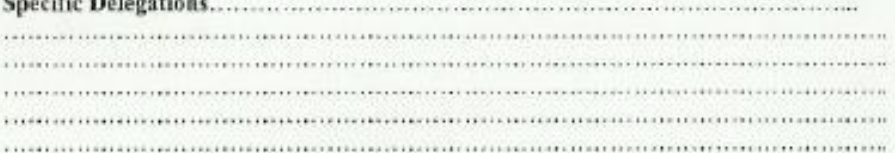

Communicate student-relatad matters to the SMT at weekly meeting with Denns. 


\section{Appendix H: Proposed job description of the dean}

\section{Responsible to:}

- Principal and senior management

\section{Responsible for:}

- Form teachers

- Students in the year level

\section{Collaborates with:}

- Students

- Staff; head of departments, form teachers, SMT

- Parents

- External Agencies

\section{Deans will endeavour to:}

\section{Promote quality teaching and learning}

- Implement and monitor a mentoring programme where the form teacher mentors students in their form class on matters of learning, achievement, and social, emotional, behavioural development.

\section{Promote positive relationships within the school community}

- Encourage positive relationships by teaching conflict resolution skills to students and staff.

- Liaise with curriculum staff (E.g., Health Department) to monitor student personal and social education and adopt similar messages in pastoral care contact times (e.g., form time and assemblies).

\section{Arrange monitoring for pupils' overall progress}

- Arrange for monitoring of pupils' overall progress by subject teachers, and form teachers. Deans should support form teachers to effectively monitor the overall progress of students (academic, social, emotional and behavioural) in their form class. Where individuals may be experiencing particular issues, deans (in association with Senior Managers) may assume the monitoring and mentoring of these students to further support the form teacher. 
- Deans will read the reports of their year level in order ascertain levels of achievement and any subject areas that may require further guidance, or individual students who may require further support from the form teacher or the dean.

- Liaise with external agencies, (e.g., Truancy officer) to provide extra support for students where form teachers have indicated an area of need.

Contribute to and take a leadership role in a collaborative, school-wide pastoral support system

- Deans will facilitate communication and collaboration between staff that teach their year level to ensure a consistency of care for all students, ensuring that all teaching staff are aware of their responsibility as pastoral carers.

- Deans will support form teachers to mentor students, address truancy, communicate with parents and enforce school standards and policy.

- Where students require extra assistance beyond the facility of the form teacher, the dean may assume a support role.

- Deans will mentor form teachers in the use of effective pastoral care strategies for example, high level interview skills.

- Orchestrate cross-curricular plans, supporting subject teachers and form teachers to implement strategies to support year-levels, classes or individual students.

\section{Promote extra-curricular activities and school ethos}

- Deans will encourage form teachers to promote student involvement in extracurricular activities.

- Deans will encourage subject teachers and form teachers to form strong positive relationships with individual students, increasing student perception of school connectedness.

- Where possible, deans will form relationships with students in their year level. Deans may take opportunities to observe classes or attend extra-curricular activities that involve students of their year level in order to create connections with students.

\section{Address the particular issues some individual pupils may be experiencing}

- Deans will support form teachers to assist individual or groups of students to solve problems and address conflict in a constructive way. Where an incident requires escalation, the dean may take more responsibility for the resolution of the issue, maintaining communication with the form teacher. 
- They will assist students in need with goal setting and ongoing support when required by the form teacher.

- Act as liaison with the external agencies and communicate with other staff members around strategies to support students in need where necessary. 